\title{
I.-TEMA URUGUAYO
}

\section{CARDYOMEGALIA E INSUFICIENCIA CARDIACA DE LA PRIMERA INFANCIA (")}

Por los Dres. J. BONABA, J. R. MARCOS, M. L. SALEUN DE RODRIGUEZ y J. A. SOTO.

\section{Parte}

\section{DEFINIOION $Y$ CONCEPTO}

Desde hace tiempo se han vinculado entre sí el cuadro de la insuficiencia miocárdica aguda del lactante con el sindrome clásico de la hipetrtrofia cardiaca congénita.

Esta relación, aunque posible en clínica, es confusa e inconstante $y$ plantea previamente' una delimitación de conceptos.

Según un concepto, que fuera hasta hace poco tiempo generalmente admítido, se llama hipertrofia cardíaca congénita e idiopática al aumento del solumen del corazón con hipertrofia de sus paredes, que no responde a una malformación de los grandes vasos o a un defecto septal. Según $\mathrm{Ab}$ bott, se puede hablar de ella en ausencia de miocarditis o de otros factores extra o intracardiacos, constituyendo por definición la hipertrofia "pura y primaria" del músculo cardíaco. Por esta razón, Abbott ubica la hípertrofia congénita en lo que ella llama la enfermedad miocárdica congénita (Congenîtal Miocardial Disease). P. D. White, dándole más elasticidad al concepto de hipertrofia congénita, admite que la hipertrofia puede verse "con o sin dilatación secundaria" debida a variados defectos congénitos (valvulares, septales $\mathrm{o}$ vasculares). El criterio de White es, por lo tanto, muy amplio, comprendiendo la totalidad de las cardiomegalias congénitas.

(*) Informe oficial de la "Sociedad Uraguaya de Pediattín" il Primer Congreso de la Confederación de Sociedades Sudamericanas de Pediatria. 
El concepto de hipertrofia congénita idiopática, descle que Henoch la describiera por primera vez en 1860 , permanece en una continua revisión hasta el presente, pudiéndose apreciar en las últimas publicaciones, una tendencia uniforme por parte de distintos autores en reconocer en esta forma impropiamente llamada, hipertrofia cardiaca idiopática, lesiones anatómicas o disturbios funcionales del ritmo, responsables de la hipertrofia.

Un punto interesante a revisar es el que se refiere al sindrome de insuficiencia cardíaca aguda del niño chico, cuadro que reviste siempre una extraordinaria gravedad clínica, al punto que, no tratado o atendido incorrectamente, lleva en general a la muerte. Este cuadro de insuficiencia aguda del corazón puede revestir dos grandes formas: a) una aparentemente primitiva, y b), otra, secundaria, que puede ser, a veces, el término final de una hipertrofia cardíaca anterior; otras veces es el resultado de un disturbio rítmico cardiaco (generalmente una taquicardia paroxística o un "flutter" auricular) y, muy a menudo, la consecuencia de factores patógenos variados (infecciones, hipertensión, avitaminosis, mixedema, tesaurismosis, etc.). La tendencia actual niega la existencia de formas verdaderamente primitivas de insuficiencia cardiaca del lactante. Los estudios histológicos modernos de tales casos y las comprobaciones electrocardiográficas, afirman cada vez más el concepto de, que la inmensa mayoría de las insuficiencias cardíacas del lactante son secundarias, si es que existen las formas llamadas primitivas o idlopáticas.

Concretando ideas, podemos decir al presente, que el sindrome de cardiomegalia congénita no es, en general, idiopático y que el aumento congénito del corazón puede responder a etiología variada, a veces difícil de delscubrir: glicogenosis, anomalías de irrigación coronariana, avitaminosis $B$, arritmias; tumores circunscriptos o difusos, como los thabdomiomas, etc.

$Y$ en lo que respecta a la insuficiencia cardíaca aguda creemos que debe encararse igualmente ésta, como un sindrome. generalmente secundario a su tiología, pudiendo presentarse como resultado de una hipertrofia cardiaca anterior, pero también sin hipertrofia cardíaca previa.

Antes de pasar adelante, queremos aclarar el punto de las distintas denominaciones que ha recibido ai síndrome.

Estamos totalmente de acuerdo en desechar el término antiguo e inadecuado de "hipertrofia idiopática congénita". En primer lugar, porque son muchas las causas que pueden 
determinar el "agrandamiento cardíaco" y en segundo lugar, porque la anatomía patológica nos ha demostrado que es más frecuente la dilatación del corazón que la hipertrofia del músculo, como causa de agrandamiento cardiaco. Algunos autores prefieren el término de "agrandamiento de la silueta cardiaca", para sustituir al viejo de hipertrofia congénita. Nosotros, preferimos la denominación de "cardiomegalia", que expresa el aumento de volumen del corazón sin particuJarizarse con un aspecto especial. ell radiológico.

Pero, más que cuestión de nombre nos interesa dejar bien establecido el concepto y como síntesis diremos:

1. ${ }^{*}$ Que existe una cardiomegalia (o agrandamiento cardíaco) del niño de primera infancia, que puede ser congénita o adquirida. En ambos casos las causas doterminantes pueden ser múltiples. Si es una cardiomegalia congénita, es decir, que existe desde el nacimiento, ella puede obedecer a malformaciones septales, o valvulares o vasculares bien conocidas, o puede responcer a otras causas, que sólo recientemente conocemos y aun en forma imperfecta. Tales son, por ejemplo, la cardioglucogenosis del recién nacido; la taquicardia con dilatación del recién nacido, de la cual tenémos una observación y la cardiomegalia de niños nacíos de madres diabéticas.

Si se trata de una cardiomegalia adquirida, ella puede responder también a causas muy numerosas. Esta cardiomegalia o agrandamiento, podrá deberse a hipertrofia o a dilatación, pero ello sólo puede aclararse en las necropsias. o presumirse por el tipo cliniço (caso de una dilatación aguda en un cuadro infeccioso o en el curso de una taquiartitmia).

2." Sobre una cardiomegalia congénita o adquirida se desarrolla comúnmente $e_{\uparrow}^{\dagger}$ cuadro de la insuficiencia cardíaca. e'sto es, la insuficiencia circulatoria congestiva.

3." Hay casos, sin embargo, en que insuficiencia cardíaca agrandamiento cardíaco parecen haber sido simultaneos. El corazón se dilata y desfallece al mismo tiempo. Claro que no es fácil, cuando se ve un lactante por primera vez, con una cardiomegalia, decir si ella es congénita o adquirida. Muy a menudo es sólo la evolución la que decidirá el diagnóstico. Pero, lo que es exigible es decir si ella se acompaña o no de insuficiencia circulatoria.

Es indudable que la insuficiencia cardíaca aguda o subaguda del lactante constituye un síndrome clínico y no una enfermedad individualizada. Este síndrome tiene rasgos clínicos fuertemente llamativos y caracteristicos. No hay nada comparable en la patología del adulto. Es una entidad roso- 
lógica nueva, que desconocíamos hasta época reciente. Se des̀arrolla con un tipismo cronológico-evolutivo digno de destacarlo. Su anatomía patológica suèe ser variable, aunque en muchos aspectos todavía es oscura $y_{r}$ desde luelgo, deja un campo promisor para futuras investigaciones. Su patogenia, aunque se ha enriquecido últimamente de conocimientos valiosos, todavía está lleina de incógnitas: la mayor parte de los mecanismos que dan origen a este sindrome, nos son todavía desconocidos. Muchas interpretaciones oonfusas pcdrán evitarse, cuando nuestro concepto de encarar la insuficiencia miocárdica aguda del lactante como un sindrome y no como una enfermedad especial, se haya difundido en la práctica médica. Vivimos todavia la etapa de difusión del su conocimiento tratando de despertar en el público médico la preocupación por esta grave afección cuyo diagnóstico y tratamiento deben conocerse bien.

Cuando ese síndrome se presente en clínica, habrá que estudiar cuidadosamentc la causa o las causas que pueden determinarlo. Lo primero es asegurarse sobre si existía o no agrandamiento cardiaco anterior, dato muy difícil de conocer en la mayoría de los casos que se ven por primera vez. El interrogatorio deberá ser meticuloso; no sólo referido a la anamnesis familiar (enfermeldades cardiacas, hipertensión, etc.) y personal (datos del racimiento, período neo-natal, desarrollo), sino también en los que atañe a la dieta alimenticia que puedel ponernos a veces, en la vía de una carencia vitamínica. El estudio del enfermo será clínico, radiológico y electro-cardiográfico. Si se llega al estudio anatómico, éste será completo (medidas, peso, aparatos valvulares, vasos, etc.). con especial insistencia en el examen histológico de la fibra miocárdica; comprendienco en particular una investigación escrupulosa de las lesiones mínimas y de la infiltración posible por material glucogénico. El estudio microscópico se llevará, además de sobre las fibras miocárdicas, sobre los elementos vasculares, en especial sobrel los vasos cotonarianos. Es así, como en muchos casos, lesiones coronatianas que en un examen superficial pudieron pasar desapercibidas, han podido ser descubiertas y ser consideradas como responsables del cuadro.

En casi todos los trabajos que hemos consultado, se suele identificar el síndrome de hipertrofia congénita con el de insuficiencia cardíaca aguda. Más aún, se llega a afirmar que las niños que padecen de hipertrofia cardíaca congénita fallecen inexorablemente en plazo breve, det semanas o meses. con el cuadro de la insuficiencia cardíaca aguda e irreductible. Este 
hecho aunque frecnente, está muy lejos de ser absoluto, puas la hipertrofia congénita es susceptíble de regresar espontáneamente hasta normalización del tamaño del corazón, como se' puede ver en algunas de nuestras observaciones. Ádemás, volvemos a repetirlo, es frecuente observar una dilatación aguda del corazón con cuadro de insuficiencia sin que haya existido hipertrofia cardíaca anterior.

El tema, como se ve, es más complejo de lo que se expresa en la mayor parte de los tratados de la especialidad y, en general no es abordado en su totalidad, con la profundidad y extensión que merece. El presente trabajo se propone dar unidad al asunto, destacar las caracteristicas generales del sindrome, al tiempo que insistir sobre los caracteres especiales de los distintos cuadros que lo componen.

Por más que la insuficiencia cardíaca del lactante etnpieza a ser reconocida más fácilmente en los últimos años, todavía es una afección que suele pasar indiagnosticada; sea porque todavía persiste la absurda creencia de la invulnerabilidad del corazón del lactante, sea porque el cuadro de insuficiencia cardíaca queda enmascarado en el proceso evolutivo de determinadas enfermedades infecciosas (síndromes broncopulmonares, tos convulsa, sarampión, etc.), o carenciales (avitaminosis B), o degenerativas.

A veces, el cuadro de insuficiencia miocárdica con dilatación se confunde con una bronconeumonía aguda. También suele suceder que se desconoce la participación miocárdica de un sindrome bronco-pulmonar o de otro estado infeccioso, Hemos visto también, confundirlo con una nefritis o con un asma, o con una sepsis. A medida que se vaya divulgando el conocimiento de este síndrome, los errores serán menos factibles. Es útil, por lo tanto, insistir repetidamente sobre sus características, mas si se piensa que ha dejado de ser una rareza y que se le encuentra con mayor frecuencia. a medida que se conoce mejor.

\section{DATOS HISTORICOS}

La evolución histórica de nuestros conocimientos sobte este sindrome, es sumamente interesante. Se puede dividir su historia en tres etapas:

La primera corresponde a la hipertrofia congénita e idiopática del corazón:

La segunda corresponde a la insuficiencia cardíaca; 
La tercera etapa, es la de los últimos años, en que se adquieren los modernos conocimientos sobre glucogénesis cardíacá, avitaminosis, lesiones adquiridas del corazón, trastornos del ritmo, pudiendo cada una de estas causas, desencadenar cuadros de insuficiencia cardíaca.

La primera etapa se inicia con la descripción de Henoch (según Muggia), en 1860, del cuadro de la hipertrofia congénita idiopática. Durante muchos años no se habla sino de la hipertrofia muscular primitiva e idiopática, que es considerada como una cardiopatía congéníta muy rara. Según Mac Mahon, que acaba de hacer recientemente (1938) una revisión del tema de la hipertrofia cardíaca en niños, las primeras publicaciones se deben a M. Simmonds (1899) y a Oberndorfer (1906).

La segunda etapa se inicia en 1914, con un trabajo de H. Mery, H. Salin y A. Wilborts, publicado en "Archives de Médécine des Enfants", intitulado: "Asistolia a repetición consecutiva a la dilatación aguda primitiva del corazón en el niño". Presentan tres observaciones clínicas, sin estudio anatómico, en niños de 6,5 y 3 años de edad, respectivamente; es decir, niños mayores, lo que le resta algo de interés. Tienen el mécito de haber llamado la atención sobre el asun. to $y$ de haber destacado que la dilatación aguda con insuficiencia se producía, en sus observaciones, por causas insignificantes en apariencia.

Posteriormente, se encuentran en la bibliografía francesa. publicaciones sobre el tema, especialmente de Debré y colaboradores, de Mouriquand. Bertoye y Charleux. Cathala, Apert y Besson, Lereboullet y Chabrun. En 1931, M. P. Gauthier y Mlle. M. Shoenar: relatan una observación de insuficiencia cardíaca aguda en un niño de 21 meses, que curć. aunque quedó con un corazón grande, por lo que los autores interpretan el caso como de posible hipertrofia cardiaca primitiva.

Debré. Buveau y Soulié publican una observación en 1933, de lo que ellos llaman "hipertrcfía cardiaca esencial". cen síntomas de insuficiencia cardiaca, que retrecedió bajo la acción de tratamiento depletivo y cardiotónico. Posteriormente, el mismo Debré, con J. Marie y J. Bernarx, presentan una observación de hipertrofia cardíaca congénita en un niño de 1 mes de edad, que falleció a los 3 meses. El ccrazóti estaba muy hipertrofíado en sus paredes: la sombra cardíaca radiológica era característica, sombra de "cotazón en 
bola". La hipertrofia cardíaca ccincidió, en su caso, con hipertrofia de timo, lo que se encuentra, según Debré, en $1 / 3$ de las observaciones publicadas hasta entonces. En la autopsia, las fibras cardíacas no estaban vacuoladas y no había sino "trazas infinitesimales de glucógeno", sin valor patológico.

En la Argentina, después de 1930 aparecen algunas pocas observaciones de síndromes mioccárdicos agudos en niños. Son las publicaçiones de Casaubon y Cossoy, en 1933; la de Vallino y Bettinotti, en 1933; la de P. de Elizalde y. F. de Elizalde, en 1934, y la de del Carril. Giustinian y Monserrat, en 1936. En todas estas últimas publicaciones se habla de insuficiencia cardíaca aguda y no de hipertrofia congénita jdiopática.

Pero, todo estc es sólo reciente, porque hasta 1927. Stoloff reunió 34 casos bajo el rótulo de "hipertrofia idioṕ. tica", con interesantes datos anatómicos.

En el Uruguay, después de la publicación de Burghi. en 1931, hemos hecho, dos de nosotros (Bonaba y Saldún de Rodríguez): una revisión del tema, eл una monografia del Instituto de Clínica Pediátrica y Puericultura "Dr. Iuis Morquio", aparecida en 1938, reuniendo 7 observaciones personales. En 1939. B. Delgado Correa publicó una observación en un. niño de 5 meses, con gran cardiomegalia. En 1942 hemos presentado, a la Sociedad Uruguaya de Pediatría, dos comunicaciones sobre cardioglucogencsis: una (Bonaba y Marcos) aparecerá próximamente en "La Semana Argentina" y otra (Bonaba, Saldún de Rodríguez'y Ferrei. ra Berrurti) ha aparecide recientemente en "Archivos de $\mathrm{Pr}$ diatría del Uruguay". En el mismo número se ha publicado un caso de Baeza Goñi (A.) y W. Bustamante, de Santiago (Chile), correspondiendo a un niño de 18 meses de edad.

La tercera etapa histórica se inicia alrededor de 1930. con los estudios histológicos modernos de Pompe sobre gluro. génesis cardíaca, y con otros estudios basados en un mayor conocimiento de los hechos completados con datos electrocardiográficos y metabólicos que han iluminado bastante la patogenia hasta entonces muy oscura de este sindrome.

En esta tercera etapa, que comprende los últimos 12 años, deben señalarse especialmente los estudics de Pompe. Van Creveld y Van der Linde, sobre cardiomegalia glucogénica: los estudios de Kugel y Stoloff, llamando la atención. sobre las frecuentes lesiones anatómicas cardíacas y coronarianas, halladas en los casos de dilatación aparentemente primi- 
tivas y el interesante trabajo de $\mathrm{J}$. Hubbard, quien recientemente, 1941, ba revisado extensamente las vinculaciones de la insuficiencia cardiaca en lactantes chicos, con las taquiarritmias del tipo de la taquicardia paroxística. y del "flutter" auricular. Analiza 19 casos de la literatura y 7 casos personales, en niños menores de 1 año. En esta tercera etapa s: acumulari también interesantes publicaciones sobre casos te insufíciencia cardiaca, atribuibles a avitaminosis $\mathrm{B} \circ \mathrm{C}$, sobre todo en el beri-beri del niño (I. Abt, Waring, Rinehart, Kato, Aballi, etc.).

R. Kreutzer y V. O. Visillac han publicado recientemente (1942) en la Rep. Argentina, 2 observaciones muy interesantes. Una corresponde al síndrome de Kugel, de degereración miocárdica no supurativa con dilatación e hipertrofia. La otra se refiere a una pericarditis exudativa, que curó después de punción. Los autores hacen una revisión breve del tema $y$, en cuanto a denominación, se deciden por la de "Agrandamiento de la silueta cardíaca en el lactante". Sostienen que debe incluirse la pericarditis exudativa. Los autores, al hablar de silueta cardiaca, le dan más bien un sentido radiológico, siendo así, que el síndrome se debe descubrir antes por la clínica que por la radiología y que al limitarlo al lactante, restringen demasiado la edad en que es dable observarlo. Finalmente, no destacan bien, con ese nombre, la importancia y frecuencia del síndrome de insufíciencia cardíaca, que es lo grave y a menudo el hecho inicial. Por todo ello preferimos la denominación de "Síndrome de cardiomegalia e insuficiencia cardiaca de la primera infancia".

Como se ve, el sindrome de cardiomegalia-insuficiencia cardiaca se ha ido completando poco a poco a medida que han progresado los métodos de estudio y que nuestros conocimientos se han perfeccicnado. De la hipertrofia, considerada hace mucho tiempo como una anomalía congéníta rara y primaria, se ha ido evolucionando al concepto de cardiopatía adquirida, con base lesional, frecuente o constante, al decir de muchos autores, como Kugel y Stoloff, de naturaleza generaimente secundaria.

De todos los últimos conocimientos, los más interesan. tes son, sin duda, los que vinculan el síndrome de cardiomegaliz-insuficiencia cardíaca, a infecciones cardíacas o extracardiacas, a carencias nutricionales, como las avitaminosis y a las arritmias del tipo de la taquicardia paroxística o del "flutter" auricular, en el lactante y aun en el recién nacido. 


\section{ETTOPATOCHENLA}

El síndrome de insuficiencia cardíaca aguda del lactante, reconoce múltiples causas que pueden ser intracardiacas o extracardíacas. congénitas o adquiridas, endógenas o exógenas; pero, cualquiera sea su medalidad, conduce uniformemente al mismo cuadro, es decir, al desfallecimiento agudo del corazón con dilatación, o con dilatación e hipertrofia del mismo. Si existe una hipertrofia cardíaca congénita del tipo llamado clásicamente "idiopática congestiva", la insuficiencia marca el último período de aquella hipertrofia y aunque tal estado es considerado muy grave, per lo general fatal, es susceptible, según nuestra opinión, de regresar y curar. Un segundo tipo es la insuficiencia aguda sin hipertrofia congénita. Consideramos que es la modalidad más frecuente. En ella el corazón se dilata y desfallece en forma aguda, en condiciones aparentemente primitivas. En realidad, no se trata de una insuficiencia primitiva sino scundaria, porque todos los protocolos de necropsia recientes, en especial cuando se ha insistido tenazmente en el estudio microscópico, demuestran que los corazones afectados presentan lesiones en mayor o menor grado, no sólo de las fíbras miocárdicas, sino también infiltración o edema intersticial, dislocando las fibras del músculo y también lesiones de irrigación sanguínea por lesiones corcnarianas. Kugel y Stoloff han insistido particalarmente sobre estas últimas lesiones.

En el estudio etio-patogénico pasaremos en revisión las distintas causas que pueden llevar a la insuficiencia cardiaca, actuando solas o combinadas. Nos ha parecido que la clasificación de Kugel es la que mejor se adapta a ese propósito.

Hemos introducido en ella una modificación importante: los trastornos del ritmo, del tipo de la taquicardia parexistica o "flutter" auricular. Hemos incluído en la clasificación, la pericarditis con derrame, dado que, si bien no es una cardiomegalia, por lo mencs, en el sentido habitual, plantea un problema diagnóstico importante, a veces insolible por otra vía que la punción pericárdica.

La clasificación que seguiremos es la siguiente: 
Claslficación etiopatológica del síndrome de cardiomegalia-insuficiencia cardiaca en la primera infancia (Kugel modificada)

1*) Anomalias congénitas $\left\{\begin{array}{l}\text { Corazón } \\ \text { Grandes vasos } \\ \text { Coronarias }\end{array}\right.$

$2^{\circ}$ Infecciones $\quad\left\{\begin{array}{l}\text { Etiologia sonocida } \\ \text { Etiología desconocida }\end{array}\right.$

$3^{0}$ Anemias $\cdots\left\{\begin{array}{l}\text { A }- \text { Primarias } \\ B-\text { Secundarias }\end{array}\right.$

4) Síndrome de degencración miocárdiéa con dilatación c hipertrofia no supurativa de Kugel y Stoloff.

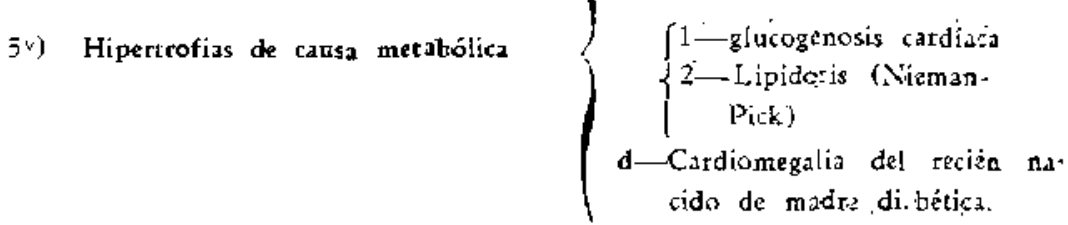

69) Taquiarritmias $\left\{\begin{array}{l}\text { Taquitadia pasoxistica } \\ \text { Flutter auricular }\end{array}\right.$

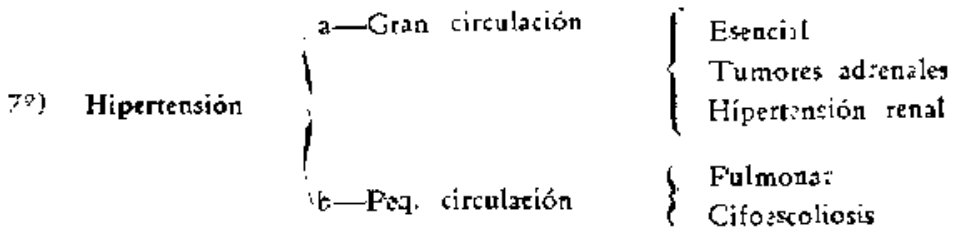

89) Tumores del corazón $\quad\left\{\begin{array}{l}\text { Primarios } \\ \text { Secundarios }\end{array}\right.$

9\%) Pericarditis exudaciva

10\%) Gropo inclasificado. 


\section{ANOMALIAS CONGENITAS}

No hatemos sino señalar las gruesas anomalias del corazón y de los grandes vasos, como enfermedades a tener en cuenta frente al diagnóstiço diferencial del cotazón grande congénito. Comentaremos este punto en el capitulo dedicado al estudio radiológico.

Otra cosa sucede con las ancmalías de las arterias coronarias, que pueden originar hipertrofia cardíac 1 congénita. Schnittker ha señalado que anomalias de nacimiento de una coronaria pueden enccitratse en esos casos: por ej: la coronaria izquierda naciendo de la arteria fulmonar, como on un caso de Carrington y Krumbhoar, o también la ausencia de una arteria ccronaria, con lo cual la irrigación miocárdica puede encontrarse comprometida. En cualesquieta de estas circunstancias pueden presentarse cuadros de insuficiencia cardiaca, aparentemente idiopáticas.

\section{INEECCIONES}

Puede tratarse de infecciones conocidas o desconccidas. Quiere decir, que en un caso, la insuficiencia cardiaca acompaña o sigue a una enfermedad infecciosa conccida y diagnosticada, como un epifenómeno de la misma, y en el otro, se trata de una verdadera miocarditis de causa desconccida, a veces complicando estados infecciosos insignificantes. Se sospecha la infección por la historia antericr, por la fiebre alta o por la vinculación con una enfermedad infecciosa. En este caso, la asistolía puede seguir a la enfermedad infecciosa $y$ acompañarla.

La tifoidea y la difteria son causas excepcionales de miocarditis èn el lactante. El reumatismo se ve en el niño de segunda infancia. En cambio, la sepsis puede intervenir en cualquiera edad, muy frecuentemente en el período neo-natal. Los síndromes bronce-pulmonares del lactante pueden originar en él dilatación e insuficiencia cardíaca, aun sin llegar a las formas bronco-neumónicas severas.

Dice V. Zerbino al respecto: "Debemos tener en cuenta esta repercusión de los estados catarrales pulmenares sobte el corazón y recordar que la cianosis, sobre todo facial, con dilatación de las venas tóraco-abdominales y yugulares, con hígado grueso y blando, con pulso venoso, con gruesa árex cardíaca, ccn tonos apagados, responde más que a la anoxemia por asfixia de causa pulmonar, a un desfallecimiento 
del corazón derecho. La miocarditis es de temer en el cuadro toxi-infeccioso. Canelli ha llamado la atención sobre la degeneración grasa del miocardio en las bronco-neumonias. La pericarditis supurada no es rara en las formas sépticas".

La preccupación del médico por el estado del corazón en el lactante enfermo de infecciones neumocócicas, en especial con síndromes bronco-pulmonares, debe set una de las obligaciones más imperativas. Sólo asi se puede descubrir precozmente y realizar la terapéutica eficaz, apenas asoman los primeros síntomas de dilatación cardiaca con insuficiencia cardiaca congestiva: taquicardia, ensordecimiento de tonos cianosis, disnea intensa, hepatomegalia, aumento del área cardíaca, sombra cardíaca radiológica aumentada. Como la disnea y la cianosis son síntomas propios de los estados bronco-pulmonares, se pensará en la insuficiencia cardiaca congestiva agregada. si elles cobran intensidad no habitual o cuando se asocian signos propios de insuficiencia cardíaca. En el capítulo de las formas secundarias presentaremos observaciones al respecto y nos ocuparemos detalladamente de este tipos especial.

Se considera que la tos convulsa puede ser causa de asistolía en el niño chico. La insuficiencia cardíaca congestiva se presenta generalmente en el periodo de las quintas de tos. sin que sea necesario para producirla. la presencia de una complicación bronco-pulmonar. Kugel y Stoloff recalcan 1a importancia de la tos convulsa. M. A. Jaureguy ha presentado dcs historias interesantes al respecto, a la Sociedad Uruguaya de Pediattía. Se trata de observaciones poco frecuentes. Nosotros podemos agregar tres casos observados en el Instituto de Clínica Pediátríca: uno de ellos (Observación 32), repitió su insuficiencia cardiaca poco después, con motivo de un sarampión. curando bien en las dos ocasiones.

Las lesiones encontradas en les casos de infecciones son de tipo miocardítico con signos de inflamación (infiltración a células mononucleares, congestión, edemas) y degeneración de las fibras cardíacas. Son particularmente importantes las lesiones de las arterias coronarias (coronaritis), que pueden ariginar disturbios en la irrigación miocárdica de la mavor importancia.

En una enjundiosa monografía, Kugel y Stoloff (1933), verdaderos especialistas en el tema y sobre la base de una monografia anterior de Stoloff. llegan a la conclusión que todos los casos de la bibliografía revisados por ellos $150 \%$ de tales observaciones- no eran de hiper- 
trofia ni de insuficiencia idiopática y que muchos están mal estudiados. "Se necesita — dicen los autores- un estudio serio y muy completo de todo el órgano, comprendidas las arterias coronarias. "antes de descartar la inflamación miocárdica o la degeneración, como "responsable del cuadro". Ellos publicaton, por ej., en 1928, un caso que al principio pareció una dilatación idiopática y luego en la autopsia mostró, en algunos cortes, signos de infección tales como infiltración linfocitaria y degeneración miocárdica. Desde entonces se preocuparon de revisar todos los casos de la bibliografía, agregando 7 casos propios con estudio anatómico prolijo, referibles a insuficiencias cardíacas rápidamente evolutivas, pertenecientes a niños de pocos meses. Es así cómo pudieron comprobar constantemente lesiones miocardíticas o degenerativas y con frecuencia, lesiones de las arterias coronarias, que hablan elocuentemente de la naturaleza infecciosa de muchos casos etiquetados clínicamente como "primitivos" e "idiopáticos".

Después de revisar la literatura, se deciden por una clasificación de los cascs publicados hasta entonces, en 3 grupos:

1: Categoría. - Hipertrofia idiopática congénita cardíaca (forma verdadera): Sin lesiones demostrables. Los autores dudan de su existencia. Sen casos que exigen demostración. Muy a menudo son casos mal estudiados o con anatomía patológica incompleta.

2. Categoría, - Forma secundaria de la hipertrofia (forma seudo-idiopática). Al examen se encuentran lesiones miocárdicas tales como infiltración celular del tipo inflamatorio, plasmolinfocitaria, degeneración y fibrosis de sustitución. También pueden encontrarse lesiones de coronaritis.

32 Categoría. - Hipertrofia idiopática del corazón (grupo discutible): En este grupo no se ha becho examen completo, según Kugel y Stoloff, y no es posible clasificar los casos definitivamente. Por esa razón, estcs autores prefieren hablar de dilatación e hipertrofia cardíacas asociadas a degeneración miocárdica y a fibrosis. Agregan que sólo puede hablarse de casos "idiopátices", cuando se ha tenido la preocupación de descartar una multitud de noxas posibles. Resulta claro, de todo lo expuesto, que el papel de la infección es cada día más importante en la patogenia de la insuficiencia cardiaca del lactante. Esta manera de pensar está de àcuerdo con la existencia frecuente de estados catarrales precedentes, de fiebre asociada o de leucocitosis. En algunos 
casos, como en uno visto por nosotros, existió una ligera infección pielítica, acompañando el cuadro de insuficiencia cardíaca. Como un dato interesante a destacar muy a menu. do. los síntomas de infección son insignificantes clínicamente, en tanto que el sindrome de dilatación cardíaca es intens's y grave. En lo que respecta a las infecciones agudas, pocos datos de interés se conocen hasta el presente, sobre los gérmenes causantes. No hemos leído nada de real valor sobre búsquedas bacterióógicas posibles, en las observaciones publicadas: no sólo sobre hemocultivos y mielo-cultivos, sino también sobre la húsqueda directa de bacterias en el tejido cardíaco. No existen, que sepamos, referencias al respecto.

La tuberculosis. y la sífilis no han sido inculpadas, en general. Es posible que la sífilis pueda desempeñar un papel predisponente. pero no ha sido demostrado.

\section{ANEMIAS DEL LACTANTE}

Los tipos graves de anemia suelen acompañarse de insuficiencia cardiaca, al final de su evolución. En cambio, la anemia bipocrómica o nutricional, aunque puede dar soplos (soplos anémicos), no se acompaña de dilatación cardíaca. Las anemias hemolíticas del lactante, sobre todo el tipo agudo de Lederer o el síndrome sub-agudo del lactante, de Von Jaksch, pueden provocar insuficiencia cardíaca. En la etiología de la dilatación cardíaca en tales cascs, deben participar, probablemente, factores infecciosos que suman sus efectos a los de la anemia.

C. G. Parsons y F. H. Wright, se han ocupado, en 1939. (Am. J. Dis. Child) de la función circulatoria en las anemias del niño. Han estudiado los siguientes puntos, en 5 niños de segunda infancia:

$1^{\circ)}$ Efecto de la anemia sobre la tolerancia al ejercicio y la capacidad vital.

$2^{9}$ ) Medida del oxígeno sanguíneo, del tiempo circulatorio y de la presión venosa.

3\%) Alteraciones del electrocardiograma.

49) Medida roentgenográfica del área cardíaca.

Las conclusiones de este valioso trabajo, realizado sola. mente scbre 5 niños anémicos de segunda infancia ( 3 con anemias crónicas eritroblásticas, 1 aplásica y 1 aguda post-hemorrágica), son las siguientes: 
1) La función se altera. Los cambios son máximos en ia anemia prolongada y mínimos en la anemia de corta duración.

2) El aumento del volumen circulatorio es el mecanismo compensador más importante.

3) La anemia crónica (3 casos de anemia eritroblástica y 1 de anemia aplásica), no llega a dar síntomas característicos de injuria cardíaca, ni alteraciones significativas en los "tests" ordinarios de funcionalidad cardíaca. En cambio, Ias medidas de capacidad vital y las determinaciones electro y roentgenográficas pueden revelar anormalidades.

4) En un niño con anemia aguda severa, a pesar de la completa ausencia de síntomas o de signos físicos de insuficiencia miocárdica, ese enfermo mostraba una respuesta defectuosa al ejercicio y en cambio no tenía ninguna anormalidad electrocardiográfica o roentgenkinográfica. También eran normales la capacidad vital, el tiempo circulatorio y la presión venosa, así como la silueta cardíaca. Concluyen los autores, después de un serio análisis crítico, que una respuesta anormal al "tests" del ejercicio no es necesariamente' una indicación de función cardíaca alterada.

5) . El tratamiento de la anemia (transfusiones) mejora la función cardíaca.

Desde el final del siglo XIX varics clínicos encontraron soplos y agrandamientos del corazón en las anemias de cierta intensidad y en los casos fallecidos, lesiones de dilatación cardíaca, hipertrofia o atrofia seudo-hipertrófica y particulatmente, infiltración adiposa del músculo. Posteriormente, esas lesiones se encontraron en distintos tipos de anemia, como ser anemias de células falciformes, anemia perniciosa y anemia del tipo eritroblástico.

En lo que atañe al lactante, no conocemos ningún estudio de conjunto sobre la función citculatoria, probablemente por las dificultades que implica el estudio.

En los niños más grandes, las leucemias agudas, que son excepcionales en los lactantes, pueden provocat lesiones cardiacas infiltrativas y degenerativas, llevando igualmente a la insuficiencia cardíaca.

Aun cuando no se trate de lactantes, hemos observado en un niño de 8 años. una anemia tipo Cooley, con cierto grado de cardiomegalia, así como también una cardiomegalia evidente, en otra niña de 12 años, afectada de un síndrome leuć́mico de De Guglielmo. 
IV. SINDROME DE DEAENERACION MIOCARDICA CON DILATA. CION E HIPERTROFIA NO SUPURATIVA

DE KUGEL Y STOLOFF

Kugel y Stoloff, en el reciente estudio ya citado, se ocupan extensamente del síndrome de degeneración miocárdica, llevando a la dilatación e hipertrofia no supurativa del corazón. La etiología del síndrome, por ahora es desconocida. Suele aparecer en la primera infancia y produce rápidamerte el cuadro de dilatación con insuficiencia cardíaca, con cianosis, disnea intensa, hepatomegalia, taquiarritmia, oliguria, edemas, evolución en apirexia o con poca fiebre. A veces pueden ocurrir fenómenos embólicos, complicando el cuadro, de por sí muy grave. Hay sintomatología completa de insu. ficiencia congestiva. Puede ocurrir muerte súbita. El pronóstico es serio. El primer caso publicado parece ser el de Simmonds, en 1899. Desde entonces, Kugel y Stoloff pudieron reunir 52 casos, agregando 7 personales con necropsia. Sprague. Bland y White, han referido, en 1931, un caso de este tipo. en una niña de 7 meses, sugiriendo lá posibilidad de una tendencia familiar, por existir idéntica disposición congénita en una hermana y varios cardiópatas en la familia. Las fíbras miocárdicas presentaban, en este caso, una degeneración vacuolar, pero aunque en ellas se investígó lipoides, no se hizo investigación de glucógeno. Se conprobó además, fibrosis intersticial.

Muchos autores piensan en relaciones de este sindrome con el estado tímico-linfático de Paltauf. Debré y colaboradores los han visto asociados en $1 / 3$ de las observaciones recogidas en la literatura médica. Steiner y Bogin (1930) también han visto lo mismo. Mac Mahon. recientemente (1938) ha hecho un análisis de la hipertrofia con insuficiencia cardíaca y se ocupa también de la asociación de este sindrome con la hipertrofia tímica.

En realidad, fueron Steiner y Bogin quienes, ya en 1930, promovieron extensamente el debate de este asunto. Estos autores hicieron referencia a casos con infiltración miocárdica de células redondas, en asociación con estado tímicolinfático, como ya había sido señalado por Ceelen y Blühdorn. Ai lado de este grupo, está el otro, constituído por estado tímico-linfático sin infiltración miocárdica (Oberndorffer-Howland) y un tercer grupo, finalmente, en que la dilatación cardíaca es lo único. Teniendo en cuenta estos hechos. Steiner y Bogin proponen la siguiente clasificación de 4 grunos de casos: 


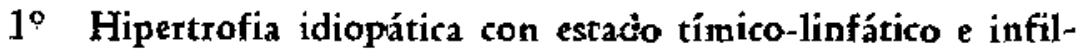
tración del miosardio.

$2^{9}$ Hipertrofia idiopática con estado tímico-linfático sin infiltración miocárdica de células redondas.

$3^{\circ}$ Hipertrofia idiopática con infiltración miocárdica solamente.

4 Hipertrofia idiopática sin otro cambio anatómico, tanto macroscópicamente como microscópicamente. La existencia de este grupo es muy discutible.

El caso clínico relatado por Steiner y Bogin es del grnpo de la hipertrofia cardíaca con agrandamiento tímico, sin infiltración miocárdica de células redondas. Se trataba de un lactante de 3 meses, cuyo corazón globuloso pesaba 63 gramos. Había engrosamiento de las paredes del corazón. Microscópicamente se encontró edema, congestión y degeneración hidrópica de las fibras. El timo era grande y pesaba 42 gramos, casi tres veces el peso normal. Los autores concluven que no pueden establecer relaciones definidas entre hipertrofia jdiopática y estado tímicc-linfático con-o sin infiltración miocárdica. Finkelstein opina en igual sentido.

Después de analizar lo que Kuge! y Stoloff incluven bajo el rótulo de tilatación e hipertrofia acociada a degenoración miocárdica: se llega a la conclusión de que tal grupo es muy heterogéneo $e$ incluye toda una serie de lesiones variables. inflamatorias $y$ degenerativas, algunas posiblemente tóxicas, fibróticas otras (¿fibrosis de sustitución?) y también, frecuentes lesiones coronarianas, como ser fibrosis peri-vascular, hipertrofia de la túnica media y proliferación de la intima, con descamación que puede obturar la luz del vaso. Es muy posible que en un futuro próximo se produzca el desmembramiento de este grupo, tan heterogéneo.

Es objetable también, el nombre elegido por Kugel y Stoloff, porque esa denominación del sindrome corresponde a lesiones comunes. en muchos tipos de insuficiencia cardíaca aguda.

\section{HIPERTROFIAS DE CAUSA METABOLICA}

Enfermedades metabólicas pueden lesionar las fibras cardiacas y llevar el corazón del lactante a la dilatación y a ia insuficiencia.

De las mejor individualizadas hasta ahora, se conocen especialmente tres: las avitaminosis, el hipotiroidismo y la glucogenosis cardíaca o cardiomegalia glucogénica. 


\section{A) AVITAMINOSIS}

Se la estudia actualmente con el mayor interés. Forman parte de los síndromes de carencias nutritivas. Pueden encontrarse carencias vitamínicas absolutas (avitaminosis) o carencias parciales o frustradas (hipovitaminosis). Las mejor conocidas derde el punto de vista de la repercusión cardíaca son las avitaminosis del complejo B, especialmente de tiamina o beri-beri infantil.

De acuerdo con el criterio que debe aplicarse al diagnóstico de las avitaminosis, es sobre todo el interrogatorio sobre el régimen dietético del enfermo y los resultados de la prueba terapéutica, que sirven prácticamente, a entera satisfacción, para el diagnóstico de una carencia vitamínica.

Avitaminosis $\mathbf{B}_{1}$ : Beri-beri infantil. - De todas las avitaminosis conocidas, la de mayor interés en lo que atañe a la dilatación aguda del corazón, sobre todo del corazón derecho, es la avitaminosis $B_{1}$ (tiamina o aneurina). Debe sospecharse su existencia por el interrogatorio de la dieta alimenticia, que siempre es deficiente: a veces, regímenes de hambre en ciertas comarcas, generalmente dietas a base de harinas o galletas, sin alimentos frescos, sin leche ri vegetales. ni carne. En Oriente y en. Filipinas. se observan frecuentemente en sujetos que se alimentan casi exclusivamente con arroz descorticado.

En Cuba. A. Aballi ha publicado 3 casos en niños de pocos meses, alimentados al seno, cuyas madres comían solamente arroz descorticado, pescado seco, porotos negros y patatas. J. Abt insiste también en la importancia de una buena historia dietética para el diagnóstico. A. Aballi describe 3 formas de beti-beri agudo del lactante: $1^{3}$ ) Forma cardiaca; el autor relata 3 observaciones de lactantes de 2,4 y 9 meses, respectivamente, de los cuales murieron $2 ; 2^{3}$ ) Forma neurológica (eclampsia), y $3^{2}$ ) Forma mixta. $\mathrm{E} 1$ beri-beri infantil se ve más frecuentemente en los primeros meses, generalmente en el primer trimestre, según Aballi. J. Waring se ha ocupado extensamente del corazón beri-bérico en la infancia, Cree que es dudoso que la falta de una sola vitamina pueda ser enteramente responsable y que seguramente se agregan, además, una carencia nutritiva global, con déficit de todos los componentes del complejc. B y carencia de proteínas: además, Waring ha relatado 13 casos de avitaminosis $\mathrm{B}$ con dilatación cardíaca, ocurriendo en niños negrcs ( 12 en 13 casos) y cuyss edades oscilaron de 14 a 48 meses, con promedio de 25 meses; 
es decir, edades muy superiores a las que da $\AA$. Aballi. J. Waring insiste en la dilatación cardíaca a predominio de las cámaras derechas, dando el cuadro de la insuficiencia cardiaca congestiva. Es frecuente que se asocien, además, signos nerviosos, tales como paresias en los miembros inferiores, calambres. atennación o anulación de reflejos tendinosos, que reaparecen con la corrección de la dieta. En algunos casos se comprobó hipoproteinemia. La corrección de la dieta alimenticia, scbre todo el agregado de levadura de cerveza y de germen de trigo, así como las inyecciones de $\mathrm{B}_{1}$ a grandes dosis, pasando los 50 miligramos por día, al principio da resultados satisfactorios, sin necesidad, en todos los casos, de recurrir a la terapéutica cardiotónica, por lo menos en los casos tratados precozmente. Los casos muy avanzados pueden no responder a ninguna terapéutica. En las necropsias, las lesiones encontradas, según Waring, se deben más a edema que a verdadera bipertrofia.

Katsuji Kato describe 4 tipos de beri-beri infantil, o sea de deficiencia en tiamina: $1^{\circ}$ ) Edematosa: $2^{\circ}$ ) Paralítica: $\left.3^{\circ}\right)$ Cerebral, y $4^{\circ}$ ) Cardíaca. Pueden ocurrir tipos mixtos.

El niño hace generalmente el tipo beri-beti agudo. En la forma cardiaca, el primier disturbio circulatorio es el pulso rápido, de $140^{\circ}$ a $180^{\prime}$. La polipnea puede ser de 40 a $60^{\circ}$ por minuto. Hay caída de la tensión del pulso. Cuando el niño grita, aparece cianosis periférica. El niño tiene expresión dolorosa y existen en general dolores. La pérdida de la alegría es precoz y constante. El corazón se dilata. los tonos cardíacos se ensordecen; la dilatación se hace sobre todo en el ventrículo derecho; el ritmo se vuelve embriocárdico. Según Kato, trastornos del ritmo, ccmo extrasistolía. "flutter" y fibrilación, prácticamente no ocurren nunca en esta forma de asistolía del lactante. Coincidiendo con el desarrollo de disturbios circulatorios, hay alteraciones electrocardiográficas. Weis y Wilkins (1937), en 35 casos de ccrazón beri-bérico, estudiados en Boston, encuentran: taquicardia, anormalidades en la onda $T$ y prolongación de la sístole eléctrica $Q-T$.

Kobayashi (1937), en 35 casos de beri-beri infantil ha visto elevación de $\mathrm{P}$ y $\mathrm{R}$ y depresión de $\mathrm{Q}$ en derivación IIIT. La onda $S$ estaba muy deprimida en los casos severos, mientras $T_{3}$ estaba generalmente aplanada, a menudo invertida, indicando lesiones miocárdicas. Otros autores han señalado modificaciones parecidas en el corazón beri-bético.

Los cambios patológicos en estos corazones beri-béricos, consisten sobre todo en dilatación cardíaca con hipertrofia a 
predominio del ventrículo derecho y, al examen bistológico, edema intersticial, dislocación de las fibras y, según Kato, degeneración hialina y grasa de las fibras; es decir, edema y degeneración. El diagnóstico se hace, frente a un caso de dilatación cardiaca en un lactante, por el interrogatorio de la dieta del niño, o de su madre, si él está a pecho, que acusa en general una franca deficiencia en tiamina. También, por la forma clinica, con predominancia ventrícular derecha, gran taquicardia y disnea acentuada. La prueba terapéutica con tiamina inyectable (más de 50 miligramos por día al principio), puede resolver una duda diagnóstica, si el caso no está muy avanzado. Otros métodos diagnósticos, como la eliminación de metilglioxal por la orina o la investigación de piruvatos en la orina o en el líquido céfalo raquídeo, son costosos y no dan más seguridad que la clínica. El "test" de la eliminación urinaria de tiamina puede ser de valor cuando los valores normales caen muy bajos, a veces a cero. No hemos encontrado en el Uruguay cascs de beri-beri agudo. Es posible que una búsqueda prolija, ahora que estos conocimientos están suficientemente divulgados, nos ponga en conocimiento de algún caso, en especial provieniente de alguna zona de campaña, donde suelen verse estados avanzados de carencia alimenticia.

Avitaminosis C: Escorbuto. - Darling en 1914, descubrió el agrandamiento del corazón en sus cavidades derechas, en el escorbuto. Alfredo Hess lo consideró frecuente y lo confirmó radiológicamente. Es el sindrome cardiorespiratorio de Hess, que se traduce por taquicardia, taquipnea, dilatación cardíaca a predominancia derecha y evolución en completa apirexia. Se encuentra poca cosa en el electtocardiograma. Clínicamente se encuentra un cuadro de escorbuto florido, por más que Erdheim (1918) descubrió el agrandamiento cardiaco en el escorbuto, sin que se observara relación estrecha con la severidad de la enfermedad.

Las lesiones más frecuentes del corazón escorbútico consisten, en el hombre, en degeneración grasa, atrofia de las fibras miocárdicas y hemorragias sub-pericárdicas (Aschoff y Koch).

Abt accnseja perisar en la enfermedad de Barlow latente, cuando no se encuentra clínicamente explícación satisfactoria a una hipertrofia ventricular derecha. Rinehart y Mettier (citados por Abt), piensan que las lesiones cardíacas se deben a una combinación de escorbuto e infección. 
Raquitismo. - La dilatación del corazón en el raquitismo es un asunto muy discutido. Experimentalmente. Park y Howland han observado el corazón grande en ratas raquíticas. Finkelstein dice haber observado el corazón grande en una autopsia y piensa que puede observarse también en vida. A. Hess dice que la hipertrofia cardiaca puede ser secundaria a severas deformaciones del tórax, producidas por el raquitismo, que no se la observa en forma independiente. Como se ve, es un tema discutido. La opinión muy valiosa de I. Abt es que, si en el raquitismo hay hipertrofia cardíaca, ésta ha escapàdo a la sagacidad de los clínicos más astutos.

\section{B) HIPOTIROIDISMO}

Mixedema infantil. - En el mixedema congénito, el corazón fuede estar dilatado. Esta dilatación puede ser progresiva y afectar globalmente el corazón o predominar en las cavidades derechas o iżquierdas. Se estima, en general, que $1 / 3$, de los casos de mixccardiopatías da una dilatación global, 1/3 dilatación derecha y $1 / 3$ dilatación izquierda. Estos son los porcentajes que da J. M. Cerviño, del Instituto de Endocrinolegía de Montevideo, en 12 casos.

Se puede encontrar bradicardia, aunque no es $\tan$ rara la taquicardia en el mixedema congénito. Se produce caída de Ia tensión del pulso y taquicardia (en esta fase). Un examen radiclógico de! tórax muestra, entonces, la dilatación del corazón.

Importantes modificaciones electro-cardiográficas se han comprobado en el corazón mixedematoso. Lo más característico es un voltaje bajo de todos les complejos, que lleva a pensar en el mixedema.

También se pueden encontrar a veces, espesamientos en G. R. S. o ligeros desniveles. Se vensó, al principio, que el bajo voltaje de los complejos se debía exclusivamente al aumento de resistencia de la piel mixedematosa, a la corriente. hipótesis que posteriormente se ha modificado.

J. M. Cerviño describe como una modificación electrocardiográfica interesante, que han encontrado en el Instituto de Endocrinología de Mentevideo, la presencia de una Q muy amplia en las tres derivaciones, pero sobre todo D II y en D III, llegando a medir $1 / 3$ más de RS. Esta onda $Q$ amplia, persiste según él. después del tratamiento tiroídeo.

Scherf y Boyd, en su libro Electrocardiografía Clínica, se ocupan de las modificaciones electrocardiográficas del mixedems. Dicen que la piel, en esa enfermedad, gruesa, seca $y$ 
pobremente irrigada, no conduce la corriente tan bien como una piel normal. El aumento de resistencia de la piel $\circ$ su clevada capacidad, son factores que pueden explicar los cambios electrocatdiográficos. Otros autores han atribuído esas modificaciones a la infiltración mixedematosa del corazón. E! hecho de poder obtener trazados poco modificados o normales (Nobel y Sanet), si se elimina la influencia de la piel por medio de electrodos insertados subcutáneamente en los miembros correspondientes, probaría que la piel tiene papel preponderante en lcs cambios electrocardiográficos del mixedema. Scherf y Boyd traen un ejemplo afirmativo de tal hipotesis. en una adolescente mixedematosa de 17 años de edad, en quien los trazados se normalizaban con la maniobra de insertar las agujas eléctricas debajo de la piel, eliminando así la ressistencia de la misma.

Sin embargo, recientes investigaciones tienden a refutar -dicen Scherf y Boyd- la hipótesis de que las alteraciones de la piel son las responsables exclusivas de las anomalías del electrocardiograma. Actualmente. se sabe que muchos casos de "agrandamiento cardiaco" en el curso del mixedema, se deben a derrame pericárdico. Este derrame se reabsorbe con el tratamiento. En el hipotiroidismo, además del bajo voltaje, se pueden ver ondas $D$ I. $D$ II $y$ T anormales $c$ aun invertidas, que pueden persistir un tiempo, aun después de haber recuperado la desviación inicial su amplitud normal por el tratamiento (Scherf y Boyd).

En síntesis. las distintas hipotesis propuestas para explicar los cambios electrocardiográficos en el curso del mixedema. pueden reducirse a 3 :

$\left.1^{\circ}\right)$ Factor cutáneo, es decir, espesamiento, sequedad y mala circulación de la piel, que se opondría al pasaie de la ccrriente. reflejándose tal hecho en un bajo voltaje de todas las desviaciones del electrocardiograma, que es la caracteristica más importante.

$\left.2^{\circ}\right)$ La infiltración mixedematosa del miocardio se aplica a los casos en que existe una cardiomegalia.

$3^{\circ}$ ) - El derrame pericárdico de origen mixedematoso, que daría por su cuenta, explicación de las alteraciones electrocardiográficas.

Estos tres factores pueden asociarse. El diagnóstico entre agrandamiento cardíaco por cardiomegalia o por derrame pericárdico en el curso del mixedema, puede ser difícil. En una observación petsonal no encontramos cambics electrocardiográficos conspicuos; sólo había taquicardia, el corazón estaba 
agrandado. Como la piel no estaba infiltrada, fodría estribar en ello la ausencia del bajo voltaje y de otras alteraciones características.

Mussio Fournier. Cerviño y Bazźano puntualizan que el bajo voltaje puede encontrarse en todas las ondas eléctricas o solamente en algunas de ellas, en especial en P y T. En casos excepcionales, el voltaje es normal, pero él aumenta desṕús del tratamiento tiroídes. En nuestra cbservación eso sucedió. Estos mismos autores se ocuparon extensamente del asunto, en un relatc presentado al $2^{\circ}$ Congreso Panamericano de Endocrinología (Montevideo. 1941). y desfués de estudiar el aparato cardiovascular de 42 mixedemas del adulto y de 18 mixedemas congénitos. llegan a conclusicnes muy interesantes sobr? afecciones cardiovasculares y alteraciones electrocardiográficas en el mixedema.

Señalan que las preponderancias ventriculates izquierdas son frecuentes en el adultc y no así en el niño, donde es más frecuente la preponderancia ventricular derecha. Han encontrado en el mixedema infantil, en algunos casos. disminución o ausencia de $S-T$, es decir, tendencia monofásica de Q-R-ST. Describen para la insuficiencia tiróidea infantil. un tipo de electrocardiograma que conserva las características del niño chico. Entre las características del mixedema infantil. T no estaria invertida como sucede en el adulto.

Mussio Fournier y colaboradcres han encontrado un aumento del área cardíaca en el $66 \%$ de sus casos. Tal aumento puede ser global o parcial y no siempre cede al tratamiento tiroideo. En el mixedema congénito han encontrado cardiomegalias en el 50 \% de los casos. Los trastornos del ritmo en el adulto pueden ser numerosos, pero en el niño se reducen casi a la bradicardia. Los extrasístoles y las taquiarritmias, que suelen encontrarse en el adulto, serían excepcionales en el mixedema infantil.

En nuestra observación de mixedema congénitc con cardiomegalia y atrofia nutritiva, existía una taquicardia discreta de 128 pulsaciones por minuto.

La opoterapia tiroídea es el únicc tratamiento que puede corregir esta mixocardiopatia y bajo su influencia, en general. el tamaño del corazón se normaliza, aunque lentamente. El diagnóstico del corazón mixedematoso es fácil en general, porque coincide habitualmente con cuadro clínico complets de mixedema congénito. Puede ser más dificil en las formas frustradas. El estudio radiológico de tórax y la electrocardiografía ayudan al diagnóstico y lo confirman o no. 


\section{C) TESAURISMOSIS}

Cardicmegalia glucogénica. - En 1933, J. C. Pompe llamó la atención por primera vez, sobre la hipertrofia cardíaca congénita, debida a una acumulación anormal de glucógeno en las fibras cardíacas. Desde esa fecha y tomando como base su trabajo original, se sabe que tal disturbio mer tabólico es causa importante de hipertrofia cardiaca, del tipo denominado comúnmente "cardiomegalia idiopática del corazón". Esta forma, de reciente conocimiento, venía a separarse netamente de la forma secundaria o pseudo-idiopática, producida por gruesas malformaciones cardiacas o por defectos vasculares congénitos coronarianos.

Antes del trabajo de J. C. Pompe existían algunos antecedentes, pero sin que nadie hubiera dado interpretación exacta de los hechos observados. Virchow (1864), al ocuparse de los miomas cavernosos dél ccrazón, destacó en su descripción, el "sistema de mallas laxas de conformación totalmente cavernosa" que, según Pompe, concuerda en gran parte con su observación original. Seiffert (1900) pasa revista a la literatura sobre miomas del corazón y sostiene, en ocasión de un caso personal. que el problema básico de su interpretación histológica es el sistema de mallas en cuyas cavidades los núcleos de las células están fíjas en los bordes o encerradios. Al discutirse el caso en la tercera reunión de la Sociedad de Anatomía Patclógica Alemana, en 1900. Marchand admitió como probable. "por analogía con lo que se encuentra en otros tumores musculares y en la musculatura del feto, que las cavidades en estado fresco estaban llenas de glucógeno (Pompe)".

Otros investigadores habían buscado glucógeno en rhabdomiomas del corazón, fracasando algunos por falta de una coloración apropiada del tejido, aunque fué hallado en alguna cbservación aislada (caso de Aschoff. 1900).

Pompt cita 4 observaciones anteriores de hipertrofia cardiaca congénita, con estudio histológico, mostrando aspectos histológicos parecidos a los de su observación. En todos ellos existía un corazón muy grande y al examen mictoscópico presentaban las fibras miocárdicas un aspecto vacuolar o hidrópico muy llamativo. El caso de Schminck, de 1922 (corazón de 46 grs.). fué presentado para reforzar la opinión de Virchow de que la hipertrofia cardíaca congénita se debía a un rhabdomioma difuso del corazón, pero interesa conocer que se encontraron las fibras con aspecto vacuolar, recordando el aspecto fetal del corazón. 
En el caso de Steiner y Bogin (1930), de un niño de 3 meses, con un corazón pesarido 63 grs. (en lugar de 26 grs.). además de un edema marcado en el tejido intersticial, se describe igualmente la degeneración hidrópica de las fibras musculares.

En el caso de Sprague, Bland y White (1931), de un niño de 7 meses, con gran corazón (175 grs), las células tenían aspecto vacuolar rcdeando el núcleo, temontando las vacuolas hasta cada polo. Finalmente, la cuarta observación que cita Pompe, parecida a la suya, es la de Rheder, de 1914 (Virchow's Archiv., 217), en la cual establece vinculación entre la jipertrofia y la rhabdomicmatosis aislada del corazón, con infiìtración de glucógeno y estado vacuolar de las fibras.

Estas cuatro observaciones, que señala Pompe como an:tecedentes de su observación oríginal, tienen un valor relativo, pues se refieren sin mayor insistencia al aspecto vacuolar y de las fibras miocárdicas y en el caso de Rheder existe sólo el propósito principal de demostrar los vínculos entre hipertrofia cardíaca y rbabdomiomatosis del corazón, reforzando con ello la antigua opinión de Virchow.

En consecuencia, es J. C. Pompe, en 1933, el primero en destacar la sobrecarga glucogénica difusa del corazón. como causa de algunos casos de hipertrofía cardíaca congénita, del tipo denominado idiopático y sus conclusiones al respecto son bien categóricas: "Nosotros emitimos la hipótesis de que una “ parte, por lo menos, de los casos de hipertrofia idiopática " del corazón y quizás de todos los casos de rhabdomiomas "localizados del corazón. es causada por un trastorno en los "cambios del glucógeno. Al decir esto, no ignoramos que, por " ejemplo. "Obernderffer y otros autores han descrito hiper" trofias idiopáticas del corazón, donde el músculo cardíaco " se encontró normal al examen microscópico; de ahí nuestra " restricción. Perc, debemos señalar, para terminar, que en " ninguno de esos casos se ha investigado la presencia de glu"cógeno":

La tesis de Pompe era fácil admitir en 1933, desde que en 1928. G. Stoloff, después de analizar 34 casos de la literatura, sobre la llamada hipertrcfia cardíaca idiopática, llegaba a la conclusión que, de ese número, sólo 17 podian resistir una crítica seria sobre su verdadera naturaleza idiopática. En el resto de los casos se encontraban lesiones miocárdicas o extracardíacas, como en el caso de Riesenfeld con riñones hipertrofiados. 
Por otra parte. estaba bien divulgada la descripción de von Gierke (1929), sobre almacenamiento glucogénico visceral, conocido hoy bajo la denominación de glucogenosis o enfermedad de von Gierke. Este autor denominó la nueva entidad como "hepato-nefromegalia glucogénica", con detalles de dos casos. Los hallazgos histológicos de von Gierke, completados con los análisis de Schoenheimer, le permitieron a este autor atribuir el trastorno, a un disturbio en el mecanismo del desdoblamiento del glucógeno.

La interpretación de Pompe encontró posteriormente su debida confirmación y en una monografía reciente sobre enfermedades del glucógeno, H. Masson y D. Anderson dedican un grupo especial para el almacenamiento glucogénico del corazón. Revisan todos los casos de enfermedad glucogénica publicados, $y$ aceptan aquéllos que resisten a un examen prolijo. Piensan que, dada la extrema variación del sindrome, es razonable dudar que todas las observaciones pertenezcan a una única entidad nosológica. Hacen una clasificación de los casos de la literatura en 5 grupos, separables clínica o patológicamente:

19) Glucogenosis hepática o verdadera enfermedad de von Gierke. - Es debida a un defecto probablemente congénito, en una parte del sistema enzimático del hígado encargado de transformar el glucógeno en glucosa e inversamente. En estos casos, el hígado puede convertir en glucógeno la levulosa, la galactosa y otros precursores del glucógeno hepático. pero no la dextrosa. La hepatomegalia es intensa y precoz. Una inyección de adrenalina no eleva la glucemia o muy poco. y hay marcada tendencia a la acidosis y a la acetonuriz. En la autopsia, las células bepáticas contienen grandes cantidades de glucógeno, el cual es incapaz de desdoblarse, tanto "in vivo" como "in vitro". Los otros órganos, entre ellos el corazón, pueden contener o no cantidades anormales de glucógeno. La curva de tolerancia a la glucosa es alta y prolongada; en cambio, la curva de tolerancia a la levulosa y galactosa es baja o normal. En este grupo. Mason y Anderson han podido reunir en la literatura 34 casos, incluyendo uno perscnal.

2\%) Almacenamiento glucogénico del corazón y de los músculos. - Piensan los autores que el defecto es similar al anterior, pero radica en otro sitio del sístema enzimático encargado del metabolismo hidrocarbonado celular. Todo músculo hace glucógeno, partiendo de la glucosa, pero no 
convierte el glucógeno en glucosa. Cuando el glucógeno es convertido en el músculo, se transforma en ácido láctico o en $\mathrm{CO}_{2}$ y $\mathrm{H}$. O. Se trata de corazones que pueden hacer glucógenos a partir de la glucosa, pero no pueden transformar el glucógerio en ácido láctico (o éste en $\mathrm{CO}_{2}$ y $\mathrm{H}_{2} \mathrm{O}$ ). Responden a la adrenalina, normalmente. No bay tendencia a la acidosis, pero sí a la insuficiencia cardiaca, por lo cual, los pacien. tes mueren en el primer año de vida. Han coleccionado 12 casos en total.

$\left.3^{\circ}\right)$ Casos con galactosuria. - Responden a un defecto en el sistema enzimático del hígado, encargado de convertir la galactesa en glucógeno o, lo que parece menos probable, directamente en glucosa. Se caracterizan por marcado retardo del desartollo físico, con hepatomegalias muy grandes y precoces. Hay albuminuria y galactosuria post-prandiales. Und dieta sin leche provoca la desaparición de los síntomas y reduce la hepatomegalia. Hay respuesta normal a la adrenalina y éxiste cetonuria solamente después de ayunos prolongados.

$\left.4^{9}\right)$ Sobrecarga hepática de glucógeno por biperdosaje de insulina o dieta con excesiva cantidad de hidrocarbonos. Ambos factores pueden coexistir. No existen pruebas, hasta ahora, de deficiencia enzimática del hígado o de los músculos. Se trata de casos que responden a la adrenalina y no hay tendencia anormal a la acidosis. El hígado puede ser extremadamente grande $y$ contiene más glucógeno que lo normal. Seckel ha demostrado que en estos casos el hígado es capaz de desdoblar el glucógeno.

$\left.5^{\circ}\right)$ Hepatomegalia con retardo del desarrollo, - Existe, en estos casos, hepatomegalia con ligero distubio a la prue$\mathrm{ba}$ adrenalínica; pero, no tienen tendencia a la acidosis y las curvas de tolerancia a los azúcares, con glucosa y galactosa, son más altas y prolongadas que lo normal. En la autopsia, el hígado tiene más glucógeno que lo normal; pero, hecho importante, el estudio enzimático, en los casos hasta ahora verificados, muestran un hepatocito capaz de desdoblar el glucógeno. Además, en muchos casos hay marcada cirrosis que, como es sabido, incapacita al hígado para metabolizar la galactosa, aunque poco se sabe sobre sus efectos en el metabolismo de la glucosa.

Podemos concluir, de acuerdo con lo expuesto, que pl almacenamiente glucogénico del corazón puede formar parte de una enfermedad glucogénica generalizada, pero también. como lo establecen Mason y Anderson, puede constituir un 
grupo autónomo con sobre carga glucogénica cardíaca sola o cardic-muscular (músculos del esqueleto y músculos lisos, como ser píloro).

Una vez que se divulgó la forma descrita por Pompe, se aceptó posteriormene dos formas de la enfermedad glucogénica: la hepatomegalia y la cardiomegalia (L. E. Finkelstein), aunque es posible exista la forma combinada. Sin embargo, de acuerdo siempre con Mason y Andersen, la verdadera enfermedad de von Gierke es la glucogenosis hepática, con sus características propias que hemos señalado.

Aldo Muggia, en 1936, publicó una observación de cardiomegalia glucogénica en un lactante de 37 dias, asociada a hipertrofia del píloro, La histología del músculo cardíaco visualizó con la tinción al carmín de Best, glucógeno en gránulos, en blcques o en barras rodeando al núcleo, sarcoplasma débilmente teñido: algunas vacuolas no contenían glucógeno. En las fibras musculares de la hipertrofia del píloro había gránulos de glucógeno en pequeña cantidad, pero indudables. También fué positiva la investigación del gluiógeno en el hígado y en los músculos estriados, perio. fué regativa en los riñones, en el bazo y los pulmones. Las reacciones de las grasas fueron negativas en todos los órganos. Un hermano de este niño falleció a los 57 días con un cuadro similar.

Antopol, Heibbrum y Tuchman describen en 1934 un caso de cardiomegalia glucogénica con almacenamiento difaso del corazón, en un niño de $4 \frac{1}{2}$ meses. El corazón pesaba 85 grs. Las fibras, cortadas tangencialmente, se presentabar como cilindros huecos y teñidos con carmín de Best; las áreas intracelulates no protoplasmáticas, aparecían llenas de gránulos teñidos en rojo brillante. Había infiltración de gránulos de glucógeno en el tejido intersticial y en las paredes vasculares. Además, fibrosis perivascular y discreta infiltración intersticial de neutrófilos y células redendas. No había glucógeno en el hígado ni en los riñones.

En 1936, L. E. Finkelstein. describe la forma circunscripta de cardiomegalia glucogénica, en ocasión. de estudiar nuevamente un caso de Carrington y Krumbhaar, presentado en 1924, con estado vacuolar o hidrópico de las fibras cardiacas, pero sin haber buscado glucógeno estcs autores. Trece años después, Finkelstein revisa nuevamente el material, a la luz de los nuevos conocimientos sentados per Pompe. Las zonas vacuolares afectaban áteas de un territorio mal irrigade, puesto que en este caso la arteria coronaria iz- 
quierda nacía de la arteria pulmonar. En las áreas de aspecto vacuolar se pudo hallar con el carmín de Best, gránulos rojos, brillantes, de glucógenos y también en el tejido intersticial, donde, además, había fibrosis.

Después del trabajo de L. E. Finkelstein aparece, en 1939. una nueva observación de Van Creveld y Van der Lince, sobre cardiomegalia circunscripta. El caso de estcs autores se refiere a un niño de 5 meses. que falleció rápidamente en 5 dias, con corazór muy grande. El mioçardio prescntala áreas diseminadas, principalmente sub-endocárdicas, ccn las características de la "degeneración glucogénica" de las fibras musculares. Estas eran largas y gruesas, con protoplasma claro y vacuolar, a veces aplastado contra el sarcolema. Los bordes de estas fibras eran a menudo estriados. Después del teñido con carmín de Best aparecían finos gránulos, alguncs alrededor del núcleo central y otros periféricamente, en los extremos de las fibras. Estos gránulos estaban presentes solamente en las áreas de evidente estructura glucogénica. Habia áreas necróticas en el miocardic, degene. ración grasa globular y esclerosis intersticial. 'En el hígado habia pequeñas zonas con infiltración glucogénicas.

Nosotros observamos un tercer caso de acumulación glucogénica circunscripta.

Van Creveld y Van der Linder discuten las distintas posibilidades para explicar la acumulación circunscripta del glucógeno y tomando en cuenta los conceptos vertidcs anteriormente por L. E. Finkelstein, dicen que el tips circunscripto podría explicarse asi:

$\left.1^{\circ}\right)$ Podría ser una persistencia del estado fetal, que puede estat ligado a una mala irrigación sanguínea. como en el caso de Finkelstein, donde habia, además, una anomalía corcnaria de origen. La circulación pobre no facilitaría ? reabsorcićn de glucógeno embrionatio.

$2^{\circ}$ ) Desarrollo dominante anormal del sistema de conducción. como en la época fetal. Parece poco aceptable esta teoría.

$3^{\circ}$ ). La acumulación circunscripta seria una etapa u1terior a la acumulación difusa o también la acumulación difusa podría ser una enfermedad metabólica y la circunscripta una etapa de curación.

De hecho pademos afirmar que no conccemos hasta ahora, ni la causa de la acumulación difusa o generalizada de 
glucógeno en el corazón, ni el orígen de la acumulación localizada o circunscripta.

\section{Característleas elinicas de la cardiomegalia glucogénica.}

A pesar de lo reducido de las observaciones con pruebas histclógicas, conocidas hasta ahora, ya es posible señalar algunos síntomas muy especiales a esta enfermedad. muy lejos. desde luego, de ser patognomónicos.

Se señala así la familiaridad (casos de Goldmann, de Muggia) y el predominio en el sexo masculino. El debut es muy precoz; en los primeros meses, a veces en el periodo del recién nacido. La afección es siempre congénita y los niños, después de una primera etapa de hipertrofia cardiaca, que adepta el tipo de la hipertrofia idiopática, caen en plazo breve, en insuficiencia cardíaca rápida y grave, que lo lleva generalmente a la muterte. La mayoria de las historias insisten en la evolución rápida e irreductible del cuadro clínico. El tamaño del corazón es muy grande y radiográficamente tiende a adoptar el tipo del "corazón en bola".

Cuando existe, además, una infiltración glucogénica en el hrigado, es el diagnóstico más fácil. por más que, prácticamente es imposible decidir en un lactante en insuficiencia cardíaca. si se trata de un higado congestivo o de un hígado glucogénico. Si existe hipertrofia del píloro agregada, como en el caso excepcional de Muggia, ese dato puede orientar el diagnóstico.

No existen signos fidedignos para afirmar un diagnóstico. El diagnóstico de cardiomegalia glucogénica se hace por los datos anatómicos.

\section{Características anatómicas.}

El corazón suele ser muy grande. El miocardio puede tho ser normal, macroscópicamente, o ser pálido, bruno o rojo pálido con estrías grises.

No se encuentran cambios especiales en el pericardio. endocardio, válvulas, aorta o coronarias. En la forma difusa, en èl examen histológico el aspecto es bien sugestivo, porque el miocardio entero, debido a su aspecto vacuotur, presenta una imagen de red y sus paredes, a mayor aumento, aparecen estriadas. Como dicen Antopol. Heilbrumn y Tuchman, en un corte tangencial, las céfulas musculares parecen 
cilindros huecos rodeades por paredes protoplasmáticas delicadamente estriadas. El aspecto vacuolar de las fibras, es bien característico y lleva a pensar en esta condición patológica. Se trata, en general, de vacuolas grandes, que pueden liegar hasta los extremos de las fibras. Estas vacuolas pueden rodear al núcleo que se sitúa en el centro de las fibras o bien éste es rechazado y aplastado hacia la periferia, contra el sarcoplasma. Los núcleos, bien formados o deformados, pero con membrana nuclear nítida se colorean bien $o$ intensamente. El sarcoplasma, al contrario, suele teñirse débilmen-. te. Muchas vacuolas, según el sitio donde las tome el corte, pueden aparecer vacías. En la zona periférica aparece un protoplasma delicadamente estriado. El tejido intersticial puede estar engrosado y en alguna observación ha presentado ligera infiltración polinuclear o mononuclear. Según Humpheys y Kato, el largo de las fibras musculares puede ser 2 a 4 veces el normal. Fibrosis periwascular y engrosamiento del endocardio han sido descriptos ocasionalmente. Se ha comparado el aspecto de la glucogenosis cardíaca al del tejido cardiaco fetal y ésa fué nuestra impresión en el 'segundo caso. Coloreando con carmín de Best las vacuolas, están llenas de gránulos de glucógeno, que se colorean en rojo bri1lante. El glucógeno puede adoptar también otras formas, como ser en masa, en barra, etc. Los gránulos de glucógeno pueden encontrarse en el tejido intersticial, en las paredes vasculares, debajo de los endotelios, en los grandes vasos $y$, desde luego, como ha sido dicho, en los músculos lisos (píloro) o estriados y en otros órganos. Además, en el miocardio pueden existir areas necróticas, atrofias de fibras o edema intersticial. Se considera hoy que la tínción al carmín de Best no es patognomónica, pues puede teñir otros materiales de naturaleza protídica. Sin embargo, tiene una signifi. ćación cusi específica, sobre todo haciendo concomitantemente la prueba de la saliva. Se puede utilizar también la deac ción al ycdo (véase más adelante).

\section{Diagnóstico, pronóstico, tratamiento.}

El diagnóstico clínico se plantea en el período de insuficiencia cardíaca, o más raramente cuando en el curso dz un examen general se descubre en un-lactante, generalmente de pocos meses, una hipertrofia cardíaca del tipo idiopático. La existencia de un corazón grande, de forma redondeada 
("ccrazón en bola"), con su punta muy redondeada, en el examen radiológico: la familiaridad cuando existe y la concomitancia de glucogenosis muscular (se puede hacer bicpsia del núsculo estriado) pueden llevar al diagnóstico. Sin embargo, el diagnóstico etiológico raramente se hace y menos cuando no se está prevenido de esta forma de insuficiencia cardíaca del niño chico.

En cambio, es frecuente que se haga diagnóstico de hipertrofia idiopática con insuficiencia cardíaca congestiva, lo que lleva a discutir el diagnóstico con otras causas de insuficiencia cardíaca aguda del lactante, como ser la taquicardia parexística o el "flutter", las avitaminosis, el mixedema, il rhatdomioma, la hipertensión con dilatación cardíaca, las anemias graves acompañadas de insuficiencia cardíaca. etc.

Para quien se interese por el tema, le aconsejamcs la lectura de la importante monografía de. Kugel y Stoloff; el trabajo de $\mathrm{J}$. Hubbard y la monografia que publicaremos próximamente.

El diagnóstico anatómico se hace for el aspecto en red del tejido. que recuerda el corazón fetal; el estado vacuclar - hidrópico de las fibras, a veces con enormes vacuolas que rechazan los núcleos hacia la periferia $\mathrm{y}$, fundamentalmente, por la investigación de glucógeno, que aparece en las preparaciones frescas, en gran cantidad. llenando las vacuolas. Tiene valor la comprobación de glucógeno cuando se presenta en cantidad abundante, con estado vacuolar de las fibras o cuando se halla, un tiempo largo después de la muerte, como en nuestro segundo caso, o en el caso de L. E. Finkelstein, p. ej., que fué identificado 13 años después.

Es importante asegurarse que se trata de glucógeno y no de ctros materiales que pueden impregnar la célula, como scr material protídico, recurriendo para ello, además de las colnraciones específicas con el yodo o el carmin de Best, al tratamiento previo con la saliva, como hicimes en nuestro caso I.

El pronóstico es considerado muy grave, casi mortal. por lo que se lee en los trabajos publicados. Sin embargo, basándose en el hecho de que se conocen formas localizadas o circunscriptas (Finkelstein, Van Creveld y Van der Linder y la nuestra), que han sido interpretadas como etapa de curación posible de uñ proceso difuso, es lógico admitir que la forma generalizada y ccngénita pueda regresar lentamente, con marcha hacia la normalización anatómica, a me- 
dida que las células se van liberando de su sobrecarga glucogénica. Pero, tratándose de corazones muy disminuídos en su funcionalidad, son aptos a desfallecer en forma grave $y$ rápida, en cualquier momento y pcr causas mínimas. El tratamiento del corazón glucogénico en insuficiencia, es el qua cortesponde al síndrome de insuficiencia aguda. es decir, digitalización, tratamiento depletivc, si el enfermo no está muy en "shock", reducción de líquidos, etc.

Se describen 2 observaciones personales de cardiomegalia glucogénica, en niños de $3 \frac{1}{2}$ meses y 2 años. respectivamente. E1 estudic clínico y anatómico correspondió enteramerite al cuadro de la cardiomegalia glucogénica. Se pudo comprobar el aspecto histológico típico de las fibras y se encontró en ellas, glucógenos en abundancía. En uno de los casos — -1 niño de 2 años-- el glucógeno fué identificado al revisar nuevamente, un año después de la autopsia, el material conservado en formalina. El riñ̃o de $31 / 2$ meses presentó una forma difusa, que lo llevó precozmente a la insufiriencia cardíaca rápida e irreductible. El niño de 2 años tuvo un cuadro sub-agude y presentó la forma circunscripta de cardiomegalia glucogénica.

\section{Lipidosis.}

M. Canmann, en 1944 (Journ. of Ped., XXIV, 335 ). ha referido un caso de enfermedad de Niemann Pick en una niña de 2 meses, que falleció a las pocas horas de su admisión al Hospital. $\AA 1$ ingresar tenía palidez, ciancsis e infiltración. Se encontró una cardiomegalia en el estudio radiológico del tórax y el autor destaca el heche. Lamentablemente, aunque se practicó la necropsia, no se menciona el estudio anatómico del corazón. No sorprende que las lípidosis den infiltración cardíaca en forma similar a la glucogenosis, si se piensa en la difusión del proceso infiltrative; reticulo-histiocitario. Fuera de esta simple mención no hemos leido publicaciones que insistan sobre el punto. 
D) CARDIOMEGALIA EN NINOS RECIEN NACIDOS DE MADRES DIABETICAS

Recientemente ha despertado una atención especial la patología de los recién nacidos de madres diabéticas. Es así como $\mathrm{P}$. White ha vigilado atentamente 125 embarazos de 119 diabéticos, comprobando una supervivencia del feto mucho más limitada y el curso materno también anormal (toxemia, hipertensión, albuminuria, coma, hipoglucemia, etc.). Se ocupa, finalmente, en tan interesante trabajo, de las características de los hijos de madres diabéticas.

H. C. Miller y A. M. Wilson han señalado, en 1943 . agrandamiento cardíaco en 10 niños nacidos de madres con diabetes "mellitus". Esta cardiomegalia, que fué notable en los primeros días, fué disminuyendo con el tiempo, de modo que al final de la sexta semana había desaparecido toda evidencia de agtandamiento cardíaco. Un hecho interesantísimo. que señalan los autores, es la comprobación de un estudio necrósico de cierto número de niños nacidos de madres diabéticas, de un complejo patológico constituído por la asociación de hipertrofia cardiaca con focos anormales y excesivos, de eritropoyesis en el hígado, macrosomia e hiperplasia de los islotes de Langerhans. Sobre 18 niños estudiados, encontrarcn en 3 de ellos esos cambios morfológicos asociados y en los que respecta al corazón, llegaba a adquitir en algunos casos, el doble o el triple del peso observado. Estos hallazgos fueron más frecuentemente observados en niños cuyo peso al nacer era supetior a 3,900 grs. Los autores analizan las vinculaciones que pueden existir entre estas alteraciones y las balladas en casos similares de "eritrobaatosis fetal".

Como puede verse, estamos ftente a hechos nuevos, que prometen un campo prolífero de futuras investigaciones. Hasta ahora no tenemos experiencia al respecto.

\section{TAQUIARRITMAS, TAQUICARDLA PAROXISTICA $Y$ "FLUTTER AURTCULAR"}

Taquicardia paroxística y "flutter" auricular pueder presentarse en lactantes, aun en recién nacidos y llevar a ia dilatación cardíaca. La taquicardia sobrepasa, en general, 200 latidos por minuto; en algunas observaciones sobrepasó 400 latidos. La taquicardia paroxística se inicia bruscamen- 
te, con desasosiego del niño, latidos precordiales, latidos del cuello. Cuando el cuadro se prolonga, aparece la sintomatología de la insuficiencia cardiaca. El corazón se dilata progresivamente, la taquicardia es intensa. el pulso incontable, el hígado se agranda. Se presenta disnea, cierto grado de cianosis y, muy a menudo, edemas de los miembros inferiores. Existe congestión pulmonar pasiva. fiebre y leucocitosis.

J. Hubbard ha publicado recieritemente, en un trabajo muy importante. 9 observaciones de este curioso síndrome, sobreviniendo en lactantes de mencs de un año. Según este autor, la taquicardia paroxística por encima del año es más frecuente, más fácil de reconocer y también recidiva más frecuentemente y su tenacidad al tratamiento es mayor. Tan abruptamente como comenzó la enfermedad, puede cesar. Su. pronóstico es muy serio en lactantes menores de un año y el ttatamiento mejor conducido en ellas, puede ser inoperante. Los ataques de taquicardia paroxística pueden detenerse espontáneamente o bajo la acción del tratamiento. Puede terminar fatalmente con el cuadro de la insuficiencia congestiva o por síncope. El crigen de esta enfermedad en lactantes, todavía es oscuro. Es dificil pensar como en el adulto. que el tiroides (hipertiroidismo) o las gonadas puedan jugar un papel importante. La alergía ha sido invocada. especialmen te, en niños mayores. Se necesitan todavia muchos datos para aclarar el origen de esta enfermedad en lactantes.

Hubbard ba coleccionado en su trabajo, 19 casos de la bibliografía, de taquicardia paroxística o "flutter" auricular en lactantes menores de un año, con documentos gráficos que eliminan toda confusión. En un caso de Shermann y Schlee, en un niño de 1 mes, había un "frutter" $\mathrm{d} e$ 464: 232. es decir, 2/1. En otro caso, de Hess, en un niño de 8 días, habia un "flutter" irregular, de 300: 170. Hubbard sostiene que estas grandes taquicardias no son simples aceleraciones del ritmo. En sus casos había ritmos ventriculares entre 220 y 305 por minuto, demostrados electro-cardiográficamente. En tcdos los casos los ritmos eran supra-ventriculares. La taquicardia paroxística se inicia bruscamente: a veces, en periodo neo-natal. Puede presentarse en el curso de otras enfermedades ( 1 caso citado por Hubbard, siguiendo a un trauma obstétrico y otro a una neumonia). No sabemos si se pueden complicar estados de hipertrofia cardiaca como ser la cardiomegalia glucógénica o el corazón avitaminósico.

En el Uruguay, W. Piaggio Garzón, publicó en 1937 una observación de "flutter" auricular en una niña de $2 \%$ 
años de edad. Esta enfermedad se presentó 8 días después de una inyección de suero andi-diftérico (1.500 U.), que fué dada con fines preventivos, Siguió repitiendo periódicamente sus crisis hasta los 4 años. En una de ellas hubo maderada dilntación cardíaca, pero runca observó el autor cuadro asistólico franco, acompañando la crisis de taquicardia paroxística. "Se trataba de un "flutter" auricular (taquisistnlia auricular). La etiología probable del caso parece haber sido alérgica, por presentarse en un niño $\mathrm{con}$ antecedentes familiares de alergia y seguir a una inyección de suero anti-diftérico, a los 8 días, es decir. justo en el momento de la reacción sérica. El autor se ocupa extensamente de la ascciación de taquicardia paroxística con manifestaciones alérgicas. Finalmente, se muestra satisfecho del buen resultado obtenido en esta niña, con el sulfato de quinidina. Su enfermita ha curado.

En la Argentina, en 1935. M. Acuña y A. Puglisi observaron un caso de taquicardia paroxística en un niño de 12 años, heredo-sifilítico. Revisando la literatura pudieron coleccionar 24 casos de taquicardia paroxística o "flutter", en niños de edades variadas, aunque predominando los niños mayores. Como tratamiento de estos estados, se pueden empiear, como dice Hubbard, les procedimientos del adulto (reflejo de deglución, compresión ocular, compresión del "sinus" carotídeo, provocación del vómito), que fracasan en general. E1 "mecolil (clorhidrato de acetilmetilcolina) ha sido preconizado por tratarse de una droga para-simpático-trópica. Pero, su uso es peligroso y en 6 casos en que fué usado por Hubbard, dió una intoxicación con insuficiencia circulatoria y colapso grave. Hasta el momento, lo más usado ha sido la digitalización a dosis fuertes y si amenaza la dilatación cardíaca con insuficiencia congestiva. el tratamiento depletivo (sangría, evacuación de derrames serosos). En algunos casos, el sulfato de quinidina puede tener éxito. En un caso nuestro fracasó.

Hemos pedido recoger en los últimos 3 años' dos observaciones interesantes sobre taquicardia paroxistica y "Flutter" con dilatación cardíaca. Uno de los casos fué seguido en el Instituto de Pediatría. Sala Lactantes "B", en el año 1938. Se trataba de una-niña de 23 meses con un "flutter" auricu. lae, gran dilatación cardíaca e insuficiencia cardíaca congestiva irreductible, que falleció bruscamente de un síncope. cuatro meses después de enfermarse. 
El ctro caso fué seguido en la Policlínica de Lactantes del Hospital "Pereira Rossel1" (Dr. Marcos) y se refiere a una dilatación cardiaca en un recién nacido (ocho días de cdad), con gran taquicardia. Este niño curó y normalizó su corazón al cabo de unos meses, aunque muy lentamente.

\section{HIPERTENSION SANGUINEA}

Poco se conoce sobre este factor de dilatación cardíaca en el lactante. Existen escasas citas bibliográficas. E1 corazón puede dilatarse y desfallecer en el lactante, sea por aumento tensional en la gran circulación a por hipertensión en la pequeña circulación. La hipertensión arterial en el lactante puede obedecer a una glomérulo-nefritis, hasta en recién nacidos ( 5 casos de Karschner). En el lactante, las observaciones son más frecuentes. En la práctica pediátrica, las medidas de la presión arterial no han entrado en la rutina de la clínica. Es por eso quizás, que el diagnóstico de hipertensión en lactantes se hace excepcionalmente.

Raussig y Remser señalan un caso de hipertensión en un niño de 2 años, cuyo corazón llegó a pesar 220 grs. En él se pudo descartar toda otra causa de hipertensión secundaria (malformaciones o infecciones urinarias, tumor adrenal o pituitario, tumor cerebral).

H. Finkelstein también señala la posibilidad de la hipertensión arterial en lactantes. Dice que suele ser idiopática y familiar. Tumores de las cápsulas adrenales, cuyo tipo es el neuroblastoma, pueden crear hipertensión general y dilatación cardíaca. Hipertensión en la pequeña circulación puede deberse a malformación torácica, como cifoescoliosis o $\mathrm{ra}$ quitismo grave. Es posible que enfermedades pulmonares, como la esclerosis pulmonar, la bronquiectasia o la atelectasia puedan dar hipertensión pulmenar en lactantes, con dilatación cardiaca secundaria.

\section{TUMORES DEL CORAZON}

Tumores congénitos del corazón aumentan su tamaño. S. Farber (1931) coleccionó hasta entonces 41 casos de rhabdomiomas. Señaló la frecuente asociación con esclerosis tuberosa del cerebro y quistes embrionarios del riñón. M. Wegmann y D. S. Eghert, en 1936 (Journal of Pediatrics), relatan un caso de rhabdomioma del corazón asociado con 
"flutter" 1/1. En la necropsia se vió que el tumor tocaba el sistema de conducción. Existían nódulos diseminados sobre las válvulas mitral y tricúspide. Además, quistes en el riñón y no había esclerosis tuberosa del cerebro.

También, Jelken y Fisher han relatado un caso de teratoma intrapericárdico en una niña de tres semanas de edad. Se trató de un teratoma ampliamente incluído en el saco pericárdico y al examen se apreciaban estructuras quísticas. músculo, cartílago y estructuras glandulares, muchas de las cuales se parecian al páncreas. Los autores recuerdan el trabajo de Hedblom, sobre 21 casos de quiste dermoide y teratoma intratorácico en niños y los casos de Grimm, en los cuales se hizo diagnóstico clínico de hipertrofia cardíaca. También Joel, en 1890, publicó una observación parecída, en un niño de 14 af̃os. 7 ...

\section{GRUPO INCLASIFICADO O MISCELANICO}

Agrupa los casos raros de etiología difícil de clasificar. Así, Finkelstein cita casos de calcinosis del corazón, pudiendo dar hipertrofias e insuficiencias. También se han citado casos de esclerosis sub-endocárdica.

\section{Parte \\ ESTUDIO CLINTCO GENERAL}

Dado que el síndrome complejo que estudiamos, "Cardiomegalia-Insuficiencia Cardiaca en la Primera Infancia", se presenta a nuestra observación, ya sea a causa de los síntomas de insuficiencia cardíca o ya por la verificación de un agrandamiento cardíaco al examen radiológico, nos ocuparemos sucesizamente del síndrome clínico de insuficiencia cardiaca $y$ del estudio radiológico general de las cardiomegalias.

I. Descripeión general del síndrome de insuticiencia eardíaca.

El síndrome de insuficiencia cardiaca en el lactante está constituído por cuatro tipos de síntomas:

1) Sintomas generales y funcionales.

2) Síntomas obtenidos del examen directo del corazón.

3) Síntomas que responden a las congestiones viscerales de la insuficiencia cardíaca congestiva.

4) Colapso periférico. Enfriamiento. Hipotensión. Edemas. 
Deseripción de cada grupo de síntomas.

1. Síntomas generales y funcionales. - Son diversos y varían según los distintos casos. No tienen valor patognomónico, pues, pueden observarse también en otras afecciones. Los signos generales más frecuentes son: decaimiento, tendencia al reposo, tristeza, vómitos, inapetencia, a veces enfriamiento y sudores. Por lo común. estos síntomas generales son precoces, pero a menudo no se les da la verdadera interpretación y pasan con la máscara de un trastorno digestivo o respiratorio.

Entre los signos funcionales se observan los siguientes: disnea, angustia, cianosis, ortopnea, aleteo nasal y tiraje. Algunas veces se agrega el síntoma dolor.

Disnea: Síntoma de absoluta constancia y de enorme valor diagnóstico. Es una polipnea que comienza por ser disnea de esfuerzo, luego disnea de decúbito y finalmente se instala con carácter permanente, exagerándose siempre con el esfuerzo, hasta tomar los caracteres de disnea violenta.

Angustia: Síntoma infaltable y en ocasiones característico en este síndrome. Se manifiesta por una expresión de sufrimiento y de temor del fascies del niño que, con verdadero terror, evita todo lo que pudiera aumentar su malestar intolerable. Se niega a moverse y se resiste a las caricias y a todo lo que puede significar un aumento de esfuerzo para su corazón.

Cianosis: Desde el comienzo de la disnea aparece la ciancsis en mayor o menor grado. Al principio se observa en labios, uñas y alrededor de los ojos. En período más avanzado se hace muy intensa y generalizada. Es una cianosis relativamente precoz, que se intensifica con rapidez y que puede alcanzar grandes proporciones.

Aleteo nasal y tiraje. - Completan el síndrome. Absolutamente comparables a los cbservados en los síndromes bronconeumónicos con considerables alteraciones pulmonares.

Dolor: Es un síntoma frecuente, pero no constante. El dolor integra en realidad el síntoma angustia, a que nos hemos referido y se traduce en la expresión ya indicada del fascies de angustia dolorosa. Como se deduce del análisis que precede, todos estos síntomas funcionales son comunes a los que presenta el síndrome bronconeumónico del lactante. Por consiguiente, los síntomas de este grupo tampoco tienen carácter patognemónico $y$ con frecuencia el síndtome de insu- 
ficiencia cardíaca se oculta bajo la máscara de un síndrome bronconeumónico:

2. Síntomas obtenidos del examen directo del corazón v sistema vascular. - Este grupo tiene valor fundamental para determinar el diagnóstico, pero es necesario buscarlos minuciosamente, realizande una fina semiologia del corazón, porque un examen general apresurado o el no pensar en la insuficiencia cardíaca, podría pasarlo por alto.

Los síntomas obtenidos del examen cardiovascular son los siguientes:

1) Aumento del volumen cardíaco comprobado por la clínica y confirmado por la radiología.

2) Alteraciones del ritmo cardíaco.

3) Modificaciones de los tonos cardíacos.

4) Ingurgitamiento de las venas yugulares.

5) Alteraciones del pulso.

6) Electrocardiografía.

Cada uno de estos síntomas tiene sus características, que es necesario conocer bien.

1) Cardiomegalia. - El aumento del volumen cardíaco es un síntoma de extraordinaria importancia. Su comprobación se hace fácilmente por la locilización de la punta đel corazón, por la percusión del área cardiaca, y por el examen radiológico.

Localización de la punta del corazón: a veces resulta difícil precisar este dato en el lactante y más aún cuando hay insuficiencia cardíaca, porque el choque puede hacerse imperceptible. Cuando se logra localizarla, siempre se encuentra descendida entre el $5^{\circ}$ y el $6^{\circ}$ espacio intercostal izquierdo y por fuera de la línea mamilar.

Percusión del área cardiaca: casi como regla puede afirmarse la constancia del agradamiento del área cardíaca, con predominancia del eje transverso. El limite derecho sobrepasa el borde derecho del esternón y el límite izquierdo se encuentra por fuera de la línea mamilar, llegando en algunos casos hasta la línea axilar anterior. El diámetro transverso puede encontrarse muy aumentado, oscilando entre 10 y 14 centimetros, siendo la mediana del lactante, 6 centimetros (H. Brüring).

2) Alteraciones del ritmo cardíaco. - La taquicardia es un síntoma constante en el síndrome de insuficiencia car- 
diaca del lactante. Esta taquicardia alcanza proporciones variables, pero en general oscila entre 130 y 250 por minuto. Pcro, hay observaciones de autores extranjeros, en que la taquicardia toma carácter predominante, alcanzando cifras elevadísimas. En la interpretación de la taquicardia hay que tener en cuenta las alteraciones del ritmo, propias de la edad, con variacionẹs según el trimestre y todavia, la aceleración emotiva. tan característica del lactante y que puede alcanzar hasta cifras de 200 por minuto, sin que existan causas patológicas. El Dr. Mariano Latorre, en interesante trabajo realizado en la "Casa Nacional del Niño", de Santiago de Chile, sobre electrocardiografía del lactante sano (1941), encuertra una frecuencia del ritmo, superior a 120 , en el $90 \%$ de. los casos. Ha comprobado una frecuencia entre 160 y 200 en una elevada proporción de casos, en el $2^{9}$ y el 3 er. trimestre de la vida.

El ritmo embriocárdico es ctro sintoma muy frecuente en el síndrome de insuficiencia cardiaca del lactante. frecuente.

El ruído de galope puede observarse. aunque no es 'mny

3) Modificaciones de los tonos cardízcos. - Pueden comprobarse por la auscultación. soplos de carácter funciona! valvular, en los casos de dilatación aguda del miocardio; soplos orgánicos. en las insuficiencias secundarias a cardiopatías congénitas. Los soplos anorgánicos son rarcs en el lactante. En algunos casos hemos hallado frémitos y latidos epigástriccs. El síntoma más común, apreciable por la auscultación, es al apagamiento de los tonos cardíacos en el curso de la insuficiencia del miocardio. Este es un síntoma que nunca falta antes de iniciarse el tratamiento $y$ a veces es tan intenso. que apenas se oyen los tonos.

El fonocardiograma no ha sido utilizado hasta ahora, entre nosotros, en el lactante.

4) Ingurgitzmiento de tâs venas. - Es otro síntoma de gran frecuencia, la ingurgitación de las venas, más apreciable en las yugulares: estos vasos hacen saliencia. presentando en relieve su trayecto a lo largo del cuello.

5). Alteraciones del pulso. - E1 pulso se hace imperceptible, a tal punto que, a veces, no es posible comprobarlo. Cuando se halla, es siempre sumamente acelerado, como consecuencia de la taquicardia ya descrita.

6) Electrocardiografia. - Ultimamente, muchos investigadores se han ocupado del desarrollado y evolución del 
electrocardiograma en el lactante normal y prematuro. sano. Entre los trabajos que hemos consultado, podemcs citar el de B. Segura, publicado en la Revista Argentina de Cardiología (1936) y el de M. Latorre. publicado en la "Revista Chilcna de Pediatria" (1941), de gran interés y con gran aporté personal. Se trata de un estudio hecho sobre 70 casos de lactantes, en el primer año de vida. con 170 trazados.

Las conclusiones del trabajo de Latotre son las siguientes:

El electrocardiograma del prematuro y el del lactante normal, difieren entre sí. pero ambes quedan dentro de ciertas características, que son:

1) Ritmo taquicárdico entre 120 y 160 . Regular en et $99 \%$ de los cascs;

2) Onda $P$ más pequeña y menos amplia que en el adulto. Plana o invertida con gran frecuencia en $D_{3}$ :

$\left.3^{\circ}\right)$ Espacio P-R más pequeño que en el adulto, oscilando entre 0.08 y 0.16 seg.;

4) Onda $Q$ muy acentuada, especialmente en $D_{s}$. Siempre iigada a un predominio derecho más o menos acentuado;

5) Onda $\mathrm{R}$ y $\mathrm{S}$ de más bajo voltaje que en el adulto, siempre con ios caracteres de la preponderancia ventricular derecha $(80 \%)$ :

6) Espacio Q-R-S menor que en el adulto, cscila entre 0.04 y 0.08 seg.:

7) Segmento S-T generalmente isoeléctrico. En algunas ocasiones desnivelado, por encima de la línea isoeléctrica en $D_{2}$. pero nunca más allá de $1 \mathrm{~mm}$.;

8) Onda $T$ algo menor que en el adulto. Muy alte-

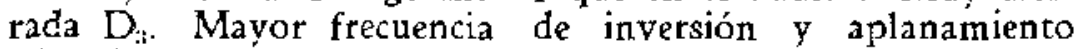
$(30 \%)$ :

9) Espacio Q-T normal en relación con la frecuencia del ritmo:

10) Predominio ventriculat detecho en $80 \%$ de los casos. Tendencia a disminuir entre el $4^{\circ}$ y $12^{\circ}$ mes de vida. Posibilidad de encontrar cambios bruscos en la dirección del eje eléctrico, sin ninguna manifestación clínica.

En un estudio reciente scbre "La electrocardiografía en pediatría", Max Schman y A. J. Mcss, llegan a conclusiones muy interesantes:

1) Existe en el prematuro y en el lactante, en el primer trimestre, preponderancia ventricular derecha. Después 
del $4^{\circ}$ mes, el complejo ventricular se aproxima cada vez más al tipo adulto.

2). La onda $\mathrm{P}$ es constante y bien definida en el lactante. Sin embargo, $P_{a}$ puede estat invertida o bifásica normalmente, ocurriendo esto en el. $3 \%$ de los trazados. No tiene mayor valor una melladura de $P$.

3) La conducción A-V es más corta que en el adulto. En el recién nacido, la duración de P-R es 0.113 de segundo como promedio $\mathrm{y}$ al final de la infancia. 0.138 de segundo. El límite superior normal es de 0.14 a 0.18 , variando según la edad y la frecuencia cardiaca.

4) La onda $Q$ pủede faltar de un modo normal. Con la edad disminuye su profundidad. Normalmente, en el electrocardiograma infantil, $Q 1$ y $Q 2$ no se las encuentra desdoblados o mellados.

5) R 1 es más baja en los primeros meses de la vida y en cambio $S 1$ es más profunda, lo que está de acuerdo con ia preponderancia ventricular derecha ya apuntada. En la infancia puede encontrarse cierto grado de desdoblamiento de R.y S.

6) La altura del complejo Q-R-S en el niño, oscila entre 10 y 18 milímetros.

7) La onda $T$ varía con las influencia exteriores. Está a menudo ausente los 10 primeros días del recién nacido. Al final de la infancia, $T 3$ se puede encontrar normalmente invertida, isoeléctrica o difásica.

Como puede apreciarse, el lactante, especialmente el recién nacido y el prematuro, tienen normalmente caracteristicas especiales en su electrocardiograma, que deben tenerse siempre presente al interpretar un trazado: ritmo mas frecuente $(120$ a 160$)$, preponderancia derecha. conducción $A-V$ más corta, modificaciones en algunas ondas, inclusive melladuras en $\mathrm{P}$ sin carácter patológico.

Electrocardicgrafía en el síndrome de insuficiencia cardíaca del lactante. - Nuestra experiencia se refiere, sobre todo, a la insuficiencia cardiaca aguda, de apariencia primitiva. En estos casos, el electrocardiograma sólo revcla ligeras alteraciones que son inconstantes. En general, manifiesta: regularidad en el ritmo. taquicardia más o menos marcada: en nuestros casos, Jas frecuencias han oscilado cntte 150 y 250 por minuto. Otros autores, como Hubbard, encuentran cifras mucho mayores. Es verdad que este autcr considera que la insuficiencia miocárdica es la consecuencia de la taquicardia. 
En varias de nuestras observaciones personales, se ha comprobado predominancia del eje eléctrico hacia la izquierda. Sabemos que en el lactante ncrmal existe predominancia derecha.

En las insuficiencias cardíacas secundarias a malformaciones cardíacas, el electrocardiograma presenta características propias del tipo de malformación. Actualmente, el electrocardiograma, en las enfermedades congénitas del corazón, constituye un elemente muy importante en el diagnóstico diferencial de las distintas cardiopatías. Recientemente, en marzo de 1942, dos autores estadounidenses, Eisenber y Gibson. de Chicago, publicaron una monografía muy original $e$ interesante: "Enfermedades congénitas del corazón y eitctrocardiograma". Pasan revista a los trabajos jublicatos al respecto $y$ hacen conclusiones de gran valor práctico en el diagnóstico diferencial de las distintos cardiopatias congénitas.

3. Síntomas que responden a las congestiones visceraIes de la insuficiencia cardiaca congestiva. - Las congestiones viscerales en la insuficiencia cardíaca del lactante. son precoces y muy pronunciadas. Las más importantes son las congestiones hepática. pulmonar y esplénica.

Hepatomegalia. - Existe en todos los casos; este síntor ma es tan constante como el aumento del volumen cardíaco. No hay insuficiencia cardiaca en el lactante sin acompañarse de hepatomegalia en mayor o menor grado. Siendo la hepatomegalia de comprobación muy fácil en clínica, este sintoma constituye un podercso auxiliat para sospechar 1 a insuficiencia $v$ precisar minuciosamente el volumen cardíaco por la percusión y la radioscopía o radiografía. En este sindrome el hígado puede adquirir proporciones extraordinarias. rebasanco a veces hasta la cresta ilíaca. Esta hepatomegalia es. con frecuencia, dolorosa a la palpación.

Esplenomegalia. - No es constante, pero la hemos observado.

Congestión y edema pulmonares. - Estos sintomas se observan en el período de estado o en el período final, realizando con los síntomas funcionales, un sindrome pseudobronconeumónico completo que, en los casos de apariencia primitiva, hace muy difícil el diagnóstico diferencial para el médico no prevenido. Estas lesiones pulmonares toman diversos aspectos clínicos: unas veces son simples procesos brónquices; otras veces adoptan el tipo de condensación del 
parénquima, dando macidez y soplos: o toman el tipo de congestión, con $o$ sin macidez $y$ estertores subcrepitantes. $A$ vaces. la lesión es revelada por el examen radiológico, lo que se presta aun más a confusión con procesos pulmonares.

4. Colapso periférico; - Enfriamiento: síntoma constante y a veces precoz. Este enfriamiento se manifiesta en especial en las extremidades. En la insuficiencia miocárdica aguda es casi constante la ausencia de fiebre. o si la hay es muy discreta. No es raro observiar temperaturas subnormales.

Edemas periféricos. - Aparecen también en el período de estado o en el período final. Predominan en los miembros inferiores, pero se observan también en cara.y en los casos evolutivos se generalizan. Estos edemas tienen los caracteres del cdema cardiaco.

Anasarca y ascitis. - Son síntomas que aparecen en la faz final del síldrome. En algunos casos los hemos observiado con gran intensidad, confirmándose en la autopsia gran derrame ascítico. En los casos que han terminado fatalmente, es muy frecuente observar derrame pericárdico con los mismos caracteres que el líquido ascítico. Ambos tienen los caracteres de los transudados.

Aparato urinario. - No presenta alteraciones de importancia. Sólo hemos observado discretas albuminurias y también. en algusios casos, hematurias microscópicas. Algunos antores (Casaubón y Cossoy) han comprobado ligera disminución de la permeabilidad renal. La urea en el suero sanguineo, en general es normal, salvo que se trate de insuficiencia cardíaca secundaria a lesiones renales, pero este hecho es excepcional en el lactante. En todas nuestras observaciones, la urea en el suero sanguíneo fué normal.

Examen morfológico de la sangre. - Hemograma: en general no revela nada de anormal, salvo en los casos en que la insuficiencia es consecutiva a anemias graves o a otro tipo de hemopatías.

\section{SINDROME APARENTEMENTE PRIMITIVO}

Existe en el lactante un síndrome de insuficiencia miocárdica, aparentemente primitivo, consecutivo a dilatación cardíaca aguda, sobreviniendo en niños aparentemente sanos. Este síndrcme aparece fuera de todo trástorno previo pulmonar, como lo demuestra la ausencia de sintomas de auscultación y percusión, así como la ausencia de fiebre y el examen 
anatómico pulmonar, negativo. Es independiente, también de toda alteración cardíaca previa, definida, congénita o adquirida, como se deduce de la ausencia de antecedentes, ausencia de alteraciones clínicas y radiológicas anteriores al accidente y en los casos con estudios anatómicos, ausencia de lesión congénita de lesiones valvulares y de hipertrofia del miocardio. Es un tipo de insuficiencia miocárdica, de etiología aun desco. nccida que, por tal razón, aceptando la clasificación de Kugel, estaria comprendida en el grupo VIII, es decir, entre las de causa indeterminada.

Dada la rareza de la literatura referente a este asunto $y$ la poca experiencia médica a este respacto, dos de nosotros (Bonaba y Saldún de Rodríguez) pablicamos, en 1938, una monografía sobre "Asistolia aguda primitiva del lactante". En este trabajo estudiábamos un total de 15 observaciones (7 personales y 8 de autores extranjeros), todas ellas con insuficiencia miocárdica de apariencia primitiva, en niños menores de. 3 años. Después de nuestra publicación, las observaciones similares se han multiplicado tanto en el país como en el extranjero. Entre nosotros, la preocupación de la insuficiencia miocárdica en el lactante existe hoy en el espíríta de casi todos tos pediatras. El Prof. Zerbino y su colaborador e] Dr. A. Norbis, han observado varios casos. El Prof. A. Carrau, los Dres. J. R. Marcos, C. Pelfort y G. Mendoza, también. Dos de nosotros (J. Bonaba y Saldún de Rodríguez), en 1941, presentamos a la Sociedad Uruguaya de Pediatría, una serie-de 3 observaciones, en niños menores de un año. En 1940. Saldún de Rodríguez presentó otra observación, en una niña de 30 meses.

En el extranjero, el Prof. Dr. Mensi, Director de la Clínica Pediátrica de Torino, publicó una observación haciendo referencia a nuestro trabajo, que acababa de leer, cuando tuvo oportunidad de ver un caso personal que evolucionó favorablemente con el tratamiento que indicábamos. En 21 Brasil, en Río Grande del Sur, tenemos conocimiento de dos nuevas observaciones publicadas. En la Argentina, además de las observaciones ya mencionadas en nuestra monografía. se ha enriquecido la literatura con nuevas publicaciones entre las que figura un caso reciente de G. Depetris, de la Clinica del Prof. José M. Valdés, de Córdoba. Récientemente, Arruro Baeza Goñi y Werner Bustamante, de Santiago de Chile, publican en Archivos de Pediatría del. Uruguay (julio 1944), un caso minuciosamente estudiado de insuficiencia 
cardíaca aguda de etiolcgía desconocida, que evolucionó favorabjemente, en un niño de 18 meses.

\section{Etapas evolutivas del sindrome de insuficiencia miocárdica de apariencia primitivo.}

Desde su iniciación hasta su terminación espontánea, la evolución clínica puede ser dividida en 3 periodos que rencesentan 3 etapas sucesivas de la enfermedad. Cada uno de estos períodos presenta su sintcmatología particular y muy constante, con pequeñas variaciones de uno a otro caso.

Primer periodo o periodo de comienzo. - Este primer período se inicia bruscamente. Se caracteriza por la aparición de los síntomas generales del sindrome cardiaco. Hay 3 sintomas que llaman, en primer término, la atención de la madre y tienen tal constancia que se repiten en casi la totalidad de estos casos. Estos síntomas son: tristeza; decaimiento o postración y tendencia al reposo. El niño, que hasta entonces gozaba de plena salud y estaba alegre, se pone triste, deja de reír, no quiere jugar, tampoco quiere alimentarse, sólo desea estar quieto y pide que lo pongan en cama cuando ya está en edad de expresar sus desecs. La tos y los vómitos son también dos síntomas que pueden observarse en el primer período, La fiebre alta. o es muy discreta y pasajera. Es muy frecuente el enfriamiento y la palidez. Esta falta de fiebre, unida a la falta de sintomatología física franca, hacen que el médico no prevenido le reste importancia al proceso; o lo interprete como un estado catarral simple, más aún cuando existe la tos y el vónlito. Este período llama más la atención de la familia que del médico y así se explica que en la mayor parte de las observaciones publicadas no se encuentran datos de comienzo, o si citan algunos, es vagamente, sin darles precisión ni importancia. Este período de comienzo es de duración variable; en general dura 2 a 8 días. Lo más frecuente es que dure de 2 a 3 días.

Segundo perícdo o feriodo de estado, - Se caracteriza por la aparición de síntomas funcionales y la comprobación franca de síntomas físicos. Reaparece disnea. ortopnea; la palidez del principio se sustituye por ciancsis, que puede llegar a ser muy intensa: hay angustia, aleteo nasal y tiraje. Llama la atención, en este cuadro tan ruidoso, ta falta de fiebre: en general, hay enfriamiento periférico. Este es el período en que el médico comprueba la gravedad evidente del proce- 
sc, pero si no está prevenido, establece el diagnóstico de bronconeumonia $y$, en general, ordena la hospitalización. Es asi cómo han ingresado la mayor parte de nuestros casos, y también la mayor de los casos recogidos en la literatura médica.

Los sintomas físicos del síndrome cardíaco son evidentes y claros en este período; en primer lugar, el aumento del área cardíaca y la hepatomegalia, acompañados o no de edemas periféricos, de congestión y de edema pulmonar.

Duración de este período: es difícil de precisar, porque sólo puede observarse completo en los casos en que no ha intervenido tratamiento, pues éste, bien dirigido, detiene en general la marcha de la enfermedad y determina la regresión de los sintomas. Sin precisar cifras, podemos afirmar que este período es bastante más largo que el primero. En nuestros casos ha oscilado entre 4 y 26 días.

Tercer período o período final. - Es muy frecuente que los enfermitos ingresen a la Clínica en el tercer período. En éste hay que diferenciar los casos abandonados a su evolución espontánea, de aquéllos sometidos a tratamiento.

a) Evolución espontánea: Abandonada la enfermedad a su evolución espontánea, va hacia la àgravación progresiva y rápida, entrando en la faz final. Se intensifican los síntomas funcionales: la disnea es violentísima, la cianosis adopta el aspecto de.la enfermedad azul y hay ingurgitación de las venas yugulares: aparecen anasarca, ascitis y edema pulmonar; aparece ruido de galope y la muerte se produce por asfixia. angustia y desfallecimiento progresivo del miocardio.

b) Casos tratados. - Con la intervención oportuna del tratamiento bien dirigido. la enfermedad marcha hacia la regresión progresiva, que puede tomar 3 aspectos distintos.

1) Curación aparentemente total, en algunos casos

2) Curación clínica, dejando cardiomegalia.

3) Curación transitoria, interrumpida por nuevas crisis de insuficiencia miocárdica, en otros casos.

Veamos los caracteres de la marcha regresiva en cada una de estas distintas modalidades de curación.

La regresión del sindrome se inicia por los síntomas funcionales; disminuye la disnea y la cianosis; luego disminuye el volumen del hígado y desaparecen los edemas; la argustia se sustituye por un estado de tranquilidad y bienestar. El aumento del área catdiaca es el último síntoma que 
se modifica; se reduce primero a la percusión, quedando por mucho tiempo en aumento, apreciable al examen radiográfico: tal vez la persistencia por mucho tiempo de este sólo síntoma es lo que ha becho considerar a veces a estos casos como hipertrofias cardiacas idiopáticas.

Duración del periodo de regresión total: es siempre largo. Rápidamente se produce la regresión de los síntomas funcionales y también de la hepatomegalia y de los edemas, pero la regresión del volumen cardíaco se hace muy lentamente. En general, los niños salen de alta, persistiendo el síntoma tadiológico del aumento de la silueta cardiaca. Hemos observado algunos casos que, ya al cabo de dos meses han normalizado las dimensiones de su imagen cardíaca; pero, lo corriente es que este aumento persista durante varios meses, y en algunos casos, más de un año. Con frecuencia sucede que algunos de estos casos se pierden de vista, ya porque funcionalmente no presentan ancrmalidades y dejan de ver al médico, a ya porque viven en campaña, resultándoles dificil y a veces imposible volver. Uno de los casos más antiguos, que hemos podido seguir; data de 1935 , y. hoy, 7 años después, su aparato cardiovascular es completamente normal. Este caso corresponde a la observación $\mathrm{N}^{T}$ XIII de nuestra monografía publicada en 1938. Este niño tiene boy. 10 años de edad. Hemos podido-seguir otro caso de nuestra primera serie, el correspondiente a la observación No XIII de la citada monografía.

Este caso tenía exámenes radiológicos de tórax, hechos por otro motivo, en fecha anterior al accidente de insuficiencia miocátdica, revelando una silueta cardíaca de forma y dimensiones perfectamente normales. lo que probó que no habia cardiomegalia congénita ni adquirida. En abril de 1937 , teniendo entonces 21 meses de edad, hizo una insuficiencia miocárdica, ingresando al Instituto de Clíníca Pediátrica en estado gravísimo, en tercer perícdo evolutivo, con la rica ruidosa sintomatologia de esta etapa comprobándose una extraordinaria cardiomegalia, tanto al examen clínico como al examen radiológico, cuyas imágenes pueden verse en las páginas 66 y siguientes de la monografía mencionada.

Este niño, un año después, conservaba un discreto aumento de la silueta cardíaca, al examen radiológico. Desde entonces se le siguió observando periódicamente: A los 17 meses, el corazón se había normalizado. Nunca más volvió a tener manifestaciones de insuficiencia miocárdica. Lo hemo. 
visto 3 años después, le hemos hecho nuevos exámenes radiológicos y electrocardiográficos, resultando totalmente normalizada su silueta cardiaca y la funcionalidad del órgano. Fuera de estos casos, son varias las observaciones de algún tiempo de evolución, oscilando entre 2 y 4 años, que se mantienen en completa normalidad clínica y radiológica, pero nos hemos detenido en estos dos, por tratarse de dos obsarvaciones de nuestra primera serie. y uno de ellos (Observ. XIII), en aquella oportunidad fué catalogado entre los que mantenían como secuela una discreta cardiomegalia.

Casos de curación clínica dejando uni aumento del área cardíaca. (Hipertrofia o dilatación). - Estos casos, en realidad son muy dudosos, pues no sabemos si ese aumento del vclumen cardíaco es debido a una hipertrofia del músculo cardíaco, como reacción de defensa, o si es debida a la persistencia de cierto grado de dilatación residual. Cualquiera sea su patogenia, parece evidente que esta cardiomegalia residual es capaz de regresar con el tiempo, como lo demuestran las observaciones Nos. XII y XIII de nuestra Monografía, que hemos podido seguir durante varios años. Por otra parte, este aumento discreto del volumen cardíaco, transitorio o no, es perfectamente tolerado y compatible con una vida normal.

Casos de regresión transitoria. Repetición de las crisis asistólicas. - Estos casos se caracterizan por la repetición de las crisis asistólicas que, en general, todas ellas ceden al tratamiento depletivo y cardiotónico, pero también conocemos casos de muerte en la repetición de las crisis. Personalmente, bemos tenido dos casos de repetición de la crisis; ambo terminados en curación. Parece existir una relación directa entre la intensidad y la prolongación del tratamiento cardiotónico y la repetición de las crisis. En los casos insuficientemente tratados y dados de alta prematuramente, se observa con más frecuencia que en aquellos tratados intensamente y mantenido en reposo durante más tiempo. Con frecuencia observamos la facilidad con que se da de alta prematuramente a estos niños; hecho en muchos casos precipitado por la propia familia, que sólo aprecia el cambio funcional en el niño. Del estado grave, ansioso, con disnea, cianosis, angustia, quejido y a veces edema, que presentan al ingresar, los ven pasar tápidamente, con el tratamiento, a un estado de bienestar, con desaparición de la disnea, la cianosis, !a angustia y los edemas. Pero. esto es sólo la primera etapa de la regresión. clínica. Quedan aún los elementos fundamentales de la insu- 
ficiencia miocárdica: la hepatomegalia, la cardicmegalia, expresión de la dilatación miocárdica, síntoma éste, que debe seguirse con exámenes periódicos, clínicos y radiológicos.

II: ESTUDIO RADIOLOGICO DFL STNDROME "CARDIOMEGALIATASUETCIENCIA CARDIACA DE TA PRIMERA TNIFANCIA"

El estudio radiológico aplicado al diagnóstico de este síndrome, nos proporciona una información de enorme valor: la verificación de un agrandamiento de la silueta cardíaca.

. El niño con cardiomegalia llega al examen radiológico por distintos motivos: ya con un cuadro clínico de lesión cardiaca -muchas veces de insuficiencia cardíaca-; ya con un cuadro sólo sospechoso de tal: ya sin diagnóstico de afección cardíaca. En este último caso suele venir para un examen pulmonar, sistemático muchas veces, más raramente para un examen de estómago, con el fin de aclarar un cuadro de vómitos en el lactante.

En el primero y el segundo casos, la radiología confitma a no la lesión cardíaca. En el tercero, ella descubre una iesión que pasaba desapercibida. En cualesquiera de esas eventualidades, el diagnóstico radiológico es primordial y no debe informar sobre la configuración y el tamaño del corazón.

Determinar radiclógicamente si existe o no un agrandamiento cardíaco, significa valorar los distintos procedimientos de que disporiemos para ello y conocer los valores normales en la infancia. Dividitemos este estudio en dos partes: en la primera, haremos algunas consideraciones sobre la silueta normal del niño de la primera infancia; en la segunda. estudiaremos el diagnóstico radiológico positivo y diferencial de las cardiomegalias en esa misma edad.

Consideraciones sobre İ silueta radiolögica normal del niño de la primera infancia. Cardiomegalias y pseudo-cardiomegalias.

El niño de la primera infancia presenta, comparado con el de la segunda y tercera infancias, algunas particularidades en su silueta radiológica cardiovascular, que vamos a analizar.

El concepto que expresan los libros, de que la silueta frontal, hasta los 3 años, es diferente de la del niño más grande, en el sentido de que los primeros tendrían normalmente 
un corazón globuloso, con .cierto ensanchamiento del pedículo vascular, no es completamente exacto. Creemos que puede existir ese aspecto globuloso, pero, que mucho depende de la fase respiratoria en que se estudie el corazón.

La radioscopía nos enseña cómo se modifica la configuración cardiaca de un lactante en las distintas fases respiratorias y sobre todo durante el 11 anto prolongado. Estas diferencias tienen su explicación en la posición del diafragma. En la posición media-apnea en semi-inspiración, el corazón se encuentra en la situatión más favorable para su estudio radiológico, pero no la podemos obtener en el niño de la primera infancia; cuando el diafragma desciende (inspitación), el corazón sufre una extensión y una rotación de su punta hacia adelante, haciéndose más vertical; cuando sube (espiración y llanto), sufre un aplastamiento y rotación de su punta hacia atrás, haciéndose más horizontal.

Los factores que influyen en la posición del diafragma son:

1) La respiración y el likntc. - El lactante siempre 1lora al radiografiarlo y si lo tomamos en ese momento, que es francamente espiratorio, tendremos corazones globulosos con pedículo ensanchado. En esa edad no podemos contar con la colaboración del niño. para fijar una apnea semi-inspiratoria $y$, para ponernes en las mejores condiciones posibles; debemos obtener las placàs en las pausas inspiratorias. estudiando previamente el ritmo del llanto.

2) El decúbito. - Un mismo corazón aparece más ancho radiografiado en decúbito que en vertical. El tórax de un lactante debe ser estudiado radiológicamente, siempre en posición vertical, usando el sistema de suspensión u otro que permita la misma actitud. Nosotros utilizamos una especie de bombacha con tiradores, que permite colgar al niño delante de la pantalla. Este dispositivo, variante del de Wood y del de Heegewaldt, lo hemos adoptado en nuestro trabajo de rutina, desde hace muchos años, y ya en 1931. Otto Riedel, del. Hospital "Roberto del Río", de Santiago de Chile, hacía notar sus ventajas en el estudio radiológico del lactante

3) La distensión abdominzi: - El meteorismo, frecuente en el lactante, la hepatomegalia y todo lo que contribuya a aumentar la presión intra-abdominal, debe tenerse en cuenta también como posible factor de deformación cardíaca. El estado en ayunas podría contribuir a disminuir el metecrismo, 
Los'3 factores enunciados, cuando se suman en el lactante, contribuyen a proporcionar esa silueta cardíaca globulosa, con pedícalo vascular ensanchado, que comentamos más arriba. Por eso, salvo los casos de gran aumento, nunca deberíamos hacer un juicio frente a una placa de lactante que impresione como un corazón grande, mismo siendo una telerradiografía. sin completar el examen con una radioscopia, que nos permita ver las modificaciones de la sombra cardiaca en las distintas fases respiratorias. Insisto en que la radioscopia en todis las incidencias, debe ser el primer tiempo oblígatorio de todo examen radiclógico cardio-vascular. La radiografia debe hacerse en forma de tele frontal, siguiendo una técnica rigurosa, para pcder obtener documentos comparables.

Nosotros procedemos al estudio del corazón de un niño de primeta infancia de la siguiente manera:

Desde hace tiempo hemos dejado de hacer el ortodiagrama en esta edad, porque aunque teóricamente es el procedimiento más exacto, es necesario para realizarlo, ta completa inmovilidad del niño durante el trazado y, salvo excepciones, ello es difícil de conseguir, aunque sea sólo por pocos segundos. Tampoco hacemos el telediagrama.

Hacemos un estudio radioscópico minucioso en todas las incidencias y luego una tele frontal en la siguiente forma: o1 niño suspendido frente a la placa, en posición vertical y bien aplicado cen el pecho contra ella: una nurse le mantiene la cabeza derecha y los brazos hacia los lados; otra nutse le tracciona los pies. por debajo de la placa, de modo de conseguir una inmovilidad del niño y una fijeza de la pared antcrior del tórax contra la placa: distancia foco-placa: 2 metros, enfocando el rayo central a la altura de ta punta deI cmóplato; tiempo de exposición: 1/10 ó 1/20 de segundo, según el equipo utílizado: exposición en las pausas inspiratotias.

Siguierdo las normas indicadas, obtenemos siluetas del lactante normal, que no son necesariamente globulosas (fig. 1), mismo se pueden diferenciar en ellas distintos tipos de corazón. Podemos observar corazones francamente pequeños y atros más o menos transversos y globulosos, pero sin presentar ensanchamiento del pedículo vasculat, ni saliente del arco medio; estos elementos, salvo excepciones, deben considerarse como patológicos cuando se observan en estudios hechos con técníca rigurọa. Cuando no nos ponemos en las 
condiciones técnicas indicadas, podríamos interpretar como agrandamiento cardíaco, lo que sólo es seudo-cardiomegalia.

Si en las condiciones técnicas referidas observamos un agrandamiento evidente de la silueta cardíaca, es obvio que existe agresión y aumento cardíacos; pero, cuandc ese agrandamiento no es franco, es cuando hay que actuar con más precisión y es entonces cuando tendrían aplicación las medidas del corazón, si ellas fueran rigurosamente exactas.

¿Tienen valor las medidas cardíacas en la primera infancia? Si en el adulto, que sólo presenta diferencias de tipo individual, la experiencia ha demostrado que las medidas del corazón tienen un valor muy relativo, en el niño y. sobre todo en el lactante, el problema es todavía más complejo. Veamos qué nos dice el estudio comparativo de les distintos procedimientos al respecto.

Valaración clinica de las distintas medidas del corazón en el niño de la primera infancia.

Volumen. - La medida del volumen sería el ideal. Es un estudio que no ha sidc hecho sistemáticamente en el lactante, para poder sacar conclusiones. Nosotros no calculamos el volumen. Los autores que han estudiadc este proce. dimiento en el adulto, concluyen que, por ahora, da un porcentaje alto de errores técnicos y que no tiene ventajas sobre las otras medidas.

Superficie. - Se usa mucho, en Estados Unidos, calculándola sobre el plano frontal de una tele y siguiendo el procedimiento de Bardeen, de completar arriba y abajo los contornos derecho e izquierdo de la silueta cardíaca; luego, se mide con un planímetro la superficie delimitada por el rontorno. Hemos tenido la oportunidad de trabajar en la clinica del Prof. Hodges, donde el cálculc del área cardíaca se hace sistemáticamente como rutina. Del estudio del área según edad, peso y talla, Ilegamos en 100 niños (20 de la primera infancia) a la siguiente conclusión: existe una relación entre el aumento del área y estcs tres factores, pero la relación es más propotcional con el peso que con los otros dos.

Hodges, Adams y. Gordon, de la Universidad de Chicago, estudiando niños normales, han llegado a determinar una fórmula de predicción del área normal, ccnociendo la talla y. el peso de los niños. Pero, es una fórmula no aplicable al 
lactante, porque sólo está calculada para niños por encima de 12 kilos de peso y $81 \mathrm{cms}$. de talla.

El cálculo del área tiene el gran inconveniente de la inseguridad de completar la silueta cardíaca arriba y abajo.

Medidas lineales. Diámetro transverso máximo. - Es la única medida lineal que se puede calcular sobre una tele; las otras necesitan datos complementarios del ortodiagrama o del telediagrama. Tiene la ventaja de la facilidad de su obtención y de que nunca hay dudas sobre los puntos que se toman como base de su medida. Falla en la apreciación de los aumentos de1 arco medio, los que en cambio serían incluídos en el cálculo de la superficie.

Existen algunas tablas que lo consideran en el lactante, aunque en general todos los estudios tratan al nin̄o después de los 3 años. Otto Riedel, de Santiago de Chile, publicó hace unos años, un importante trabajo con tablas de medidas lineales para niños normales, desde 1 a 12 años y también según peso y talla. Estas medidas fueron calculadas sobre tolediagramas. Saca como conclusiones que los únicos diametros de valor práctico son el transverso y el longitudinal; es decir, los grandes diámetros: los diámetros parciales le dieron resultados menos constantes.

Ultimamente. J. R. Diaz Niclsen, de Buenos Aires, en un trabajo muy completo, estudia el tamaño del corazón del niño normal sobre la base de 284 observaciones y como resultado. Ilega a confeccionar una tab!a de cifras normales del corazón en la infancia, basadas en la medida del diámetro transverso, en relación con la edad, altura y peso y también en la relación cardio-tcrácica. Se trata de un estudio profundo y de una tabla de gran utilidad, porque es de las pocas que incluye medidas dentro de la primera infancia: está ca'culada para niños desde 1 año de edad y por encima de 9 kgre de peso y $80 \mathrm{cms}$. de talla.

Métodor correlatives. - Consideraremos la relación cardio-torácica y los métcdos de predicción del área cardíaca y de! diámetro transverso.

Relación cardio-torácica. - A pesar del empleo sistemático que se hace de ella, estudios modernos han llegado a precisar que existe un errcr matemático en buscar cotrelación entre el diámetro traneverso cardíco y los diámetro inter. nos torácicos (Josephi. Ungerleider y Clark). Es un método que indica equivocadamente ensanchamiento cardiaco en $\mathrm{CO}$ 
razones normales de tipo transverso y que, por lo tanto, es poco aplicable al niño de la primera infancia, quien, por las características de su silueta se encuentra muy a menudo en esa situación. El aceptar de modo absoluto que una R. C. T. por encima de $50 \%$ significa en el lactante un aumento cardiaco, nos conduciría a muchos errores. En él, el límite normal debería ser alrededor de $55 \%$ y calculada esta relación como cociente cardio-torácico. los valores normales oscilarian entre 1.65 y 2 . Es una guía práctica y fácil de obtener, que siempre debemos calcular, pero creemos que debe set a considerat en cada caso según el tipo de corazón.

Tablas de predicción del área cardíaca y del diámetro traniverso. - La de Hodges. Adams y Gordon ya la hemos comentado al tratar las medidas de superficie. Ungerleider y Clark han construído una tabla de predicción de los diámetros transversos teóricos, según diferentes pesos y tallas, tabla que Kreutzer, de Buenos Aires, ha convertido al sístema decimal. No es aplicable al niño chico, porque está calculada para niños por encima de $152 \mathrm{cms}$. de talla y de 37 kilos de peso.

Conclusiones sobre medidas cardíacas. - En la primera infancia, las medidas cardíacas han sido en general poco consideradas en las tablas respectivas. Los valores obtenidos por los distintos procedimientos no son constantes ni comparables entre sí.

No hay que conceder valor a las cifras aisladas, sino cuando son referidas a otro examen anterior o posterior. hecho en las mismas condiciones y teniendo en cuenta siempre las variaciones fisiológicas determinadas por el crecimiento. Los métodos proporcionales son siempre más exactos que $1: s$ medidas aislada.

Perv, a pesar del acuerdo general sobre el valor relativo de las conclusiones cbtenidas por los procedimientos radiológicos, en la determinación del tamaño del corazón, debemos de reconocer que, por ahora, son todavía ellos los métodos más directos para llegar clínicamente a esa determinación, siempre que se use una técnica rigurosa y que se conozcan las causas de error.

Qué valor le debemos dar? ¿Debemos dejar de lado las medidas y guiarnos exclusivamente por la configuración?

Creo que honestamente podemos decir:

1) Cuando hay un aumento franco del área, global o parcial. o de un coeficiente, eso tiene un valor positivo. 
2) Cuando no haya ese aumento franco, debemos actuar con criterio a interpretar el caso según el tipo de corazón y su posición en el tórax. Las medidas no pueden ser aceptadas sin reservas, sino solamente como elementos a tener en cuenta según los aspectos clínicos del caso. La radiología clínica, y no la radiología, es la que debe dar la impresión definitiva en cada caso.

Aspectos radiológicos del sinđorome. Cardiomegalia e insuficiencia cardíaca de la primera infancia.

\section{Su diagnóstico positivo y diferencial.}

Con las bases del criterio formulado sobre el aspecto normal, abordaremos el estudio radiológico de este síndrome.

Se trata, siempre, de una alteración evidente de la silueta cardiaca, que se caracteriza por un agrandamiento general de la misma, que no deja dudas sobre la agresión del corazón.

Este agrandamiento constituye una base fundamental para el diagnóstico, a tal punto que se identifica con el concepto mismo del sindrome, tanto que. algunos autores consideran que la expresión "agrandamiento de la silueta cardiaca" es la que define mejor el estado patológico que estamos estudiando. La cardiomegalia radiológica se superpone, pues, al concepto anátomo-clínico de cardiomegalia y comprende todos aquellos casos que se manifiestan radiólógicamente por un agrandamiento general o global del corazón.

La sombra cardíaca se ensancha en todo sentido, determinando, cuando to hace lateralmente, en el sentido anteroposterior y verticalmente, una configuración "en bola", muy caracteristica (Fig. 2) : otras veces, el aspecto es èl de un corazón globuloso a gran diámetro transverso (Fig. 3). Las proyecciones oblicuas y laterales revelan que el agrandamiento es generalmente global.

El cálculo de las medidas nos da siempre valores francamente por encima de lo normal, como corresponde a los grandes agrandamièntos. No se trata nunca de pequeños aumentos del corazón. La relación cardio-torácica ( $\mathrm{R} . \mathrm{C} . \mathrm{T}$.) correspondiente a la tele de la Fig. 2 , es de 75,8\% y la correspondiente a la tele de la Fig. 3 , es de 64,1\%.

Este aspecto radiológico puede tener una etiología múltiple, como ya ha sido consignado en el capítulo cortespon- 
diente de este trabajo. Puede responder a lesiones de tipo ccngénito, como veremos más adelante, o a lesiones adquiridas. Se encuentra muy a mentodo, aunque no siempre, dentro de un cuadro de insufíciencia cardíaca, pero el aspecto radiológico aislado no puede llegar a identificar esta última, lo que en cambio siempre puede hacerse por el cuadro clínico.

Este cuadro radiológico nunca es patognomónico. Constituye tal vez, el elemento más importante en el diagnóstico pesitivo de estas cardiomegalias, pero no permite diferenciar las distintas causas que pueden producirlas, porque todas ellas determinan lesiones que se expresan radiológica. mente por deformaciones similares de la silueta cardio-vascu1ar. Corresponde a la clínica y a la anatomía patológica hacer. en lo posible, la diferenciación etiológica.

Sin embargo, además de fundamentar el diagnóstico positivo de una cardiomegalia global. creemos que el estudio tadinlógico es necesario, ya para seguir la evolución de la dilatación cardiaca, en los casos que van a la regresión, ya para destacar algunas particularidades que necesitamos conocer en pl diagnóstico diferencial de las cardiomegalias con ciertas cardiopatías congénitas y con las pericarditis con derrame.

Comentaremos nuestro material, agrupándolo dentro de 3 capitules y en el orden siguiente; Cardiomegalias e Insuficiencia cardíaca: Cardiomegalias: y malformaciones congénitas: Cardiomegalia y pericarditis con derrame:

\section{A) Cardiomegalia e insuficiencia cardiaca.}

Salvo las cardiomegalias globales debidas a algunas malformaciones congénitas bien definidas. que comentaremos en el capítulo próximo, la mayot parte de los agxandamientos cardíacos totales los hemos observado en la etapa de insuficiencia cardíaca. Una sola tez (Obs. XXXIV) llegamos a observar la cardiomegalia en la etapa de dilatación e hipertrofia previa a los fenómencs de insuficiencia, los cua1er aparecieron poco tiempo después.

En 3 casos bemos observado cardiomegalias globales xegresibles. que nunca hicieron fenómenes de insuficiencia (Obs. XXXVI y XXXVII y Observación publicada por el Dr. De'gado Correa).

En los casos cbservados en la etapa de insuficiencia cardíaca. el corazón éstaba aumentado a expensas de cus cavidadades derechas e izquierdas, y cuando fué fracticada la necropsia, al estudio anátcmo-patológico demostró que las la- 
siones de dilatación eran las que dominaban, siendo más li. mitados los signos de hipertrofia. Hemos visto formas aparentemente primitivas $\mathrm{y}$ formas secundarias, consecutivas a dilataciones cardíacas en el curso de algunas enfermedades infecciosas, cuadros respiratorios, trastornos del ritmo, tesaurismosis y glomérulonefritis. También hemcs observado furmas secundarias a malformaciones congénitas bien definidas. En la casuistica general están descritos los detalles de cada observación.

La figura 4 reproduce la silueta cardiaca de la Obs. VII, estudiada en plena insuficiencia cardíaca. Se trataba de una forma aparentemente primitiva que evolucionó favorablemente.

Los casos de las Figs. 5 y 6 corresponden a insuficiencias cardiacas secundarias a trastornos del ritmo. El primero (Obs. XXXVIII) se refiere a una taquiarritmia del tipo de! "flutter" auricular, en una niña de 23 meses, con signos de insuficiencia cardíaca congestiva: el corazón estaba aumentado, sobre todo a expensas de los segmentos ventriculares y dei arco medio: la $\mathrm{R}$. C. T. era $58.7 \%$. El segundo (Obs. XXXIX) corresponde a una cardiomegalia congénita en un recién nacide, con taquicardia permanente, que liegó a la curación.

En los casos de insuficicncia cardíaca que evolucionaron a h regreion. el corazón se mantuvo grande durante mucho tonpo despites que los signos de insuficiencia hubieron desa recido inande finamente a notmalizarse. En estos crens. el cstudto retiado, comparativo, es de gran valor para el concimiento de la evoluciún y de la curación; el signo radiclógico es el que desaparece en último término. Las Figs. 7 y 8 reproducen las radiografias en serie que documentan la evolucion regresiva correspondiente a la observación IV. En este útimo caso fué de nucha utilidad la existencia de un Examen ródiológico anterior al accidente asistólicc, que nos frermito descatrar en absoluto. la posibilidad de una hiFurtrofia cordiaca anterior a este reriodo. En otras observacicnes, la regresión radiclógica se hizo más rápidamente.

Fin la Obs. XXXIV es donde pudimos verificar un

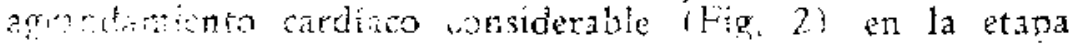
tosti a instibiencia crdíaca esta se prodajo paco tiem-

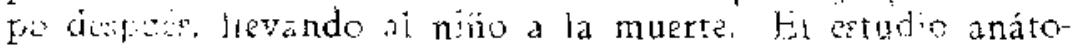
inc-ratécóico permitió llegar al diagnóstico etiológico de cardiomegaia glucogénica. Este niño fué llevado al examen 
radiológico para aclarar un cuadro de vómitos del lactante y el estudio del tórax hecho en esa ocasión, reveló el aumento cardíaco que era desconocido hasta ese entonces. Demuestra la importancia del examen radiológico en este síndrome. Se trataba de una cardiomegalia glucogénica, a la que se agregaba, muy posiblemente, una infiltración glucogénica del músculo pilórico.

Los dos casos siguientes corresponden a cardiomegalias regresibles, que en ningún momento hicieron fenómenos de insuficiencia cardiaca. El primero (Obs. XXXVI) fué una cardiomegalia mixedematosa, que regresó después de varios meses de tratamiento (Fig. 9). Las Figs. 10 y 11 documentan la osteosis hipotiroidea que presentaba esta niña. El segundo está reproducido en la Fig. 12: se trataba de una cardiomegalia del tipo mal Jlamado hipertrofia idiopática, en un niño de 5 meses de edad, en la que no se pudo determinat sa etiología y que, en un examen practicado 4 años después, se llegó a verificar la normalización del corazón. Nunca se manifestó por signos dínicos, ni nunca hizo insuficiencia cardiaca. Podemos decir que fué una cardiomegalia radiológica, que regresó espontáneamente y cuya etiología sólo habría podido aclararse con el estudio anátomo-patóógico. Esta observación fué publicada por el Dr. B. Delgado Correa en "Archivos Uruguayos de Cardiología" (1939).

No tenemos material de cardiomegalias secundarias a anemias, ni a leucemias de la primera infancia, pero sí en niños grandes. J.a Fig. 13 muestra e1 aspecto del corazón en un case de anemia eritroblástica del tipo Cooley, estudiado a la edad de 8 años, con signos de aumento del área cardíaca. En la Fig. 14 se documentan las típicas alteraciones óseas del cráneo observadas en este tipo de anemias congénitas. En la . Fig. 15 observamos también una cardiomegalia en una niña de 11 años, afectada de un sindrome leucémico de De Guglielmo, que lleva 7 meses de evolución. 
B) Cardiomegalias y malformaciones congènitas.

Un corazón congénito puede expresarse radiológicamente por una cardiomegalia global, aunque no es lo habitual. Pata este estudio dividiremos las siluetas radiológicas congénitas en tres grupos:

a) Aquéllas que poseen detalles en su configuración, que desde un principio orientan hacia el diagnóstico de un cotazón congénito.

b) Aquéllas que son normales o presentan pequeñas modificaciones no caracteristicas.

c) Aquéllas que se caracterizan por un agrandamiento global y evidente, verdaderas cardiomegalias, que son las cardiopatías congénitas que entran en el cuadro radiológico del sindrome que estamos estudiando.

En el grupo " $a$ ", consideramos: las salientes del arco medio, las deformaciones en zueco, los distintos tipos de dextrocardia y las anomalías de posición de los grandes vasos. Estos elementos, que pueden presentarse aislados o combinados, nos llevan de inmediato a pensar en la posibilidad de una afección cardíaca congénita, sin llegar a individualizarla totalmente, porque son signos comuries a muchas de ellas, aunque es posible en algunos casos. Los signos clínicos de cianosis y de soplo y las modificaciones electrocardiográficas completatán el diagnóstico dentro de lo posible.

En el grupo " $b$ " consideramos: las siluetas normales - poco modificadas (pequeños agrandamientos segmentarios. en general del ventrículo izquierdo, o corazones algo transversos). Aqui, el diagnóstico positivo es hecho por la clínita; la tadiología es un elemento complementario.

En el grupo " $c$ " consideramos: los aumentos globales. verdaderas cardiomegalias congénitas, que son los aspectos que vamos a analizar. En ellos, como en todo cardiaco, congénito, siguiendo las bases de la clasificación de Maude Abbott $\mathrm{y}$ dz las modificaciones propuestas por Cossio, debemos tener en cuenta para el diagnóstico diferencial, la presencia o ausencia de cianosis (ocasional o permanente) y la presenzia o ausencia de soplos.

Consideraremos. pues. las cardiomegalias globales dentro de los tres grupos clínicos siguientes: 


\section{Cardiopatjas congénitas acianóticas.}

En las formas acianóticas sin soplo, la cardiomegalia puede ser dada por anomalias de las arterios coronarias, Su mala implantación, sobre todo de la coronaria izquierda, saliendo de la arteria pulmonar en vez de la aorta, trae una degeneracion del micardio, que es seguida de dilatación y agrandamiento cardiacos. Radiológicamente puede existir una dilatación aneurismática del ventrículo izquierdo. Son casos sumamente raros. ILos casos publicados babían sido tomados clinicamente por hipertrofias idiopáticas y la necropsia teveló su verdadero origen.

Las anomalîas del pericardio, que también se diagnostican, en general. en la mesa de autopsias, pueden, a su vaz también. dar un agrandamiento cardíaco. Se trata de lesiones sin significación clínica. El caso de las Figs. 16 y 17 nor revela un aumento cardiaco a-expensas de su contorno derecho, comprobado a los 6 años de edad, en un examen sistemático. Aunque no se trata de un caso de primera infancia. creemos de intetés dccumentarlo aquí, por tratarse de una lesión congénita que fué tomada por una hipertrofia idiopática. Actualmente tiene 20 años, nunca hizo fenóm?nos de insuficiencia cardíaca y persiste el agrandamiento que ahora es más una deformación sacciforme scbre è contorno derecho. La importancia del caso es demostrar cómo un aspecto que en la niñez hizo pensar en una cardiomegalia a expensas dəl corazón derecho, se transformó con el crecimiento, en una deformación bien localizada. La gran tolerancia, el tipo de deformación sin signos clínicos y el aspecto dado por la tomografía, hacen pensar en un divertículo del pericardio. No hemos podido conseguir practicar un estudio kimegráfico, que nos hubiera proporcionado dates de sumo interés en este caso. Las Figs. 18 y 19 documentan el aspecto actual.

Entre las cardiopatias acianóticas con scple. no se observan francas cardiomegalias. Entran en este grupo, las estenosis aórticas, cuya silueta radiológica puede mostrarnos: hipertrefiz ventricular izquierda, dilatación de la aorta ascendente y a veces, ausencia del botón aórtico sobre el lado izquierdo. Estos elementos le dan un aspecto bastante caracteristico, aunque creemos de difícil reconocimiento en el lactante. En los casos de coartación, las típicas erosiones costales no son signos precoces; el caso más joven publicado, co- 
rrespondió a un niño de 6 años (Brcwn). Cuando estos casos van a la insuficiencia cardíaca. ésta se bace en forma insidiosa. En esta etapa, el corazón puede agrandarse, pero el cuadro clínico anterior permitirá, si era conocido. relacicnar esa cardiomegalia a su verdadera causa.

\section{Cardiopatias congénitas con cianos is tardía.}

En el grupo de malformaciones con cianosis tardía no se cbservan verdaderas cardiomegalias y cuando las bay, es que exisitn otras anomalías asociadas. Estos casos entran casi todos en el grupo "a". con aspectos radiológicos característicos. Solamente la comunicación interauricular. que representa el tipo de ciancsis tardía sin soplo, puede expresarse por un agrandamiento global, pero presenta, además, particularidades en sus contornos, que la hacen reconocible: arco medio saliente, corazón en zueco, aurícula derecha grande, hipoplasia de la aorta, estasis hiliar con danza arterial. Es rata como malformación aislada, en el $75 \%$ de los casos hay asociaciones valvulares (Abbott). Cuando se asocia a una estrecbez mitral, constituye la enfermedad de Lutembacher y en la silueta radiológica puede observarse, aunque no es obligatcrio. una dilatación de la aurícula izquierda.

En los casos de ciancsis tardía y soplo. la diferenciación radiológica puede llegar a hacerse entre sus tres representantes más drtinidos cenfermedad de Roger. persistencia dal canal artía: y etrechez pulmonar con tabique interventricular cerrocic: cuando existen: en el canal arterial, un arco medio salicate: en la estrechez pulmonar, un arco medio saliente $y$ un a: :ón en zueco, revelando una hipertrofia ventricular dereha. Pro, estas modificaciones no son absolutamente consartes, porque ellas dependen: en el canal artérial, del ta. mito det onificio y de la corriente que permite pasar: en la esteno is de la pulmonar, de la localización y del grado de 1 a estria l.a coservación siguiente nos demuestra estas difi-

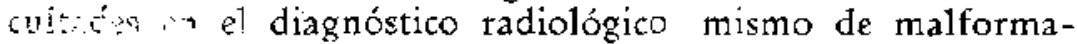
cirnce nanicas bien definidas: en un niño de 5 años, con signos cininicos y electrocardiográficos de cardiopatía congénita derecha, en el cual la necropsia evidenció que se trataba de una sinequia valvular de la arteria pulmonar con tabique interventricular cerrado $y$ una comunicación interauricular. la imagen radiológica sólo mostraba un arco medio rectilíneo, sin mayores modificaciones del ventrículo derecho, las 
que, sin embargo, eran evidentes en la pieza necrópsica (Figs. 20 \% 21. Observación clínica del Dr. B. Delgado Correa). Cuando es posible practicar la angiocardiografía. ella puede ser un complemento de diagnóstico de gran valor.

Todas estas malformaciones, cuando hacen insuficiencia cardíaca, dan corazones globulosos. La fig. 22 muestra el aspecto en un niño de 2 meses, en la etapa de insuficiencia cardíaca, el que representaba anteriormente un scplo con los caracteres de un Roger.

\section{Cardiopatias congénitas con cianosis permanente.}

Es en este grupo donde volvemos a encontrarnos con cardiomegalias globales.

Los casos sin soplo y con grandes siluetas globulosas. corresponden generalmente a corazones bi o triloculates, malformaciones muy graves y con gran cianosis. Los otros representartes de este grupo: atrepsia tricuspidea con comunicación interanricular; transposición de los grandes vasos con tabique interventricular cerrado, dan defcrmaciones más localizadas, con disminución de! pedículo vascular en frontal en la transposición vascular. Las Figs. 23 y 24 documentan dos cardiomegalias congénitas con cianosis permanente y sin soplo, las que demuestran la imposibilidad de llegar al exacto diagnóstico por el estudio clínico y radiológico. Se puede. por pequeños signos, llegar a un diagnóstico de probabilidad, que podrá ser confirmado o no por la angiocardiografia $y$, sobre tcdo, por la anatomía patológica.

Dentro de los casos de cianosis permanente con soplo, el tipo más definido es el corazón de Fallot (Fig. 25), que tiene caracteristicas radiológicas precisas y entra en las malformaciones que consideramos en el grupo "a". Fuera de él, del complejo Eisenmenger y de la dextrocardia complicada, que también corresponden al grupo " $\mathrm{a}$ ", los otros tipos congénitos con ciancsis y soplo, pueden dat verdaderas cardiomegalias, las que responden a maiformaciones múltiples, en general en relación con defectos de ambos tabiques asociados a lesiones valvulares y a transposición de los grandes vasos. La Fig. 26 reproduce una cardiomegalia congénita con intensa cianosis y soplo, que no presenta los caracteres de un Fallot.

Resumiendo este capítulo, podemos decir que entre las cardiopatías congénitas, salvo excepciones del grupo acianótico sin soplo. donde alteraciones en la irrigación del miocardio pueden determinar un cuadro de insuficiencia cardiaca similar 


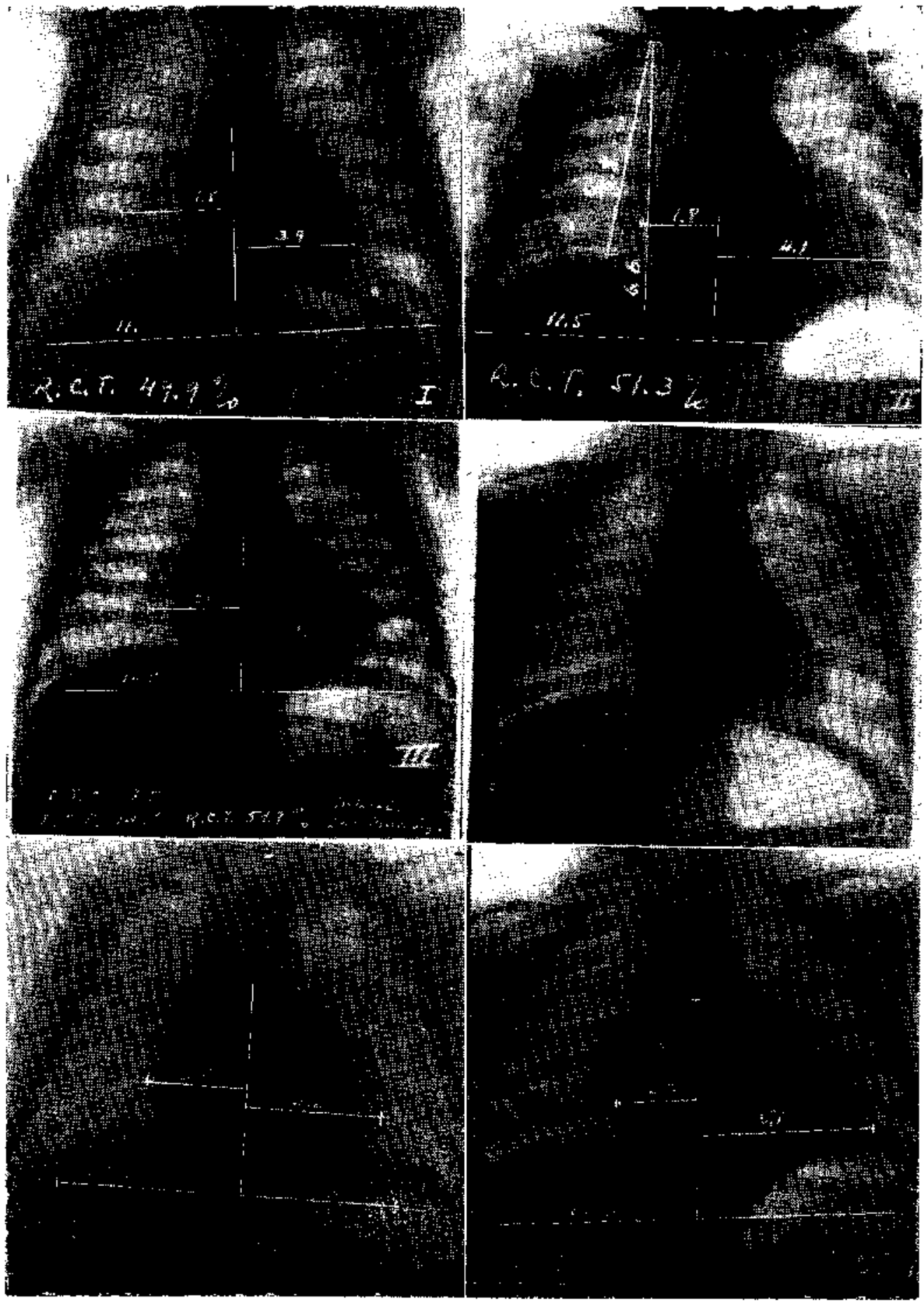

FIG. 1

Siluetus carciovasculares de laktantes normales obtenidas con la técnita indieada in tel texto. Se pueden apreciar distintos tipos de cotazón normal. Referencias de edad: I $\gamma$ II tres mescr; IIl, sikte nteses; IV, diez meses; $V$, doce meses; VI. trece rieses. 


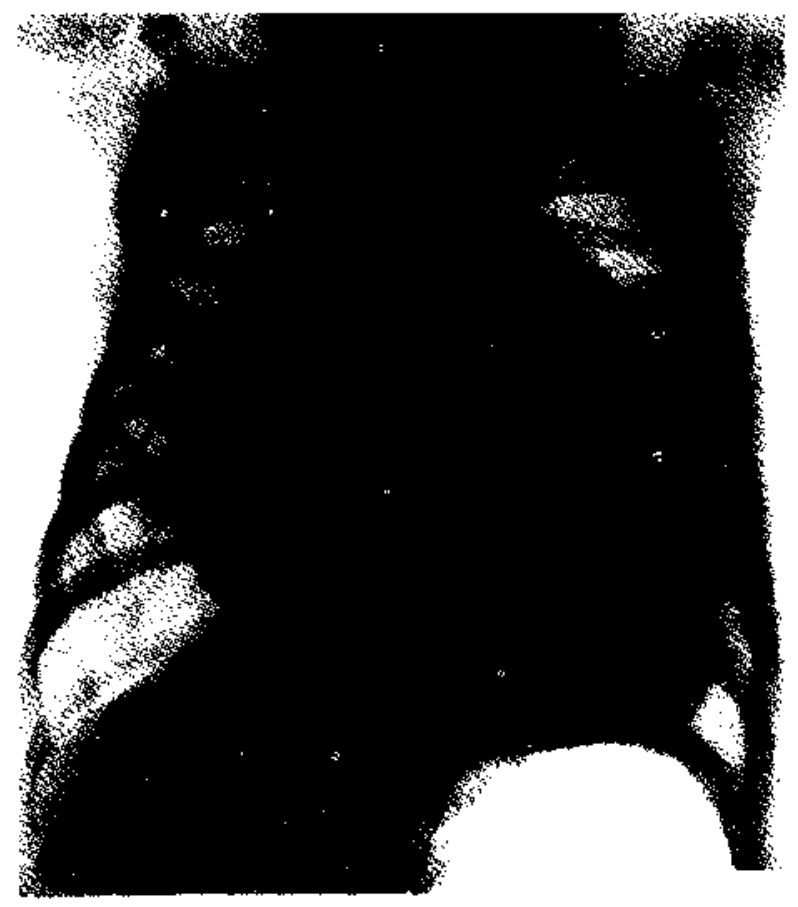

FIG. 2.

Catdiomegalia glucogínica en un niño de $31 / 5$ meses de edad. Controlor aná. tcrio-patológico. Aumento global dal corazón. Imagen en bola. R. C. T: $75.8 \%$. Radiogiafia del Setvicio del Dr. H. Bazzano. Hospital peciro viscal. 


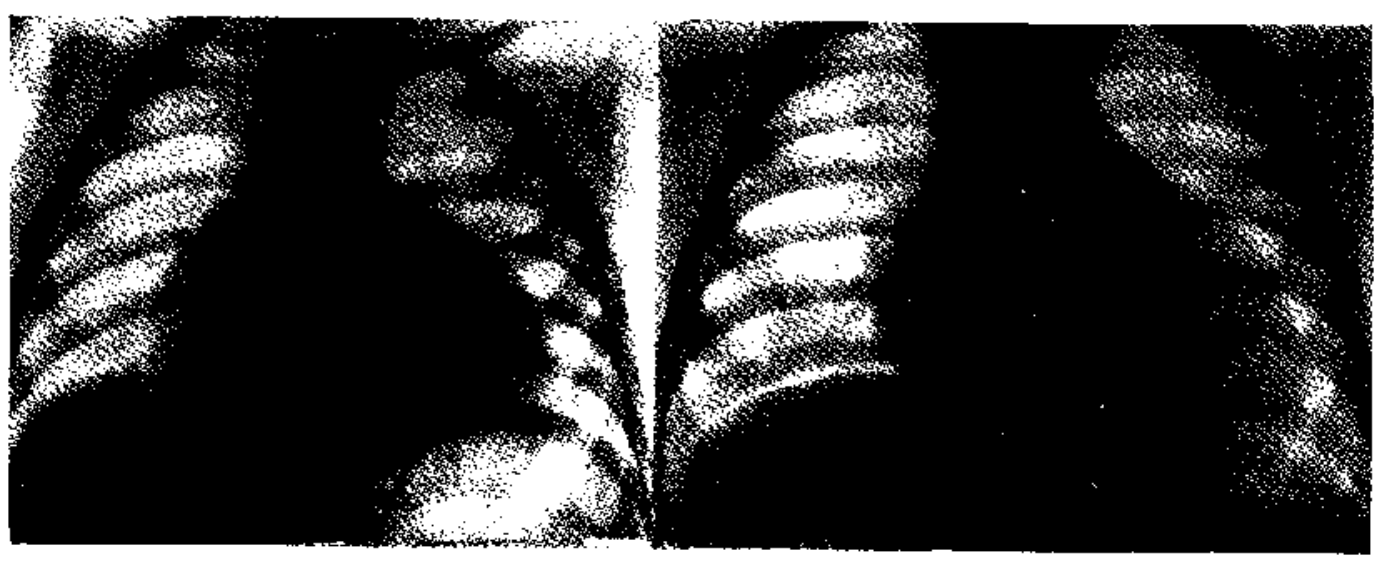

FIG. 3.

Cardiomegalia por ditatación cardiaca. Niño de 20 meses que hace insuficinncia cardiaca aguda aparenteminte primitiva. Dilatación de cavidades derechas $\circ \mathrm{iz}$ quierdas. R. C. T. $64,1 \%$.
FIG. 4.

Cbazrvación VII. Corazón dilatado a gran diámecro transvero. $R$. C. $T$. $60.5 \%$.

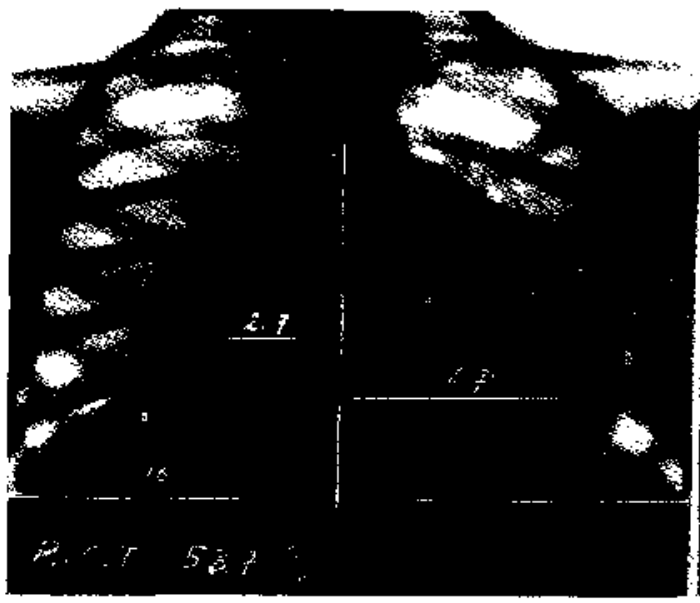

FIG. 5 .

Nitia de 23 meses con dilatación o in. suficiencia cardiacas secundazía a un flatter auricular (Obs. 38). La placa corresponde al período final de la eafer. medad y revela un aumento cardíaco J expensas de los segmentos ventriculares y del arco medio. R. C. T. 58,7\%.

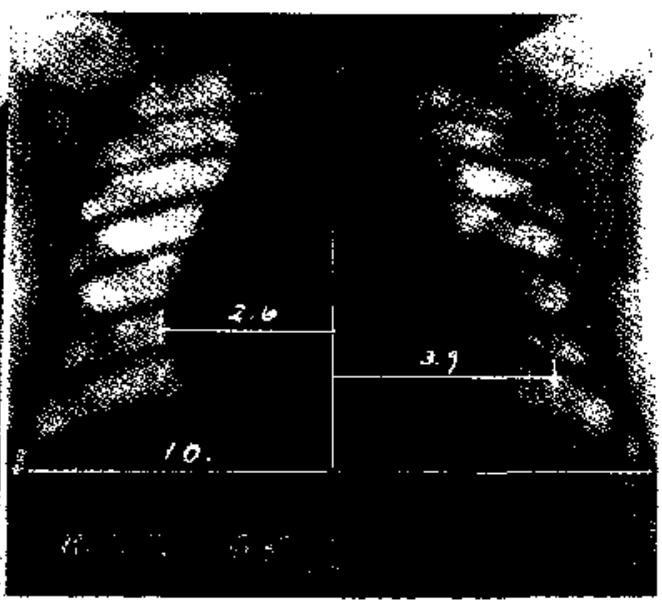

FIG. 6 .

Niño de 8 dias con cardiomegalia $y$ taquicirdia pesmaninte. R. C. T. $65 \%$. livolución lavarable. Observación 39. 


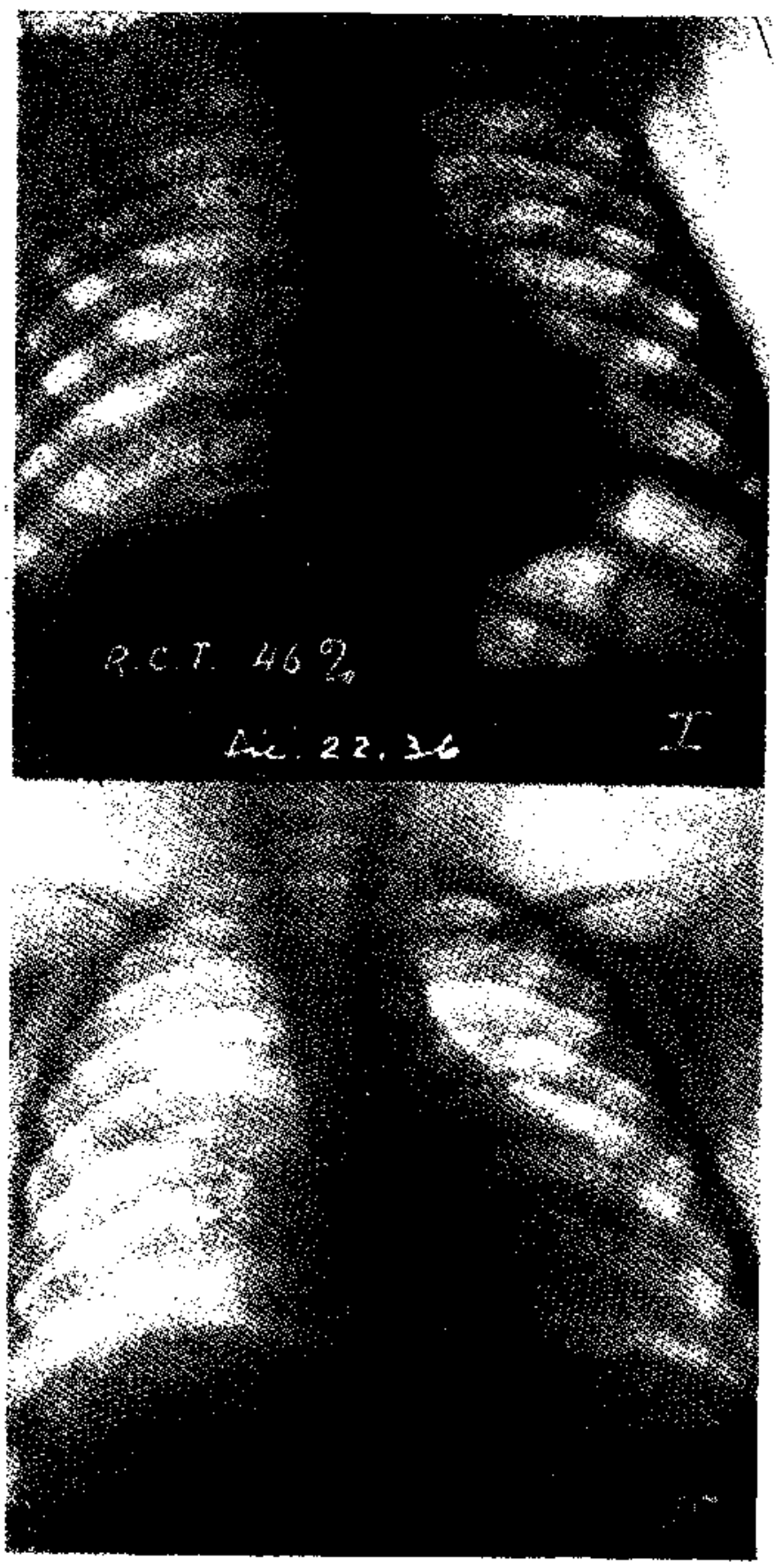

FIG. $\vec{r}$.

Obse: vación IV. I: Tislerradiografia obtenida varios meses antes del accident: de insuficiencia cardiaca y que revela un corazón de aspecto y tamaño normales R. C. T. $46 \%$. JI: Aspecto en plena insuficiencia cardiaca. Dilatación de a vidades decechas e izquierdas. R. C. T. $58,4 \%$. 

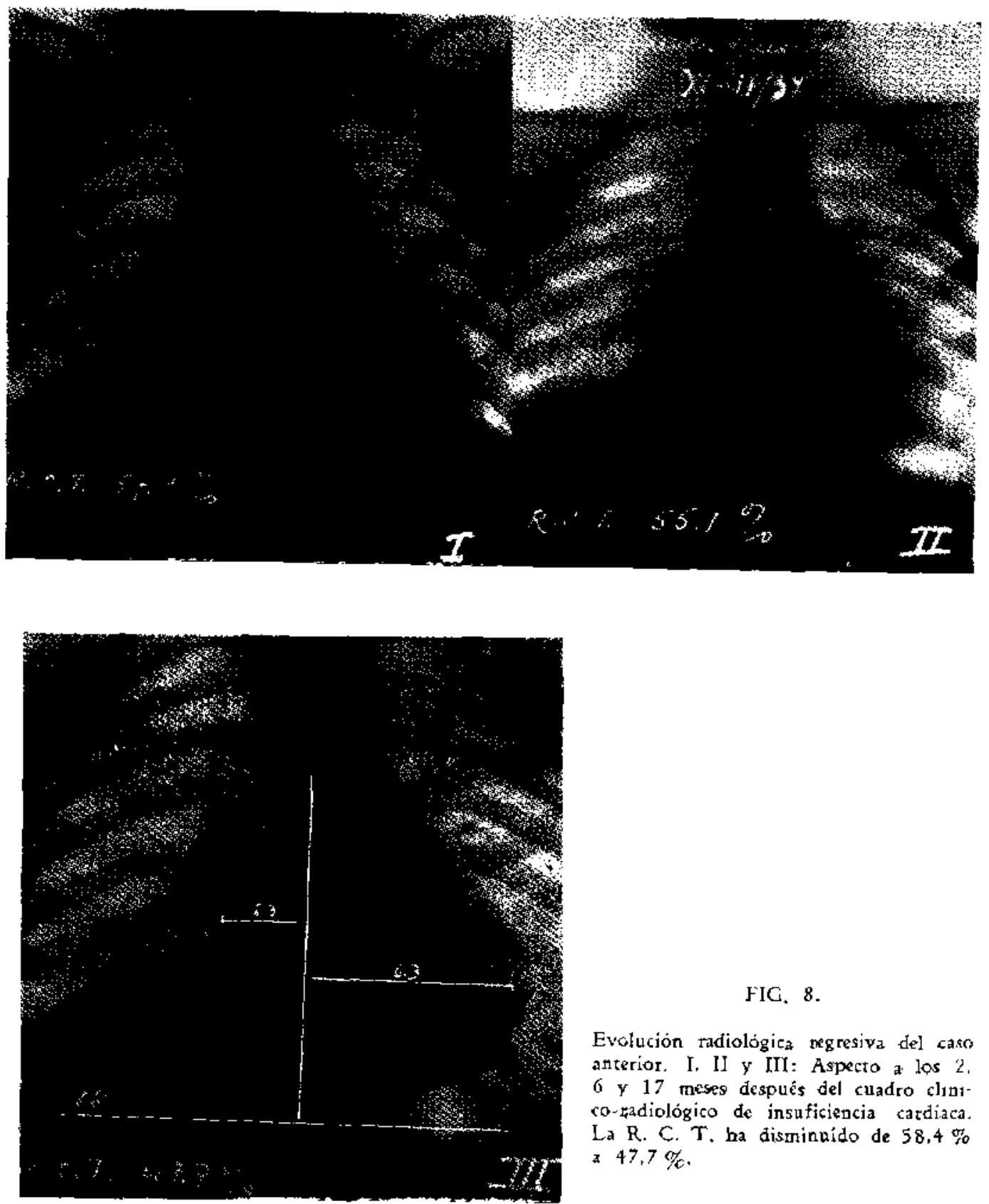

FIG. 8 .

Evolución tadiológica negresiva del caso anterior. I. II y III: Aspecto a los 2. 6 y 17 meses después del cuadro cluayco-adiológico de insuficiencia cardiaca. La R. C. T, ha disminaido de 58,4\% a $47,7 \%$. 


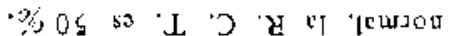

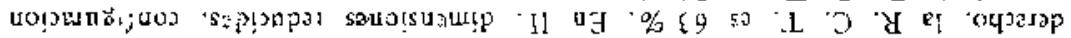

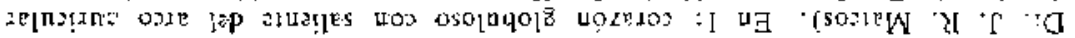

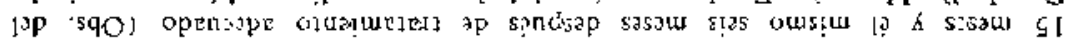

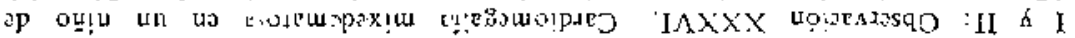

\section{OIJ}

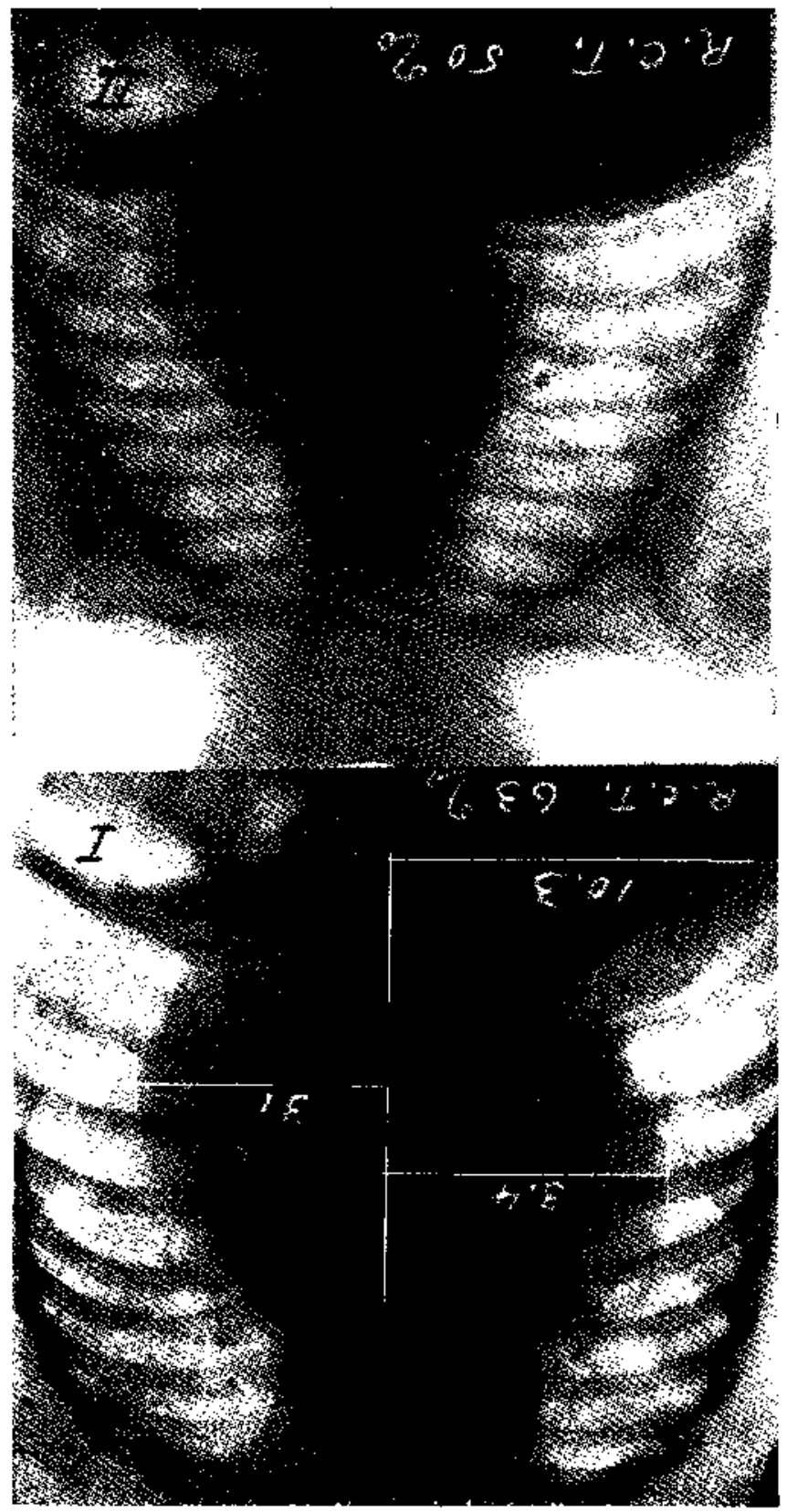



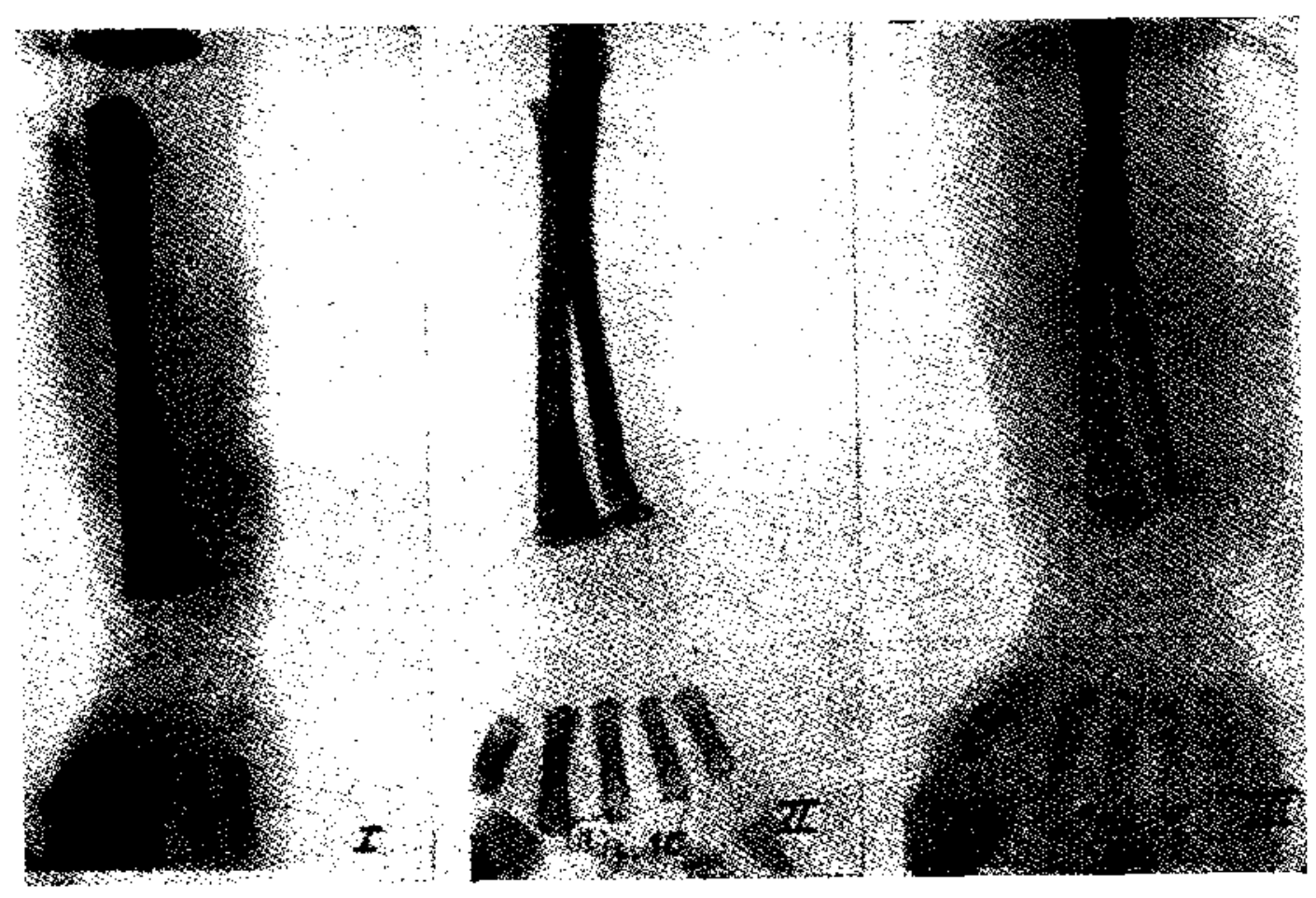

FIG. 10.

I. II y III: Osteosis hipotiroidea del misme caso. Denatrollo del puño a la eded de 15.17 y 20 mescs, revela qae existe un evidente ría do de la udad ósal. Capo simpre vacio. tar s:dinentacićn cálcica metatisaria, obsarvada a los 15 meses. se transiorma en los meses sub siguientes pu lineas de sricimiento.

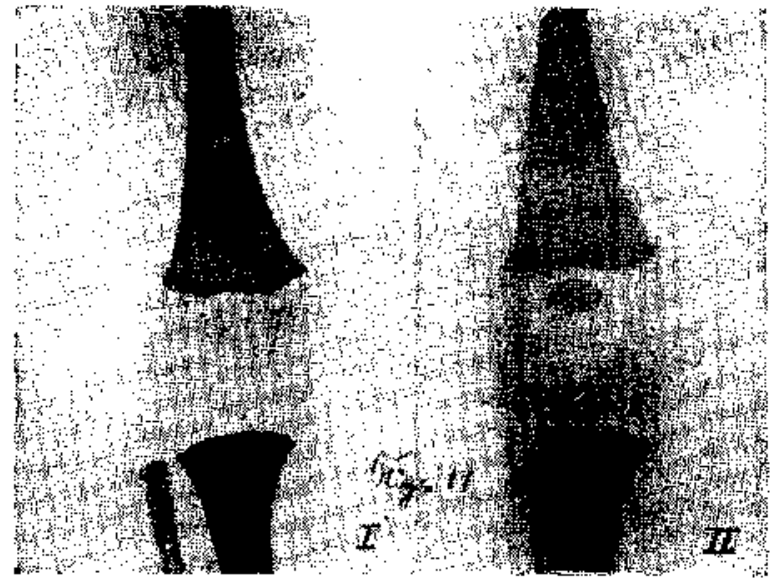

FIG. 11.

I y II: Aspecte de la rodiula del misno niño a los 15 y a los 20 meses. En I: se obsery marcado retardo en el desariólio de la redilla, no existe ni el punto in ferior del fémur. que hace nor malmente su aparición antes dei naciminto $y$ las metáfisis presentan esa sedimentación sileica que ya consignamos en los puños. En 11: dispués de 5 ntess.s de tratamiento, la diferenciación epifisizia ha aparecido francament? y la s:dimentarión cálrira metafi. saiia se ha ttansformado, como en los mismbros superiores, en lineas de cracimiento. 


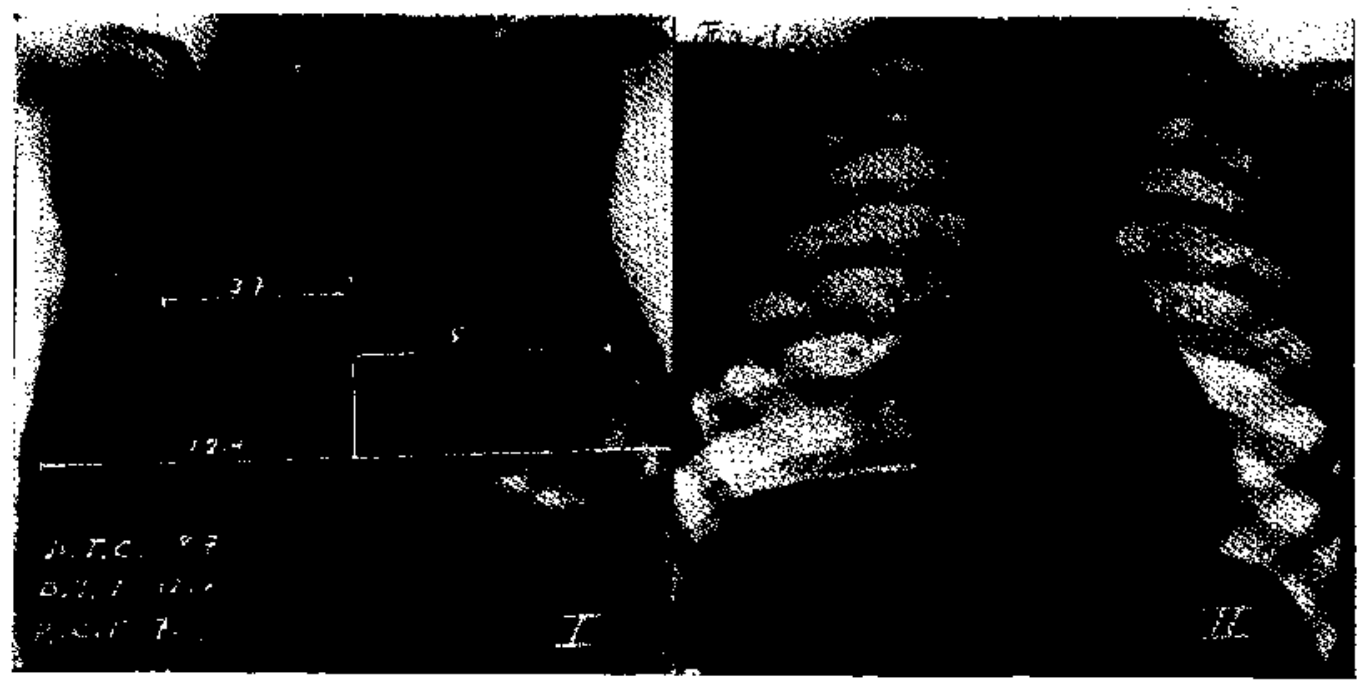

FIG. 12.

Olesirizrión publicada por el Dr. B. Delgado Correa. Cardiomegalía idiopática en un niño da 5 nieses. I y II: Aspectos a los 5 meses y a los 4 arios después, cuando se pvidanció la notmìización del corazón.

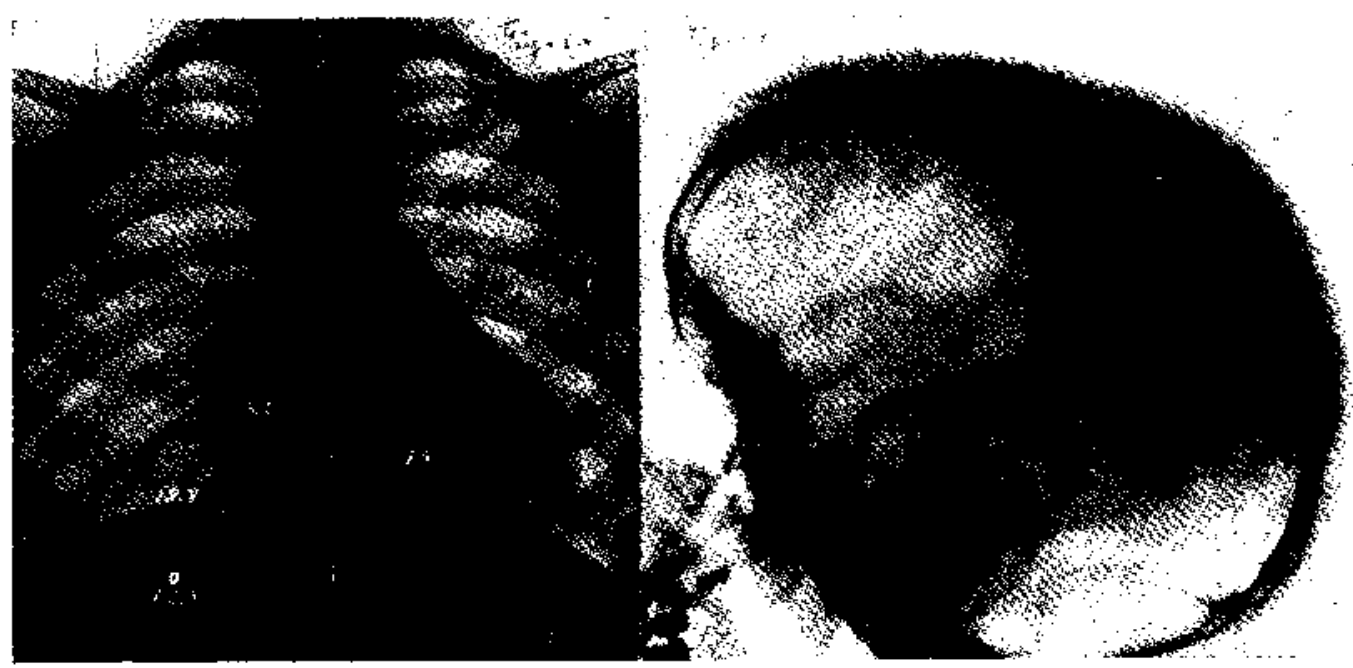

FIG. 13.

Cardiomegalia en un caso de anemia congénita de tipo Cooley estudiado $\#$ 1 edad de 8 años. R, C. T. $59 \%$.
FIG. 14.

Aspecto de las alteraciones de la estructura cratreana del caso anterior: evidente y característica estriación transversat a nivel del diplo: que está ensanchado: tabla externa ausente. Osteoporosis difusa. 


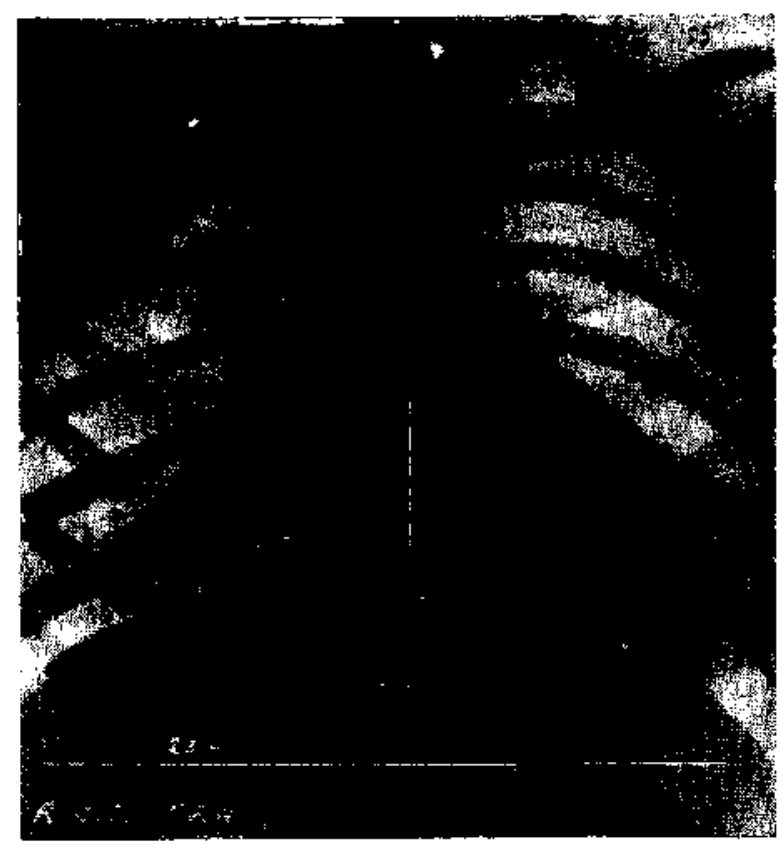

FIG. 15 .

Cardiomegalia observada en untaso de sindrome leucénico de De Guglizelono en una niña de 11 años. 


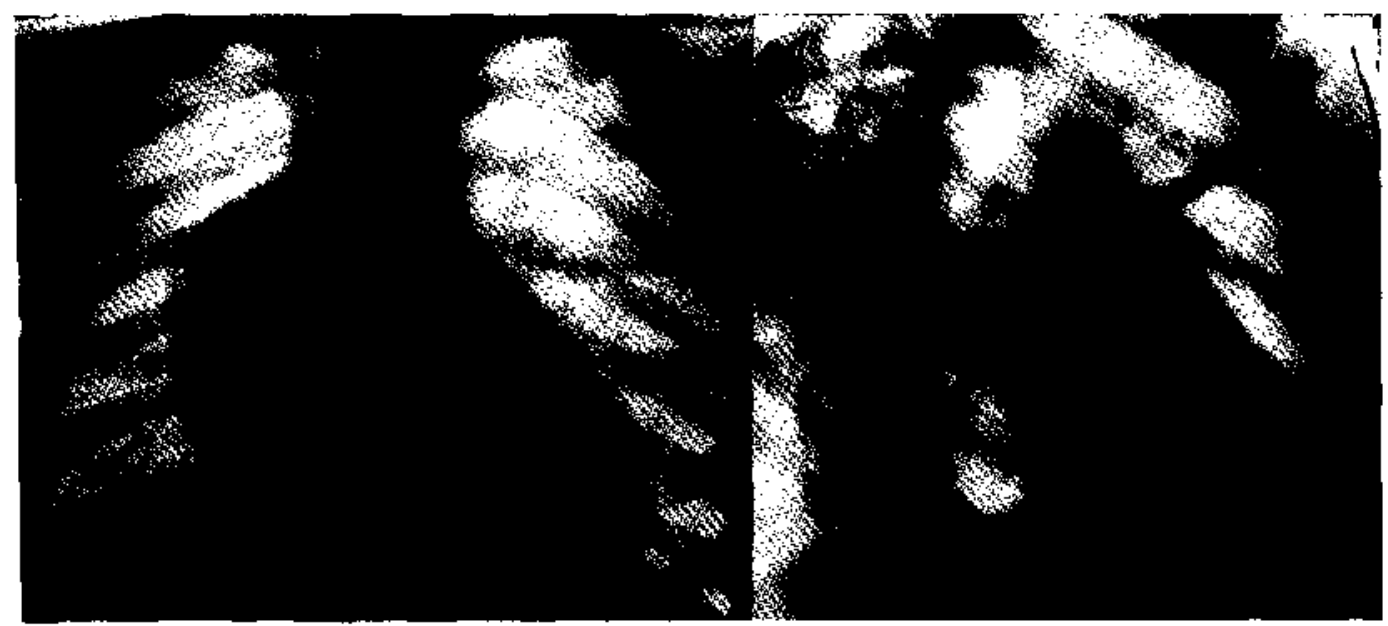

FIG5. 16 y 17.

Fsence ; otlicua derecha anterior. Deformatión sobre el contorno detrecho de la silata caidiaca. casacterizada por una saliente que forma cuerpo con la sombra ciśrdiovascular. Niño

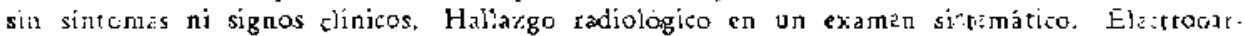
diograma notmal.

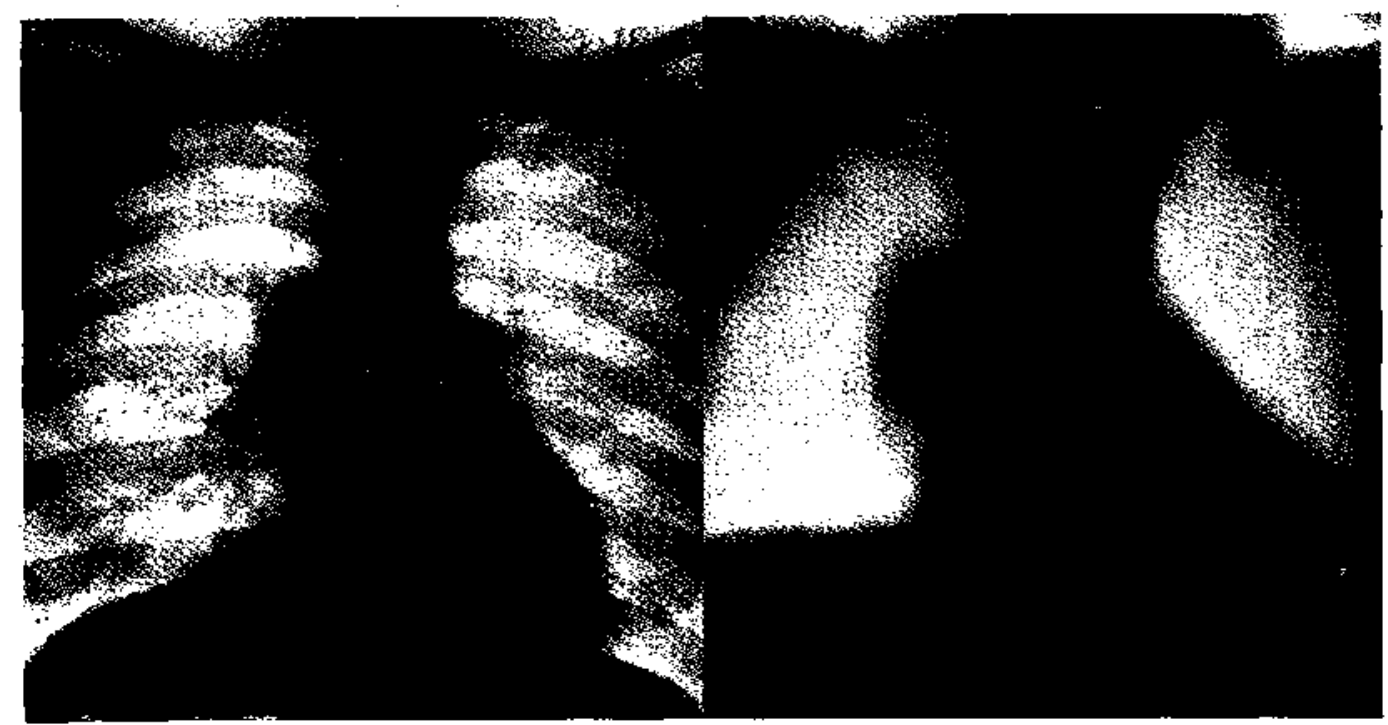

\section{FIG5. 18 y 19}

Misma caso catore años despús. a los 20 años de edad. Nunca manifestó signos de aft: ción cirdíca. La silueta cadiaca se mintiene deformada, pero ahora es más una deforma-

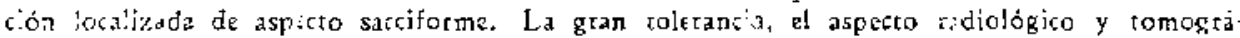
fict, hacen considerar el caso como un posible diverticuk ciel peticardio. 


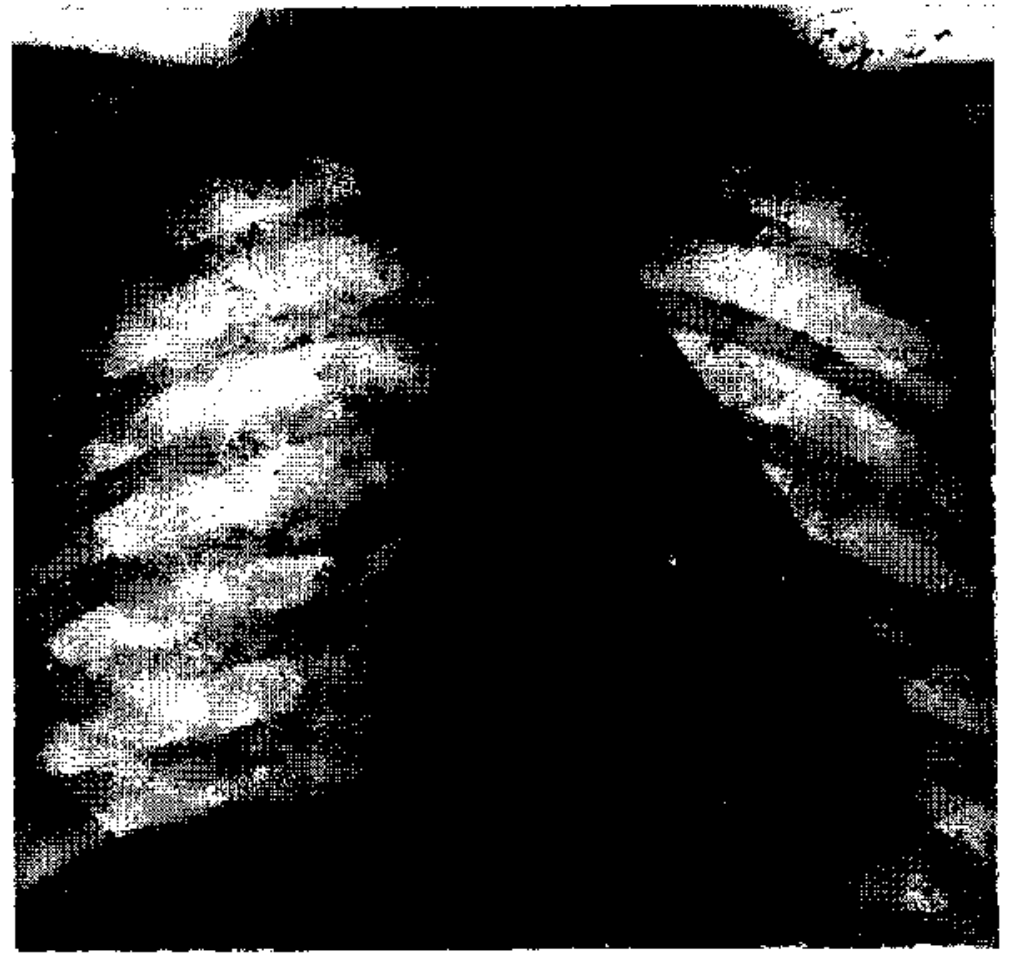

FIG, 20.

Niria con ligera cianosis. Frérito $y$ soplo sistólico sobre el It cspacio izquierdo, con propagación a la clavicula, desuiación a la derecha dal eje alectrico Diagnóstico: estrechez pulmonat congénita con tabiju. intervencriculas csrrado. Confirmacion rectópsica que revela, además. una comuniención interauticular. La silueta radiológica no presenta, sin embargo, las caiacteristiclas observadas generalmente en eso cardiopatía. No existe suierte del areo medio ni deformación en zueco, sino solamente un arto medio rectilinzo.

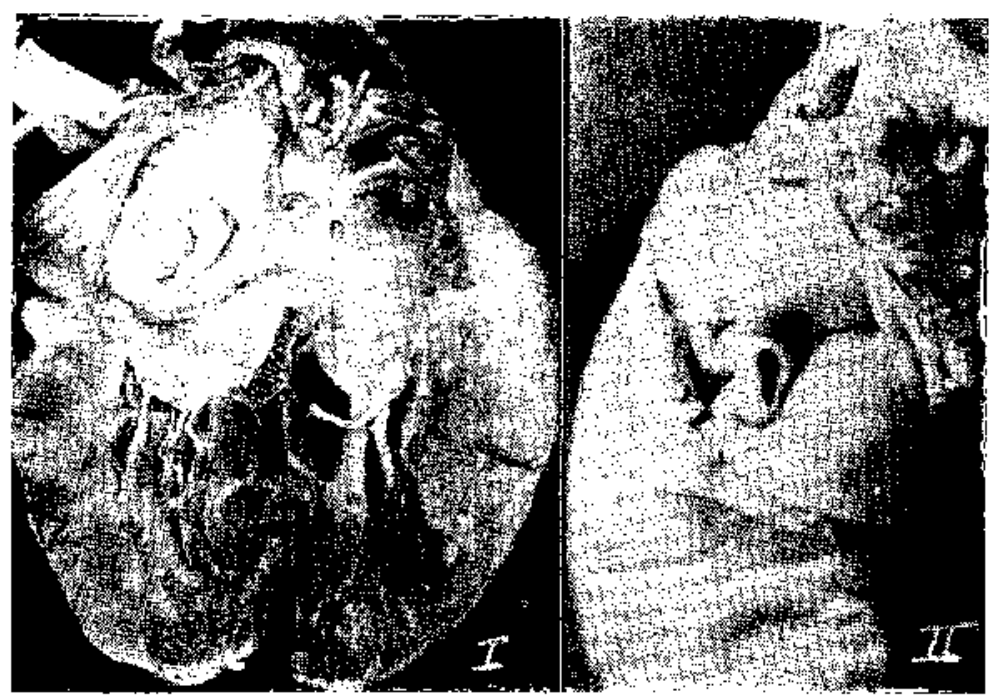

FIG. 21 .

Pieza nezrópsica del caso anterior que muesta la sincquia ralvuliur de la prai. monar (I) $Y$ la hipertrofia dal ventriculo tirecho (III. 


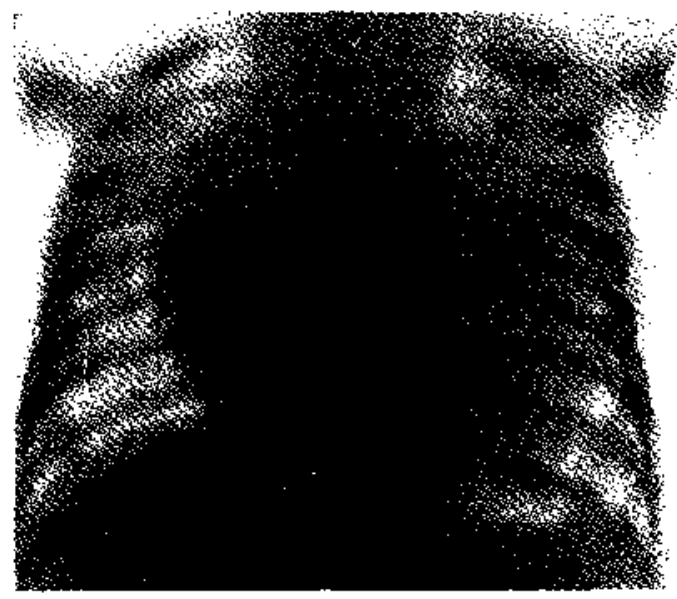

FIG. 22.

Aspecto de enfermedad de Roger eil etäpa de insuficiencia cardiaca. Niño dz 2 mases. Silueta muy globulosa aumentada en todo sentido. Corresponde a la Obs. 48 .

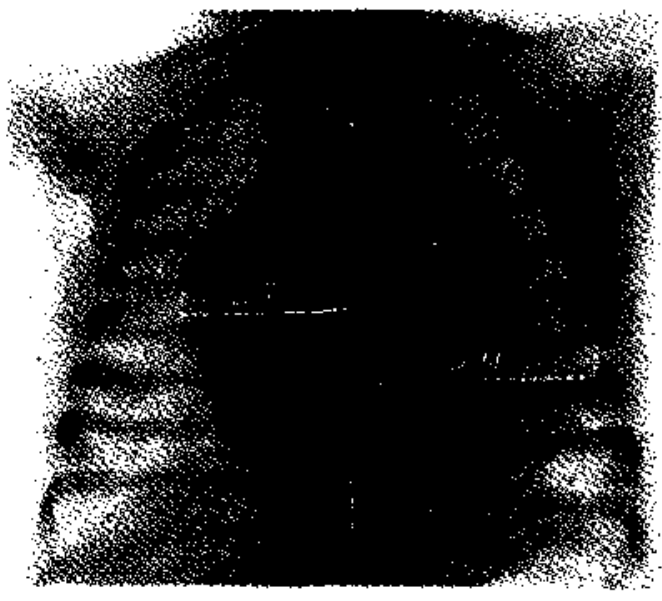

FIG. 24.

Otta niña con cianosis permanente $y$ sin soplo observada a los 28 dias de edad. Siluets uniformemente aumentada con cierta saliente del arto auricular derecbo. No es posible llegar a un diagnóstico definido, sino solo de probabilidad. Failleció dias después. No se hizo necrorsia.

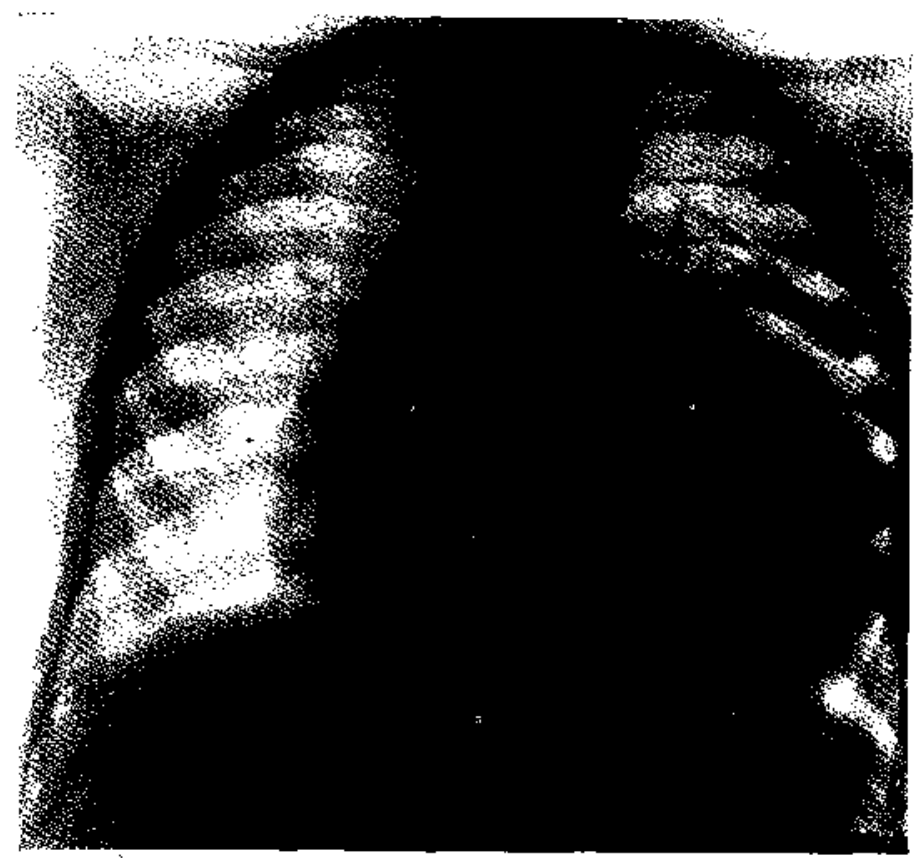

FIG, 23.

Niña de 18 meses con cianosis permanrate $y$ sin soplo, Silpeta globalosi sid caracteristicas defini. das. aspecto cardiomegalico con pedículo vascular angosto. Posible transposición vascular o corazón bi o trilocular. Faneció un mes después en insuficizncia cardiaca. No se practicó necropsiz. 


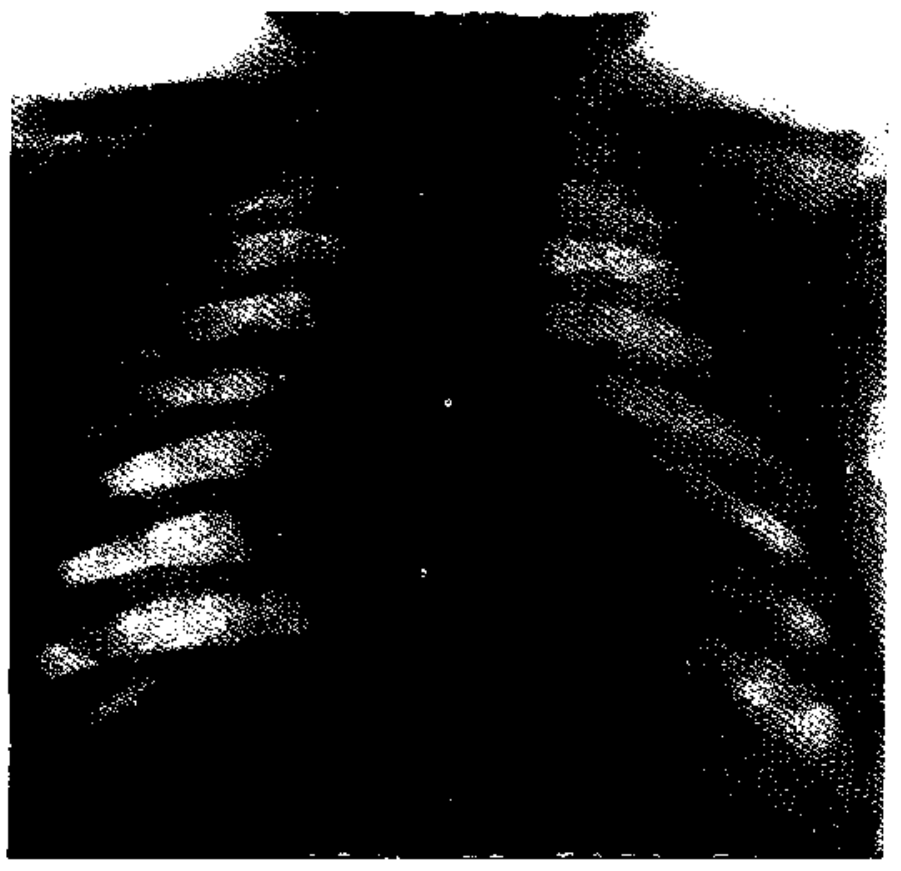

FIG. 25.

Situeta de Fallot en una niña de $1 \frac{1}{2}$ año de écid, con cianosis permanent: $y$ soplo. La necropsia confirma ese diagnóstico. Los cáactiores de esa si. lueta son: punta levantada por hipertrofia wentricular derecha, dando ut co:azón en zueco; atco medio ausente. debido a una aplasia de la arteria pulmonar; ausencia de la sombia de los vasos sobte el lado izquierdo. los que se observan parcialmente por una sombra tenue sobra la zona igaratta. queal derecha. Es una de las sifuetas más definidas dentro ce last cardiopa. tías congénitas $y$, como dice Papp, el diagnóstico de esa malformación puede haserse tadiológicamente. 


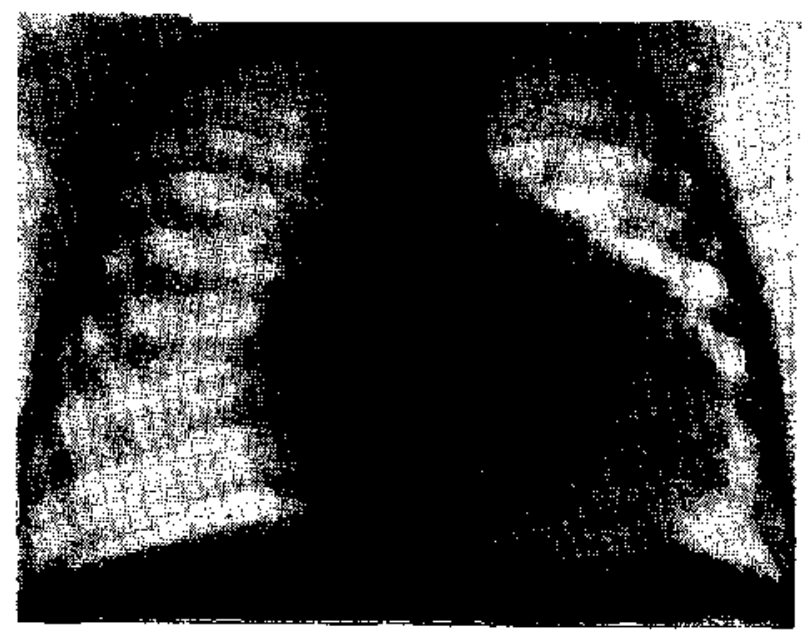

FIG. 26.

Niño de 21 meses, con sianosis pimanteote y soplo. No presenta ia silucta de Fallot ni del Eisenmenger, sino un corazón globuloso con aumento da las izvidades direchas e izquiordas y con $\$ \mathbf{u}$ pedículo vascular más visibla dei lado derecho. Podría cortesponder a una transposición qascular con tabique interventricular abierto. o a utta malformación más compleja del tipo de ia persistencia del astium común. pero no lo podemos asegurar. Se trata de un riño mongólico, estado que se asocia muy z menudo a esta última malforma. ción. Falleció al moss siguiente. No se praticó necropsia, 


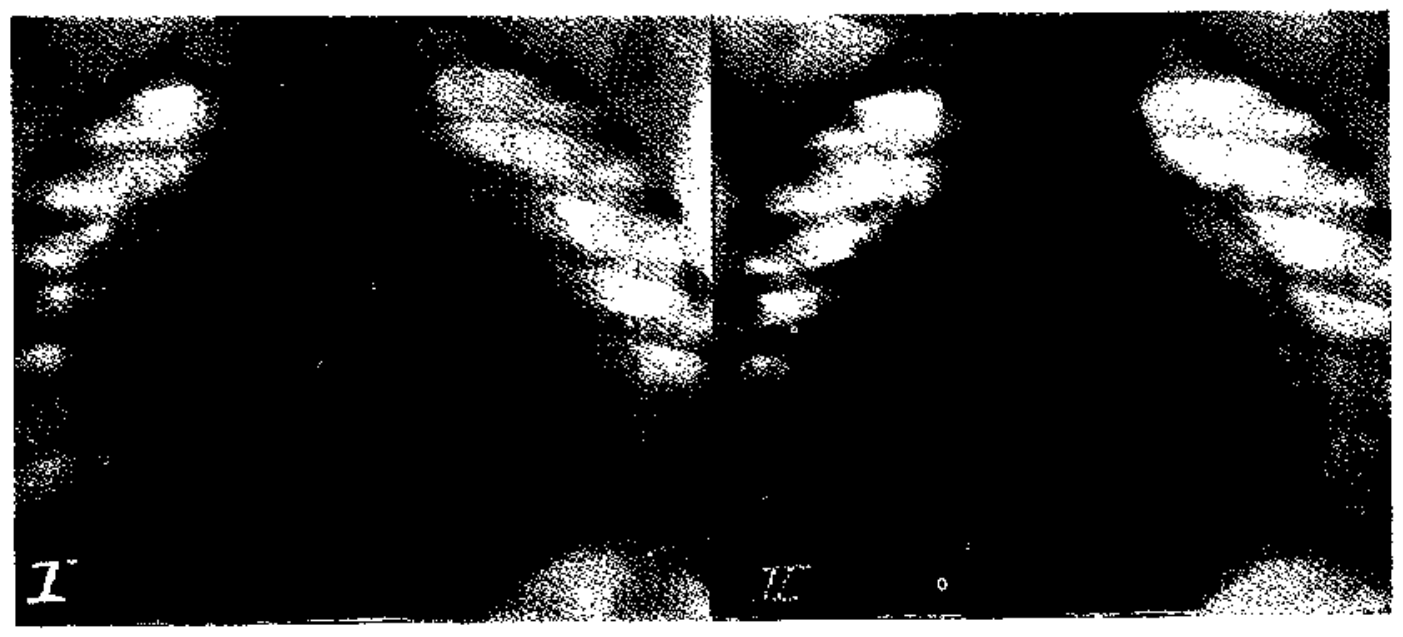

FIG. 27.

I y II: Aspecto de una pericarditis con derrame antes y después de la punción en un niir de 19 rezsos. Sifueta a diámetin exageradamente transvetso, con pediculo corto y con ángulo cardicfénici agudo. Observación correspondiente a los Dres. Ramón Guerra y Bizzano, det Hospital Yeeto Visca.
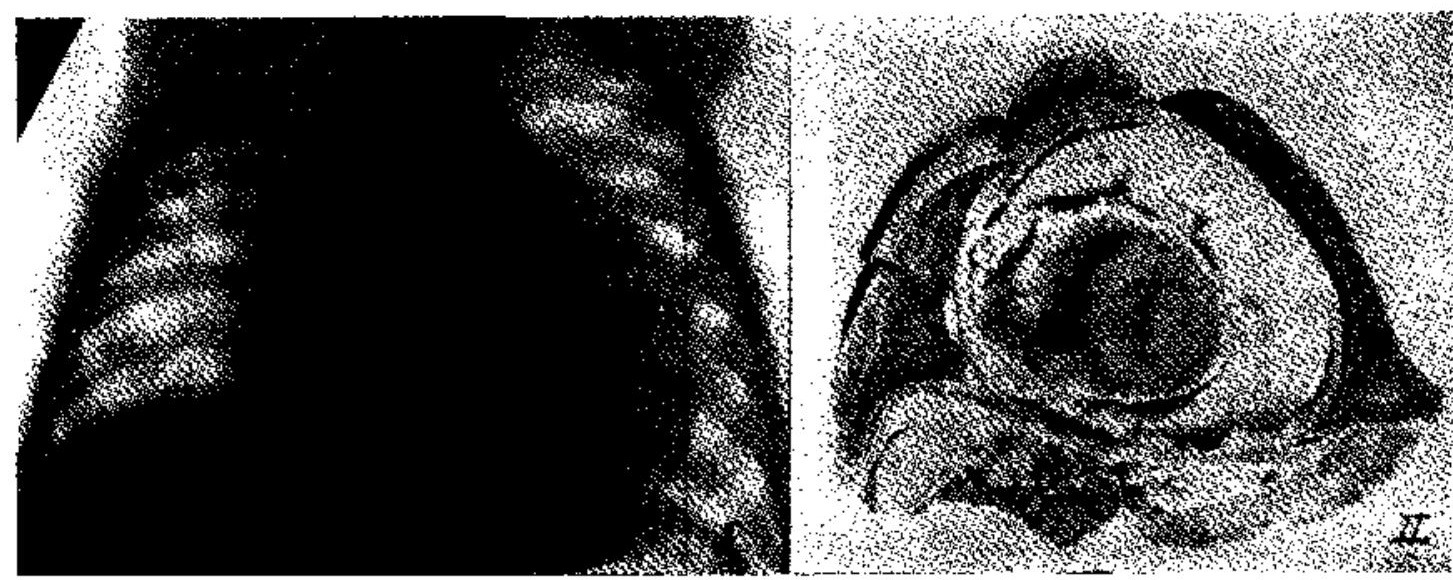

\section{FIG. 28 .}

Otro ciso de pericarditis con derrame an an niño da 7 meses. It Se manifiasta por una imagen sinilar a la de las catdiomegalias globalies. Se trutaba de una pericarditis con exudado sero-libtino-putalento. En la pieza nectópsica (II) se obsesvan los espesos grumos de pes retraidos por la acción del formol. Observ. de los Dres. Pelfort, Cassinelli $p$ Bazzano. 
a los tipos descritos en el capitulo anterior, lis cardicmegalias globales se encuentran en el grupo caracterizado por cianosis permanente. Tienen siempre una clínica bien definida y son generalmente expresión de malformacicnes complejas. Cuando se observan en los otros grupos, constituyendo corazones deformades por la dilatación e insuficiencia cardiacas.

\section{C) Cardjomegalias $\mathbf{y}$ pericarditis con derrame.}

Arana, Kreutzer y Aguirre han insistido, con razón, en to difícil que es, en muchos casos, hacer el diagnóstico diferencial entre una pericarditis con derrame y una dilatación cardíaca en un lactante. Como ellos hacen notar, los signos de percusión del ángulo cardio-hepático (ángulo de percusión agudo en la dilatación cardíaca y ángulo de percusión obtuso en los derrames pericárdicos), no tienen en las pericarditis con derrame, una correspondencia absoluta con la imagen radiológica. No debe esperarse encontrar siempre en la imagen radiológica de una pericarditis con derrame, un ángulo cardio-hepático obtuso, porque éste se manifiesta así cuando el derrame es pequeño, pero cuando el derrame es abundante. distiende el saco pericárdico, y determina la producción de una imagen en ángulo agudo, similar a la observada en las dilataciones cardíacas.

Mostraremos dos ejemplos que valorizan el concepto sobre el que insisten los autores citados. La Fig. 27 corresponde a una pericarditis exudativa, radiografiada antes y después de la punción pericárdica, en un niño de 19 meses. Se observa una sombra globulosa, de gran diámetro transverso, de pedículo corto, que se continúa con contornos a tendencia horizontal que terminan en ángulo agudo sobre el diafragma (Observación de los Dres. Ramón Guerra y Bazzano). La Fig. 28 reproduce también una imagen globulosa, similar a las observadas en las grandes cardiomegalias y que corresponde a un derrame pericárdico. Se trataba de una pericarditis supurada, sero-fibrino-purulenta, como puede observarse en la pieza necrópsica (observación de los Dres. Pelfort, Cassinelli y Bazzano).

De modo que, para el diagnóstico de un derrame pericárdico deben guiarnos: la configuración a gran eje transversal, los contornos a tendencia horizontal, el pedículo vascular corto que tiende a desaparecer en la posición de decúbito, la disminución $\mathrm{y}$ a veces la ausencia de latidos. Cuando el ángulo cardio-hepático es obtuso, podemos hablar de de- 
rrame fericaldico moterab; pero, en los grandes derrames, el

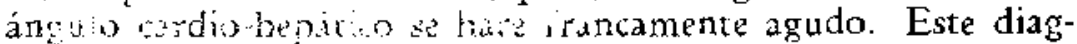
now sompre serd de pububilidad y debe estar apoyado For la cinica, porque los mismos signos pueden observarse cou más o menos intensidad, en las dilataciones cardíacas.

\section{Conclusiones}

J. La radiologia proporciona una base fundamental para el diagnotico pusts v, del sindrome "Cardiomegalia e Insurvens Cordiac is la Primera Infancia", y constituye su mejor documentación.

2. Esle estudio debe ser radioscópico y telerradiográfico, usando una técnica rigurosa y conociendo los factores que pueden llevar al error.

3. Se trata, siempre, de deformaciones cardiacas muy apreciables, caracterizadas por un agrandamiento global de la silutta, sin diferenciaciones típicas.

4. Estos cuadros están generalmente asociados a una insuficiencia cardiaca, la que, si puede sospecharse por el examen radiojógico, sólo puede asegurarse por la clínica. I.a insuficiencia cardiaca no es obligatoria en el sindrome que estudiamos.

5. En los casos que van a la reparación, el estudio radiológico seriado permite seguir la evolución regresiva de los signos de dilatación.

6. El síndrome radiológico no permite ir más allá de un diagnóstico positivo. Los datos clínices y de la electrocardiografía, muchas veces 1 a anatomía patológica. son completamente necesarios para la exacta interpretación etiológica de cada caso. Es un ejemplo más que nos enseña que, si el estudio radiológico es siempre necesario al diagnóstico, debe haber una relación estrecha entre él y el estudio clínico.

7. Se comenta el material radiográfico desde 3 puritos de vista diagnósticos: cardicmegalias e insuficiencia cardiaca: cardiomegalias y cardiopatías congénitas; cardiomegalias y pericarditis con derrame.

\section{PRONOSTICO}

El pronóstico está en relación con la precocidad con la intensidad y con la prolongación del tratamiento. El resultado que se desprende de la experiencia de los casos aue hemos seguido más de cerca y con mayor dedicación, puede condensarse en las afirmaciones siguientes: 
1) Qu el pronóstico depende, en gran parte, de la intervencion del tratamiento heroico de este sindrome.

2) Qula kis iratamiento, en muchos casos, merece bien sale nomba t: hercico y salvador, dejándonos la impresión de quat: a la evolui in inubiera sido fatal.

3) Que la eficacia del tratamiento está evidentemente en ralación con la precocidad de su aplicación, to que quiere decir que es necesario establecer, desde el primet momento, el diagnóstico exacto.

4) Que a pesar de la mejoría inicial que presentan ciertos casos, es preciso continuar la medicación cardiotónica, el reposo y la vigilancia estricta del enfermo, sin apresurarse a darles prematuramente por curados, pues hemos visto recaídas, que unas veces han podido ser contenidas por la nueva aplicación del tratamiento digitálico y otras veces han sido seguidas por la muerte.

Creemos que los conceptos anteriores son sumamente importantes y que si son bien tenidos en cuenta, permiten mejorar seguramente, según nuestra propia experiencia, el pronóstice de este proceso, obligándonos, por una parte, a esforzarnos en el reconocimiento lo más precoz posible del sindrome de insuficiencia cardiaca aguda, a la institución simultánea y rápida de la terapéutica digitálica indicada. que debe ser intensiva y suficientemente prolongada. como para ponernos al abrigo de las recidivas que hemos visto produciese en algunos casos, donde nos hemes mostrado. par una parté, demasiado prudentes y temerosos en cuanto a $1 \mathrm{t}$ dosis y a la nocividad de la digital $y$. por cotix demas ado confiados en la matcha favorable del prociso, cuando apenas se había iniciado la mejoría.

En suma: para concretar bien nuestro pensamiento, creemos que hay que diagnosticar pronto y, en seguids go?pear intensiva y prolongadamente, teniendo al enferme bryo vigilancia estricta durante un plazo suficiente. Estamos fi:memente convencidos de que esta conducta aumentará los buenos resultados.

\section{IMPORTANCIA MEDICO SOSIAL}

Es casi imposible, como ya lo hemos visto al hablar de Ja frecuencia. poder precisar el número de niños que en un ambiente determinado fallecen de insuficiencia cardiaca aguda; pero este número, sin ser de una magnitud muy grande, 
a modo de constituir una verdadera enfermedad social, no es de ningún modo despreciable. Consideramos que la importancia médico-social del proceso radica más que en su frecuencia, en su considerable gravedad y en los beneficios que pueden obtenerse de un tratamiento precoz y bien aplicado. De modo, pues, que las proyecciores médico-sociales de evidente utilidad son:

1) La difusión del conocimiento del síndrome en el doble aspecto de su diagnóstico y tratamiento. Difusión de estos conccimientos entre los médicos, en general, y en esprecial entre los pediatras.

2) La necesidad de la misma difusión entre los profanos. lo que podría hacerse en forma sencilla y clara, de modo de incorporarla a la conciencia sanitaria de la población. tal como ba pasado, por ejemplo; con la difteria, la apendicitis, la diabetes, etc.

\section{v. DIAGNOSTICO}

Los elementos en que se basa el diagnóstico de la insuficiencia cardíaca aguda del lactante, son, en primer término, la comprobación del sindrome de insuficiencia, que hemos descrito y que es común a todas las insuficiencias cardíacas del lactante, de cualquier origen que ellas sean. Es necesario pensar en este síndrome; tener la preocupación de la insuficiencia cardíaca en el lactante, para que no pase enmascarado bajo otros diagnósticos de mayor frecuencia en esta edad.

En la insuficiencia cardiaca del lactante, de apariencia primitiva, los elementos del diagnóstico son:

a) La forma de iniciación, que hemos analizado al describir el primer perícdo evolutivo de este proceso.

b) La constitución de un síndrome bronconeumónico de origen cardíaco.

c) La ausencia de procesos pulmonares suficientes para explicarlo.

d) La ausencia de fiebre o la poca fiebre.

e) La eficacia indudable y a veces maravillesa, de la terapéutica tonicardiaca y deplectiva, indicadas.

f) La comprobación de un aumento de volumen cardiaco evidente (inspección, percusión, palpación y radiclogía).

g) La ausencia de signos de cardiopatía congénita o adquirida, la ausencia de soplcs y de cianosis previas. 
h) La hepatomegalia. con las características del hígado cardíaco.

i) Finalmente, cuando el caso permite una obsetvación suficientemente prolongada. los signos de congestión y de edema pulmonares, así como los edemas generalizados.

\section{Diagnóstico diferencial.}

El diagnóstico diferencial debe bacerse. en primer término, con la bronconeumonía, sindrome de extraordinaria frecuencia en el lactante $y$ con el cuial vemos confundirlo muy a menudo, especialmente porque la sintomatología, durante el segundo y el tercer períodos, coincide en gran parte, en ambos procesos. En la práctica, también hemos podido observar la confusión de este sindrcme con la crisis de asma. Menos corriente es la confusión con otros procesos: pericarditis, hipertrofia cardiaca, etc.

Diagnóstico diferencial entre el sindrome bronconeumónico y el sendo-bronconeumónico de la insuficiencia cardíaca agada del lactante.

a) Síndrome bonconeumónico.

1) Debat progresivo en un niño con catarto rinofaringeo.

2) Disnea que st acompaña de ciano sis cuando el proceso es may grave.

3) Fiebre con marctha irregular y pro. Jongada.

4) Evolución prolongada con silternativas.

5) El tratampiento cardiotónico no ibasta por si colo para detener e! proceso.

5) No bay anmerto del volumen cardíaco o apitece tardíamente.

7) Signos físicos de percusión y zuscultación pulmonar desde el comienzo.

3) Ausencia o aparisión tardía y moderada de la bepatomegaliu:

3) Ausencia de anasarca y asciris. b) Sindrome seodobroseonermónico de la insuficiencia cardíaca agada

1) Debut brasco en un niño completamente sano hasta entonces.

2) Disnea que. desde que empieza, se acompaña de cianosis.

3) Ausencia de fiebre $y$, si existe, es muy poca' y pasajera.

4) Evolnción progresiva hacia Ia curación o hacì Ia agravación rápida.

5) Acción prontamente eficaz del kn tamiento cardiotónico y deplectivo.

6) Aumento considerable del volumen candíaco.

7) Ansencia de signos físicos a aparción may tardía de los mismos, en. relación con-el edema pulmonar.

8) Hepastomegalia intensa y precoz.

9) Anasarca $y$ ascitis en el periodo final. 


\section{Diagnóstico diferencial con el asma bronquial en el lactante.}

a) Xsma.

1) Amlecodentes familiares de la dia. tesis.

2) Historia de crisis anterioies.

3) Ausencia del sindrome tatiaco de insuficiencia.

4) No hay inmeno del área cardiaca.

5) No hay hepatomegajia.

6) No hay edemas ni ascitis. b) Insuficiencia cardíaca aguda.

l) En general, ausencia de intecedentes.

2) Ausencia de crivis anteriorcs. salvo que se trate de recidiya diz una insuficiencia cadiaca ya conocida $y$ tratad.

3) Presencia del síndrome cardiaco de insufticiencia.

4) Hay aumento del área cardiaca.

5) Hay hepatomegalia.

6) Hay edem:s y ascitis.

\section{Diagnóstico diferencial en las pericarditis agudas primitivas y la} insuficientia aguda del lactante.

a) Pexicarditis aguda primitivi.

1) Intenso dolor precordial qui pocas vieces falta,

2) Levantamiento precordial.

3) Dolo: en el trayecto del frévico.

4) Choque de ha punta alejdo por dentro dé mamelón y par encima del to spacio.

5) Frecuentia de roces a la auscuitación

6) Hepatomegridia nuIa o distreta,

7) Dreminusion $y$ is veces ausencia de latidirs eartidicos al examen radiosetpico.

8) Sigtso de Roth pasitiva: Sorrimionro. sis ánaulo cardiohtpático a la patcusión

9) Fanión pericádica positiva.

10) Iivolución ftbill.

1) Pronóstice muy grave.

12) Laia sinisis del peicardio. b) Insuficiencia agada primitiv 1.

1) Ausencia de dolor, o si existe es muy discreto y vago.

2) Falta el levantamiento precordiai o es muy discreto.

3) 'Ansencia dz dolor en il tratamiento fréjico.

4) Choque débil, por fue:a del ma. melón y por dehajo del $4^{*}$ espacio intercosial.

5] Nunt: hay roces.

6) Gran hepatomegalia.

7) Fir:sencia de latidos al examen tadiescópico.

8) Signo de Roth negatvo petsit tetrias del ángulo c'rdiobepalico.

5) Punción pericárdica mugativa.

Jo) Evolución aptrélica o con muy poca fitb: $:$.

11) Proncistio fracucalement? favo. rithle.

1.2) Vo deja sintiris del pericatdio.

También debe hacerse el diagnóstico diferencial con la granulia: cen las cardiopatias adquiridas, reumaticas, infecciosas. et.., las endocarditis infecciosas. En realidad. los ca. racteres particulares de cada una de estas afectiones son tan distintos de los de la insuficiencia cardiaca aguda, que la samejanza aparente con éstas no induce a la confusión. Hay 
que tener en cuenta, además, que la enfermedad reumática y la endocarditis infecciosa son excepcionales en la primera infancia, edad en que hemos visto desarrollarse los cuadros que presentamos.

\section{TRATAMIENTOO}

Nos ocupamos, en primer término, del tratamiento del síndrome y no del tratamiento etiológico, que debe hacerse, además, en aquelles casos que presentan etiologia conocida, capaz de ser influenciada por un tratamiento determinardo, como en el beri-beri a forma cardíaca, o en el mixedema, etc.

El criterio que debe orientar en la terapéutica, es la necesidad de oponer a una claudicación del miocardio una terapéutica cardiotónica eficiente, que bien podría llamarse de urgencia. Esta medicación debe tratar de conseguir: 1) la depleción circulatoria, marcada por la ingurgitación de las venas. sobre todo de las yugulares y la acción tónica sobre el miocardio. Las medicaciones fundamentales son: la sangría y los preparados digitálicos (digitalina, ouabaina).

Sangria. - Indicada principalmente en los casos avanzados, cen gran cianosis. angustia y edemas. En los casos menos graves, con poca cianosis y sin edemas, puede iniciatse el tratamiento cardiotónico sin sangría previa. Cantidad de sangre extraída: en proporción a la edad y al peso dil niño, las sangrías deben ser abundinnte's. de 80 a 200 e.c.

Técnica. - La simple punción de la yugular, con aguja de calibre grueso. es suficiente.

Tonicardíacos. - Los tonicardíacos que hemos usado como base de la medicación, son la digitalina en solución al milésimo y la ouabaina por vía intramuscular.

La digitalina es una droga muy bien tolerada por los lactantes y por $z 1$ niño, en general. En proporcion laenes usade dosis elevadas, muy superiores a las indicadas en los tratados clásicos. Estas dosis han variado entre 40 y 60 gotas, en cada serie.

Hacemos una primeta serie de 40 a 60 gotas, fraccionándola en dosis diarias de $\mathrm{V}$ a $\mathrm{X}$ gotas. Estas dwis han sido suficiéntes para lograr la curación clínica de la enfermedad; pero, como en la mayor parte de los cosos queda como secuela, çurante algún tiempc. un aumento del volumen cardíaco, hemos hecho una segunda cura digitálica 20 dias o un mes. después de la primera. 
La ouabaina es un heroico auxiliar en los casos muy graves, por la precocidad de su acción y es, en todos los casos, un excelente complemento de la digitalina, por su rápida eliminación. En general, damos por vía intramuscular $1 / 4$ de miligramo, durante los 2 primeros días, continuando después con $1 / 8$ de miligramo, si es necesario, durante la primera semana.

Otras indicaciones; es necesario mantener al niño estrictamente en posición de sentado, mientras dure el síndrome seudo-bronconeumónico. Aun en el momento de practicar la sangría es necesario mantener al niño con el tórax y la cabeza más altos que el plano del lecho.

Pueden usarse como coadyuvante otros medicamentos, como la Coramina, el aceite alcanforado, etc., pero todos ellos tienen una eficacia muy secundaria.

Este es el tratamiento de la insuficiencia cardiaca del lactante de apariencia primitiva.

En el tratamiento de las insuficiencias secundarias, debe hacerse el tratamiento de la enfermedad causal: tratamiento con vitamina $B_{1}$, en el beri beri agudo a forma cardíaca del lactante; tratamiento con sulfommidas, en los casos de bronconeumonía con insuficiencia cardíaca secundaria.

Tratamiento endocrino en las insuficiencias glandulares, en especial la tiroides. En fin, en cada caso se aplicará la terapéutica etiológica correspondiente, completada con el tratamiento del síndrome de insuficiencia cardíaca.

Resultados del tratamiento. - El tratamiento dirigido en forma intensa y sostenida, que acabamos de indicar. produce resultados inmediatos sorprendentes. Hemos observado casos que parecen verdaderas resurrecciones. El resultado inmediato es maravilloso. El resultado tardio, podemos afirmar que hoy se orienta hacia la curación definitivu. aun en los casos en que, por algún tiempo, persiste el aumento de la silneta cardíaca al examen radiológico.

En cambio, en los casos en que por no haber hecho el verdadero diagnóstico, no fué realizado el tratamiento que indicamos, han evolucionado hacia la agravación progresiva, terminando todos fatalmente.

Una tercera categoría de estos casos corresponde a los que som tratados insuficientemente, con temor $y$-quedando por debajo de los límites útiles para obtener un resultado favorable. 
VIII. ESTADISTICA DE OBSERVACIONES PERSONALES, QUE CONSTITUYEN EL MATERIAL DE ESTE TRABAJO

Hemos reunido 50 observaciones, pertenecientes al Instituro de Clínica Pediátrica, a excepción de una, del Dr. C. Felfort, quien nos la cedió gentilmente.

Todas corresponden a niños menores de 3 años.

Según la clasificación etiológica que adoptamos. pueden agruparse así: calares.

1) 'Insuficiencias por anomalías congénitas cardio.vas-

9 casos, de los ctiales fallecieron 7. La mortalidad alcanza a $78 \%$. Esto confirma el pronóstico, casi siempre fatal, de cardiopatías congénitas descompensadas.

2) Insuficiencias cardiacas en el curso de infecciones.

17 casos en total, de los cuales tenemos:

a) Procesos respiratorios agudos ..., 11 casos

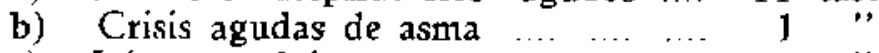

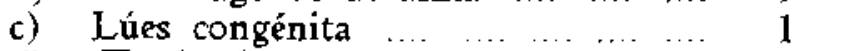

d) Toxicosis

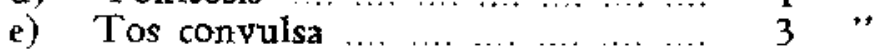

En estos 17 casos hubo 7 fallecidos, lo que arroja una mortalidad de $41 \%$. El tipo más frecuente corresponde a los procesos pulmonares aguidos. Generalmente son procesos bronconeumónicos, de pronóstico severo.

La insuficiencia cardíaca se instala en el periodo de estado del proceso pulmonar, o cuando éste ya está en vias de represión, en plena apirexia o casi en apirexia: El pronóstico depende, en gran parte. de la rapidez con que se haga el diagnóstico, porque permite realizar el tratamiento tonicardiaco. Los casos que curan no dejan secuela.

3) Anemias. No hemos observado casos en la primera infancia.

4) Síndrome de dilatación miocárdica no supurativa de Kugel y Stoloff.

1 caso. Corresponde a la observación VIII. Terminó fata'mente, pocos momentos después del ingreso. 
5) Hipertrcfias de causa metabólica.

Hemos reunido 4 casos; 2 corresponden al tipo de tesaurismosis glucogénico y 2 al hipotiroidismo congénito. Los 2 casos de tesaurismosis glucogénica fallecieron: los 2 de hipotircidismo mejotaron con tratamiento.

6) Taquiarritmia. 2 casos.

7) Insuficienciis cardíacas por hipertensión. 2 casos. Ambos corresponden a glomérulo-nefritis aguda difusa hipertensiva.

8) Tumores. No tenemós observaciones.

9) Pericardiris exudativa. Las considerames exclusivamente desde el punto de vista del diagnóstico diferencial, sin consignar las observaciones.

10) Grupc no clasificado. 15 casos, de los cuales fallecieron 6 y 9 curaron. La mortalidad es de $40 \%$. A este grupo corresponde el sindrome que hemos descríto con la designación de "insuficiencia cardíaca aguda de apariencia primitiva". Este síndrome resulta sumamente interesante. no sólo por su frecuencia. sino porque sometido al tratamiento correcto se obtiene una alta proporción de curaciones totales, como lo comprueban los nnmerosos cascs que bemos seguido ya durante varios años. La curación ha sido total, funcional y cen normalización de la silueta cardíaca. La etiología de este grupo. hasta ahora nos es desconocida; no puede incluirse en ninguno de los casilleros de la clasificación que exponemcs. Los antecedentes patológicos de nuestras observaciones no permiten establecer relaciones constantes entre ellos y la insuficiencia, sin negar que en algunos casos podrian desempeñar algún rol determinante, las infecciones que figuran en el pasado de alguncs de ellos.

La avitaminosis $B_{1}$, que juega rol tan importante en otros países - Cuba. por ejemplo y las Filipinas. como puede verse en las importantes publicaciones del Dr. Aballi, de La Habana-. no ha figurado en nuestros casos. En uno de ellos, publicado en Archivos de Pediatría del Uruguay; de marzo de 1940, por uno de nosotros (Saldún de Rodríguez). se encontró una degeneración del miocardic, de tios granular y vacuolar, con abundante edema; que podría corresponder a la forma descrita por Kugel como degeneración miocárdica no supurativa. 
En todos estos casos de apariencia primitiva. al examen macroscópico del músculo catdiaco se ha encontrado como característica saliente. el gran aumento del volumen global del corazón (corazón derecho y corazón izquierdo): múscuto cardiaco fláccido, sin hipertrofia de las paredes ventricalares, sin lesiontes orificiales de las válvulas ni del miocardio; ausencia de lesiones fericárdicas. salvo el líquido trasudado. No se observan malformaciones congénitas. El aspecto del músculo cardíaco, en estos casos, es muy distinto del otservado en las cardiomegalias glucogénicas.

Clínicamente, el cuadro de las insuficiencias cardíacas del grupo X, de etiolcgía no clasificada, se puede sintetizar en pocas palabras, como sigue: se trata de un niño eutrófico o distrófico, habitualmente sano. que inicia su enfermedad en la forma sigaiente: hasta entonces alegre y contento, la madre lo nota triste y decaido, con tendencia a la quietud en la cama: no tarda en aparecer disnea, que llama la atención de la madre, pero que no encuentra, de parte del médico, causa evidente que la explique, por to cual se le resta impertancia, hablándose vagamente de catarro respiratctio y. de congestión. La disnea se intensifica, apareciendo cianosis más o menos marcada; en general bien evidente; tiraje, aleteo nasal, quejido espiratorio, ingurgitación de las venas del cuello, ortopnez y angustia. En algunos casos se agrega tos de tipo espasmódico. El vómito es un síntoma frecuente. En suma: síndrome seudobronconeumónico, que engaña fácilmente al médico no prevenido. Este singular síndrome no se acompaña de fiebre o si existe ésta, tiene siempre poca importancia. También faltan los signos francos de auscultación y perclsión. salvo en la faz final, en que aparecen como consecuencia de los fenómenos asistólicos (ccngestión y edema). En cambio, existe francamente un aumento del área cardíaca, de percusión y de sombra radiológica, traduciendo un aumento global, siempre bien apreciado $y$ a veces muy considerable, del volumen cardiaco. Paraleiamente aparece una hepatome. galia muy acentuada. En los días siguientes, los síntomas se exacerban y se perciben entonces en ambos pulmones, sig. nos difusos de congestión y edema, fredominando en las bases, lo que da más similitud, todavía, con los cuadros bronconeumónicos, haciendo el diagnóstico sumamente difícil para quien no conoce la cuestión. En la faz final aparecen edemas periféricos $y$ ascitis.

Evolución y pronóstico de este grupc: sin tratamiento, el proceso se agrava progresivamente, hasta la terminaciśn 
fatal con el cuadro asistólico completo: edemas generalizados, ascitis, estasis venosa, etc. Tratado correctamente, en general regresa rápidamente, hasta la curación completa, la que se realiza del modo siguiente: desaparición de los síntomas funcionales, desaparíción de los edemas y de la congestión venosa: reducción del volumen hepático. Lo último que se normaliza es el volumen cardíaco, cuyo aumento moderado puede persistir meses; en un caso demoró un año y medio en normalizarse.

\section{BIELIOGRAFTA}

ABALLI, A, S. y PANICELLO, F, S. - Las avitaminosis " $B$ " del niño en Cubrs. Boletin Soc. Cubana Ped. Vol. XI, 443, 1939.

ABAI.LI, A. S, y ESCOBAR A. - Beriberi agudo del lactante en nuzstro media, Bol. Soc. Cubana Ped. Vol. XII. 1941.

ABBOT'T. M. E, -- Atlas of Congenital Cardiac Disease. Vew York. The Am. Heart Ass. 1936.

$A B T$, ISAAC A, - The child's heart in avitaminosis. The Journ, of Ped. $50,1935$.

ACUNA, M, y PUGLISI. A. - Taquicardis paroxística en la infancia. Arch. Arg. de Ped. VI, 349, 1935.

ANTOFOL, W.; HEILBRUM, J, and TUCHMAN, - Enlargement of the heart due to abno:mal glycogen storage. Am. J. M. S. 188, 354, 1934.

ARANA, R.; KREUTZER, R. Y AGUIRRE, R. S. - El ángulo cardiohepático en las pericarditis con derrame. Arch. Arg. Ped. Xil. 44. 1939.

ARANA, R. y KREUTZER, R, - Estadio radiológito del corazón reum' tico en los niños. El Ateteo. B. Aires, 1942.

BAEZA GONI, A, y BUSTAMANTE, W. - Insuficiencia cardica agda en un lactante. Arch. Ped. Unug. XV, 395, 1944.

BAKWLN, H. and BAKWIN, R. M. - Body build in infants, Am. J, Dis. Child, 49, 870. 1935 .

BARDEEN, C. R. - Deteimination of the size of the heart by means of X-rays, Am. Journ. Anat, XXIIL, 423, 1918.

BONABA, J, y SALDUN DE RODRIGUEZ, M. L. - Insaficiencia cardiaca agada del lactante. Monografia No 1 del Instituto de Clinies Dedíatrica y'Puericultura. "Dr. Luis Morquio". Montevideo, 19?8.

BONABA, J, y SALDUN DE RODRIGUEZ, M. L. - Nuevost casos de insoficiencia cardiaca aguda en el lactate. Arch. Ped. Urug. XIIr, 373. 1942.

BONABA, J.: SALDUN DE RODRIGUEZ, M. L, y FERREIRA BERRU'TTI, P. - Tesaurismosis glucogénica. Arch. Fed. Urug. XV, 402, 1944. 
BROWN, J. W. - Congenital heirt diseass. London. 1939.

BRUNING. H. - Elementos de propedéutica infantil. 1926.

BURGHI, S. E. - Hipertrofia cardicta idiofática. Arch. Ped. Urug. I, 472, 1930.

CARRINGTON; G. L. and KRUMBHOAR, E. B. - Soralled cardiac hypertrophy in Infancy. Am. J. Dis, Child. $27^{\circ}, 449,1924$.

CARRY MC CLURE. — Am. Heart Jaurn. 76. 1931.

CASAUBON, A. y COSSOY, 5. - Sindrome irdiaco agudo, Areh. Argent. Pred. 1933.

CASELLI, EDUARDO G. - Hipertrofia eardiaca esencial en un lactante. A.chivos Argent. Ped. XXII, 234, 1944.

Cossio, P. - Aparato circulatorio. Buenos Aires, 1944.

COSSIO, F.: ARANA, R.; BERCONSKY, I, y KREUTZER, R, - Cardiopatiás congénitas. La Semana Médica N 33, pág. 364. 1938.

DE CASTRO, FREIRE y MOREIRA, BRAGA. - Contribucao para ó estudo da doenca de V. Gierke. Rev. Portuguesa Ped. Paer. Lisboa. 1942.

DEBRE, M. R.: BROCA, R, et SOULIE. P. - Un cas d'hppertrophiz alsdiaque idiopathique. Bull. Sor. Péd. París, 193?, pág. 262,

DEBRE, M. R - Les hépatomégalies polycoriques. Bull. Soc. Med. des Hop. de Pavis, 50, 1023, 1934.

DEBRE, M. R. et SEMELAIGNE. - Hepstomegalic polycorique. Fresse Med. 43, 857, 1935.

DEI. CARRIL, M.; GIUSTINIAN, V. y MONSERRAT, L. -- Un cAso de miocardia en el.lactante. Atch. Arg. Ped. 1936.

DELGADO CORREA. B. - Hipertrofia cardiaca idiopitica en el lactante. Arch. Urug. Card. LII, 27, 1939.

DEPETRIS. P. - Insufíciencia cardianca agudu del lactante. Arch. Ped. Urug. XIII. 363. 1942 .

DIAZ NIELSEN. J. R. - El tamaño de! coazón del niño en la trítét diografia. Arch. Arg. Ped. XX, 85 y 182, 1943.

EISENBER y GIBSON. - Enfermedades congénita del corazón y elictriardiograma. Chicago, 1942.

DE ELIZA:DE, PEDRO y PELIPE. - Sindrome miocárdico a repetición. Arch. Arg. Fed. 1934.

FARR y WEGMAN. - An. - Mcd. Sc. T. 190, $19 \hat{35}$.

FAREER. - Am. J. Path. 7. I05. 1931.

FlNKELSTEIN, H. — Tratado de las enfe:medades del lactante. 1941.

FINKELSTEIN, L. E. - Cardiomegalia glucogénica circunscriptia. Am. i. Med. Sc. 1936.

GARDNER. E. and SIMPSON, K. -- Suddin death from von Gierke's (glycogen) disease. Lancet. 1, 659, 1938.

GAUTIER. M. S, et Mlle. SCHOENAN. - Un cas probable d'hypertroptiz du coear primitive cher le nourrison. Bull, Soc. Péd. Paiŕs. 1931. 
GIL. J. B. - Un caso de enfermedad Bonaba-Saldún. Boletin de Soc. Mad. Quir. Centro República. Uruguay. Abril de 1942.

GOLDBLOOM, A and SEGALL, H. N. -. Auricular fibrillation in infancy. Am. J. Dis. Ch, 58, 587, 1938.

GOLDMAN, F. - Enudes sur le maladie glycogenique, Rey. Franc. Ped. 14, $494,1938$.

GORDON, W. and ADAMS, W. - Estimation of cardiac transvirse diameter in childzen and comparicon with esediac area. Am. J. Med. Sc. 188 , $491,1934$.

HARYEY, R. A. - Restraining device and technical factors for chest roengenography of infants. Am. J. Rocnt. Rad. 47, 322, 1942.

HENOCH. — Citado por Muggia.

HERRIQUEZ, GEORGER H. - Enf, de Von Gie!ke. Rev, Chil. Ped. XIII, $646,1942$.

HODGES, P. C. - A comparison of the telcoroentgenogram with the ortbodiagram. Am. J. Roentg. and Rad. XI, 466, 1924.

HODGES, P. C. ADAMS, W. and GORDON, W, - Esctimation of cariac area in thilitren. J. A. M. A. V. 101;914, 1933.

HOL T, L. E, y HOWLAND, J. - Diseases, of inf, and Childen. N. York. Pág. 1.361.

HOWARD. H.; MASON and ANDERSEN. D. - Glycogen disease. Am. J. of Dis, of Child. 61, 795, 1941.

HUBBARD, J. P. - Paroxysmal tachydardia and its treatment in young isfants. Am. J. Dik. Child. 61, 687. 1941.

HUMPHREYS, E. and KATO, K. - Glycogan storage disease. Am. J. Par.. $10 ; 589,1934$.

JAUREgUY, M. A. - Asistolias ggodas 20 la tos convalsa. Arch. Fed. Urug. IX, 34, 1938.

JCSEPHI, M. G. - Medidas del conzón en los niños normales. Am. J. Dì. Child., 1935.

KATO. K. - In Brennemann's Pinact. of Ped. Vol. Ill, cap. 24, pág. 5 , 1941.

KREUTZER - Taquicardia de retién nacido teatada por prostig. intany A rch. Arg. Ped. 1942.

KREUTZER, R. y VISILLAC, V. - Agrandamiento de la silueta cardiaca en el lactante. Arch. Arg. Ped. XVII. 360 y 439. 1942.

KUGEL, M. A. - Elargement of the heart in infants and young ohildren. Am. Heart. T. 17, 602, 1939.

KUIGEL, M. A. and STOLOFF, E. G, - Dilatation and hipertrophy of the Hear: in infonts and young children. Am. J. Dis. Child, 45, 828, 193\%.

LATORRE, M. - Desarrollo y evolución del electrocandiograma en el lactanta cormal y prematuro sano en su fímer año de vida, Rev. Chil. Ped. XII. 1941. 
LEVINE, H. D. - Cardiac hypertrophy in infancy, Am, J. Dis, Child. 48, $1072,1934$.

LORENZO Y DEAL Y MENDOZA, G. - Asistolia aguda con dilatación cardiara en un lactante. Arch. Ped. Urug. IX. 220, 1938.

MAC MAHON. - Hypettrophy of the heart in infants. Am. J. Dis. Child. 55. 93.1938.

MASON. H. and "ANDERSEN, D. - Glycogen disease. Am. J. Dis, Child. 61, 795, 1941 .

MAX SCHMAN y MOSS, A. J. - Archives of Fediatrics. Julio de 1942.

MENSI, E. - Insuficiencia candiaca aguda infantil. Policlínica Infantil, To. rino, marzo de 1939.

MERY, M. H. SALIN, H. et WILBORTS. - Asistolie á repetition consceutive a la dilatation aigue primítive du caur chez l'enfant. Arch. Med. des Enf. 1914.

MILlER, C. H. y WILSON, M. H. - Journal of Ped. XXIII, $251,1943$.

MUGGIA, A. -- Hypertrophie caxdiaque congenitale primitive avae sténose pylorique hypertropbique. Rev. Fanc. Ped. 1936.

MUSSIO FOURNIER, J. C: CERVINO, J. M. y BAZZANO, J. J. Aparato cardiovascular en la insaficiencia tiroide.i. II Congreso Panamericano de Endczrinologia. Montevideo, 1941.

PAPP, L. -m Acch. Maladies du coenr. XXIV, 249. 19?1.

FARSONS, C. G. and WRIGHT. F. H. - Circulatory function in the ancmias of children. Am. J. Dis. Child. 57, 15 y 330 y 851: 58: 250. i 939 .

PELUFFO, E. y EMERIC. E. — Contibución al estudio de las bipatomegalias policóticas. Arch. Ped. Urug. X, 433, 1939.

PIAGGIO GARZON, W, - Taquicardia paroxistica en una niña de 2 añes. Arcb. Fed. Urug. VIII, 562, 1937.

POMPE, J. C. - Hypertrophie idiopathique du coeur. Am. d'anat. par?. 10. 23. 1933.

RIEDEL, O. - Determinación del tumaño del corazón dil niz̃o normal por nedio del telediagrama. Axch. Hosp. Robrito del Río. Santiago de Chile. Marzo de 1931.

RUIZ C. -- Probable caso de hepatomegalia glucogénica. Arch. Arg. Féd.

SCHLRF. D. Y BOYD. L. - Electrocardiografía clínica. Buenos Aites, 1942.

SEGURA, R. S. - Registro e interpretación de la actividad cardiovascular dal lactante normal. Buenos Aires, 1937.

SPRAGUE, H. B.: BLAND, E. and WHITE, P. D. - Congenital idiopatic lypertrophy of the heart. Am. J. Dis. Child. 41, 877, 1931.

STELNER, M and BOGIN, M. - Idiopatic cardiac elargement associated with thymico-limphaticus, Am. J. Dis. Child. 39, 1255, 1930.

STOLOFF, E. G. - So-called idiopatic elargenent of the beart in infaniy and to childhood. Am. J. Dis. Ch. 36, 1204, 1938. 
TAUSSIG y REMSEN: - Esential Hypertension in boy of 2 years of age. Bull. John Hopk. Horp. 57, 383, 1935.

TELIEN and FISHER, - Intrapericardial teratoma. Am. - Dis. Ch. 51. Join. 1936.

THANNHAUSER, S. J. - Lipidoses, London, New Yotk, Toronto, 1940.

UNGERLEIDER, H. E. y CLARK, C. P, - A study of the transverse diameter of the heat silhonette wich prediction table based on the teleroentgenogram. Am, Heatt Joun, 17, 92, 1939.

VAI.LINO. M. T. y BETTINOTTI, S. - Sindrome miocárdico agudo. Arch. Arg. Ped. 1933.

VAN CREVELD, S. - Glpcogen disease. Medicine, 18. 1. $19 ? 9$.

VAN CREVELD S. and VAN DER LINDE. - Cardionegalia glycogenica ciretensctipta. Arch, of Dis. of Child. Vol. 14, March 1939.'

VON GIERKE, F. - Hepato-nephromegalia glycogenica. Berth. z. path. anat, n, z. allg. Path. XLVIII. 683, 1931.

WARING, J. I. - Beriberi in infants. An. J. Dís. Ch. 38. 52, 1929.

WARING. J. I. - Nutritional Heart diserse in children, Am. J, Dis. of Ci. $55,750,1938$.

WEGMAN, $M$, and EGBERT, D. $S$ - Congenital thabdomyoma of the heart associated wirh arrhytmia. Jonrn. of Ped. 6, 818, 1936.

WHITE. $5 .-$ Heart Disease. New York. 1941.

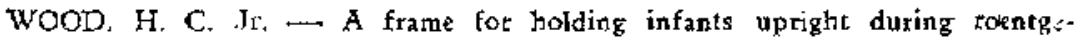
nography. Am. J. Roentg. and Rad. 31, 396. 1934.

WRIGHT, F. H. - Paroxysmal nodal tachycardia treated with mecholşl. Am. J. Dis. Ch. 56. 1334, 1938.

TERBINO. V; GLANELLI, C: MARCOS. J. y BAZZANO, H - Lecriores de Clivica Infantil. 1938. Mortevideo. 


\section{DISCUSION}

E] Dr. Rodolfo Kreutzer, de Buenos Aites, hace extensas consideraciones sobre el tema. Por falta de espacio, publicamos sólo an retamen, proponcionado por el autor, que dice corno sigue:

1. Se dan las razones por las que se prefietie englobar estos ohorivaciones con. el nombre de "agrandamiento de la silueta cardiaca", prefiriendo mantenter el concepto clínioo de "cardiomegalia". para los casos de igrandamiento cardíaco sin causa aparente, segura o probablenrante congénitos.

2. Como los problemas que ox plantean son diferentes, según la edad de1 riño en que bacen sa aparición y segín los signos clinicos más falientes que orientan el diagnóstico hacia la cardiopatia, se consideran por saparado:

1. Ia insuficiencì cardíaca;

2. La cianosis;

3. Los coplos;

4. Las altegaciones de $1_{a}$ imager rudiológida cardiovaseular:

a) En el recién nacido (de 0 a 30 días):

b) En el lactante:

c) En la primeta y segunda infancia.

\section{RECIEN NACIDO:}

a) Se pasa rerista a las causas del agrandamiento cardiaco en el tecisn nacido, destacándose que en elíos la aparente anormalidad de la imagen cardiaca normal, podria inducir al no exporimentado a formular un diagnóstico incomecro de cardiomegalia.

b) Se analizan las causas de cianosis $y$ disnea en el rexién nasido. que no dependen de ana cardiopatia. Se destaca que en la cardiomegalia congénita. a difentacia de to sostenido por Abbott $y$ posteriormente par Cossio. Arana, Berconsky y el autor. la cinnosis es intensa.

c) Aunque Jos soplos abservados en el reoien nacido son die gran valor para afirmar en casos de cardiomegalia congénita una malformación cardíeca concomitante. se destaca que su valor puede ser engañoso. porque pueden no observarse en combnicaciones anormales dzi tabique y pucten, pot el contrario, observarse en casos en que luego des. apircten.

d) La insuficiencia cardiaca parde aparecer en el recién nacido. sin zue exista en verdad una ordiopatía:

1. En el ciecre precoz del foramen ova:;

2. En las tuquicardias patoxísticas.

puntualizandose los signos que permiten llegaz al diagnóstico en ambas condiciones: insuficiencia cardiaca precoz, tipo edena agudo del pul- 
món, en el primer caso, e insuficiencia cardiaca congestiva con taquicardia incontable en el segundo.

e) Se aralizan los colapsor pariféritos del recién razido, imputables unos. a perturbación dal merabolismo abaminoideo, y otros, a factores exógenos. de lics que se tefieren dos observacionest: una, debida probabléminte a intoxicación bulbar for gases anestésicos recibidos por la madre duratte el parto y otra, que sucedió a la ingestión de vasslina líquióa.

f) Se analizan los agrandamientos cardiacos debidos a nna causa patologica gus individualiza el cuadto clinico: mixedema congénito. eritroblastosis fetal, enfermedades infecsiosas. supeditados tados al curso de la enfermedad causal y que deste el punto de vinta clinico no pueden englobarse en las "cardiomegalias".

g) Dentro de las vardaderas catdiomegalias congénicas se prefiere mantenet el concepto clínico de bipertrofia sardiaca "idiopática" en el sentido de que no es "compensadora" de una atomalía congénita. Su cuadro clinico, fácilmente reconocible, se caracteriza por: agrandamiento cardiaco, taquicardia contable, disnea y cinnosis exacerbada por los esfuerzos, apatia, quejidos, facies de angustia y de dollor con raidos cardiacos particularmizste intensos, que se palpan como latigazos $y$ se auscultan con un timbre clangoroso. De pronóstico gravisimo, generümente mueren bruscamente, casi nunca en insuficiencia cardiaca.

h) Al lado de estas hipertrofias "idiopáticas'" puede observarse en el recién nacido la cardiomegalia tipo Kngel-Stolof, que' sc diferencia de la anterior, porque los ruidos cartizicos se presentan disminuidos de intensidad con ritmo de galope. La insuficinacia cardiaca congestiva es la regla, padiendo evolucionar en forma recurrente. en uno de cayos episodios el niño muere. Se cimenta la esperanza que en el porvenir esta cardiamegalia pueda responder a la medicación antiinfecriosa sulfatiazol, penicilina, etc.

i) Entre las cardiomegalias congénitas sin soplo, diagnosticables clinicamence por las alteraciodes encontradas en el segmento ST-T, se inciuyen las anomalias de las cotonarias. de las que se tefiere una observación en que la coconaria derecha nacía def ironco de la palmonat.

j) Al Jado de estas cardiomegalias se kstudian las cardiomegalias "complicadas", O sea, "compensadoras" de una anomalía congénita, destacíndose el valor de la angiocardiografía para llegar al diagnóstico correcto.

k) Se relata una observación de cardiomegalia por endocarditis plástica frotal. sobrevaznida en un caso de gestación en plena actividad reumática.

\section{IACT ANTE:}

a) Se analizan las modificationes radiológieas de la silueta cacdiovascular que poeden indecir a un error de diagnóstico: 
1. Se relara una observación de pericarditis idiopática con marczdo agrandamiento de la siluata cardiaca. fácilmente contundible con una cardiomegalia congénita. en la que el diagnóntico pudo hacerse cons ayuda del slectrocardiograma, lo que fué confirmado por la punción $y$ con evolución alterior sumamente favorable:

2. La posición a la derecha del cayado aórtico puede hacer formular un diagnóstico incorrecto de ganglio paratraqueal derecho o de hipercrofia dil rimo cuando persiste un doble arco átuco.

b) Al igual que en el recién nacido, puede sobrevenir en el lactante una insuficiencia cardiaca, como consecuencia de una taquicardia paroxistica. Pero en esta edad de la vida el diagnóstico as gás fácil y la terapéutica con el prostigmin de efectos manos dramáticos.

c) Se menciona la tesaurismosis como causa de cardiomegalit, sin aportar ninguna observación.

d) Igualmente las avitaminosis B o C, que puede provacar en niños deficiencemente slimentados, agrandamientos de la silueta cardiaca. Se oeñala que Finkelstsin acepta que frecuente encontrar an el raquitismo observaciones de hipertrofias cardiacas, que maeren con sintomas de asma catdiaso.

e) En el corzzón mixedematoso dé1 lactante, el agrandamiento de la sifueta cardiaca es debido a la dilatación $y$ al derrame pericárdico.

f) Se señala que las cardiomegalias por bipertrofia "idiopática del corazón" se han exteriorizado ya procozmente desde los primeros meses de de la vida.

g) Más focuente que esta hipertrofia "idiopática" es en el lactante las ardiomegalia de tipo Kagel-Stolof, que comienza bruscamente con signos de insuficiencia cardíaca, que orientan el diagó́stico hacia una enfermedad del aparato respitatotio -bronconeumonia sine materia-.. Hay agrandamiento cardíaco y ritmo de galope con disminución de los raidos $\%$, a veces. con soplos debidos a la agresión de los mícculos Fapilates por el proceso digenerativo que caracteriza anatómicamente la enfermedad. E: curso de la enfermedad es generalmente fatal a breve plazo, pero se relata una observación en que la mejotia obtenida es tan marcada, -que cabe esperar la curación.

Se señala que probablemente no existen lazos de parantesco entre estos dos tipos de cardiomegalía --bipertrofia "idiopática" y síndrome de Kuget-Stolof-, dado que en un caso de Willius pudo verificarse, en un examen radiológico anterior. que no existia agrandamiento cardiaco: pero se hace notar la similitud de este sindrome con la miocarditis aislada de Fiedler, annque no pueden identificarse, porque en esta última existen groseras al zaracionés electrocardiográficas constantes.

b) Se llacen algnnas consideraciones sobre f2s cardiomegalias asociadas "compensidoras" de anoualias congénitas. 
i) Se analizan los agrandamientos de la silueta cardíaca debidos a infecciones por gérmenes conocidos. que incluyen las miocarditis y las peticarditis, destacándose a este respecto la frecuencia con que esta últiona ha pasado inadvertida a los pediatras $e$ insistiendose sobre los signos que permiten reconocerla: disnea, ortopnea y cianosis sin causa justi. ficada; agradamiento catdiaco; signo de Pins por comprasión del pulmón izquierdo: signos provocados por el taponamiento cardíaco (bipertensión venasa) y afteraciones caracteristicas del electeocardiograma: ST positivo en todas las derivaciones.

\section{PRIMERA Y SEGUNDA INFANCLA:}

a) Se rencionan los casos de agrandamiento cardiaco observados en los niños distróficos, que desaparecen con el ejercicio. Se habla de las deformaciones de la imagen cardiaca provocadas por la escoliosis y por los cambios de posición del diafragma.

b) Las cardiomegalias congénitas no entran prácticamente en juego en e! diagnóstico diferencial de los agrandamientos de 1 a silueta cardiaca en esta edad de la vida. La taquicardia paraxistica es fácil de reconocer, bo mistno que las perturbaciones del metabolismo - hipo e hipertiroidismo- y las avitaminosis.

c) Annque parezca superfluo se insiste en que dibe aceptarse un diagnóstico de cardiopatía congénita a esta edad, aunque la madre del niño aregure que ha sido cuidadora y repetidamente examinado en oportunidades anteriores. sin que se la registrafa.

Se habla especialmente de la persistencia del conducto arteriovenoso fácilmente diagnosticable por el soplo continuo de la base, acompañado de intenso frémito, señalándose que en esta condición debe indicarse la intervención quirúrgica. cuando en ausencia de despiación a la derecha del eje eléctrico, haya agzandamiento cardíaco o endocarditis bacteriana del ductus.

d) Se repite que las anemías de larga daración pueden acompañarse de agrandamiento cardiaco $y$ soplo, $y$ que este agrandamiento retrograda con la mejoría de la hemopatía.

e) Eñtre las enfermedades infecciosas a germen desionocido, provocadoras de agrandemiento cantiaco a esta edad, se cita en primer término a la fiebre reurnática, đestacándose que desde este punto de vista, el corazón reumática del niño puede dividirse en cuatro grupos:

1. Ed rocazón no aumenta de tamaño, a pesar de là agresión relumá tíca, sea cualquiera la valvula afectada;

2. E1 corazón aumenta de tamaño en los periodos de actividad rumítica $y$ se estaciona o disminuye en los periodos dz inactividad;

3. El cotazón aumenta de tamaño en forma progresiva: 
4. Comprende los casos de agrandamianto de la silueta cardíaca, debidos cxclusivamente a un detrame pericátdico.

Se menciona en segundo lugar a la miocarditis aislada a enfermedad de Fiedler, provocada por un germen desconocido, caracterizada clínicamente por ritmo de golpa y groseras alteraciones electrocardiográticas, sin que al comienzo de la enfermedad ste cuadro aco acomañe de 1lamatipas perturbaciones funcionsles. Por regia general, la muerte sobreviene por insuficientia cardiaca irreductible en plazo de 6 a 12 meses, pero se cita un saso en que la infermedad se prolonga desde hace dos años, persistiendo el rítmo de galope.

f) Entre las enfermedades infecciosas por germen conocido, sa menciona, en primer tétmino, a $\mathrm{l}_{\mathrm{a}}$ difteria, insistiendo que ningớn caso de diftêt ria de mediana importancia deberia ser dado de alta sin estudio elextrocardiográfico previo.

Se menciona después a la enfermedad de Chagas como causa de agrandamiento cardiaco, haciendo notar que se acompaiia de groseras alteraciones electrocardiográficas. Se indican los medios de diagntistico: examen de gota gxuesa; xenodiagnóstico, reacción da Machado Guerreito $Y$ biopsia gatglionar.

g) Se menciona, por último, a la glométulonefritis difnsa aguda como provocadora de agrandamiento cardíaco (hecho conocido descle la época de Bright), con insuficiencia cardiaca, anomalias en la orina y alteraciones electrocardiográficas del tipo de las encontradas en el infatto del miocardio. caracterizadas por su rápida reversibilidad. 